\title{
ALTERAÇÕES DA TAXA METABÓLICA POR PROVIMENTO DE OXIGÊNIO ADVINDO DE ALTERAÇÕES DO SISTEMA CIRCULATÓRIO E RESPIRATÓRIO E POR SUBSTRATOS DA CADEIA DE TRANSPORTE DE ELÉTRONS MITOCONDRIAL
}


HYLANE LUIZ DAMASCENA

\section{ALTERAÇÕES DA TAXA METABÓLICA POR PROVIMENTO DE OXIGÊNIO ADVINDO DE ALTERAÇÕES DO SISTEMA CIRCULATÓRIO E RESPIRATÓRIO E POR SUBSTRATOS DA CADEIA DE TRANSPORTE DE ELÉTRONS MITOCONDRIAL}

Dissertação apresentada ao Programa de Pós-graduação “Stricto Sensu” em Ciências e Tecnologias em Saúde da Universidade de Brasília, como requisito para a obtenção do título de Mestre em Ciências e Tecnologias em Saúde.

Orientador: Prof. Dr. Alexis Fonseca Welker

Brasília 


\section{ALTERAÇÕES DA TAXA METABÓLICA POR PROVIMENTO DE OXIGÊNIO ADVINDO DE ALTERAÇÕES DO SISTEMA CIRCULATÓRIO E RESPIRATÓRIO E POR SUBSTRATOS DA CADEIA DE TRANSPORTE DE ELÉTRONS MITOCONDRIAL}

Dissertação defendida no Programa de Pós-graduação "Stricto Sensu" em Ciências e Tecnologias em Saúde da Universidade de Brasília, como parte das exigências para a obtenção do título de Mestre em Ciências e Tecnologias em Saúde defendida em 27 de junho de 2016 para a banca examinadora constituída pelos seguintes membros:

Prof. Dr. Alexis Fonseca Welker

Universidade de Brasília

Faculdade de Ceilândia

Programa de Pós-graduação em Ciências e Tecnologias em Saúde da Universidade de Brasília

Prof. Dr. Eduardo Antônio Ferreira

Universidade de Brasília

Faculdade de Ceilândia

Prof. Dr. Guilherme Eckhardt Molina

Universidade de Brasília

Faculdade de Educação Física

Profa. Dra. Kelb Bousquet Santos

Universidade de Brasília

Faculdade de Ceilândia

Programa de Pós-graduação em Ciências e Tecnologias em Saúde da Universidade de Brasília 
Dedico este trabalho ao meu Deus, que me guia e ilumina meus passos e caminhos, e à minha família. 


\section{AGRADECIMENTOS}

Agradeço a Deus por sempre me guiar e por me permitir conhecer pessoas maravilhosas durante este processo. Agradeço meus pais, Alcides e Terezina e a minha irmã Hyara, que me fazem ser cada dia melhor, que são minha base e nunca me deixaram desistir apesar dos desafios e agradeço a todos os demais familiares.

Agradeço ao João, meu namorado, por se fazer presente nesta caminhada. Agradeço aos meus amigos, Lara, Lu, Débora, Inês, por toda preocupação partilhada a respeito deste trabalho e aos demais amigos

Agradeço ao meu orientador, Prof. Dr. Alexis Welker, por me ensinar o caminho cientifico em suas diversas formas, por me mostrar novos horizontes dentro deste projeto e por todas orientações concedidas.

Agradeço ao Prof. Dr. Marcelo Hermes, que me permitiu participar do grupo GPRO, por nos instigar com seu amor pela ciência, por me orientar e não me fazer desistir do meu projeto.

Agradeço ao Daniel e Marcus, por me ensinarem a trabalhar na bancada, por toda paciência e companheirismo e por toda generosidade em compartilhar seus conhecimentos.

Agradeço a Mariana, Raudsom, Talita, Igor, Lara, Isadora e todos, os quais, em algum momento, pude compartilhar momentos de trabalho de bancada, de risadas e angústias no laboratório de radicais livres. E a todo grupo GPRO, que me acolheram e que de alguma forma me ensinaram o amor pela ciência, a perserverança, a generosidade, e todos as virtudes que me tornaram uma profissional e uma pessoa melhor.

Agradeço à Rander, na qual foi adquirido os girinos para o estudo, em especial o Evaldo, que com toda sua paciência e dedicação ao trabalho, me auxiliou em todas as dúvidas referentes a criação.

Agradeço ao Prof. Dr. Eduardo Antônio Ferreira, Prof. Dr. Guilherme Eckhardt Molina, Profa. Dra. Kelb Bousquet Santos, por aceitar participar da minha banca examinadora. 
"A tarefa não é tanto ver aquilo que ninguém viu, mas pensar o que ninguém ainda pensou sobre aquilo que todo mundo vê." Arthur Schopenhauer 


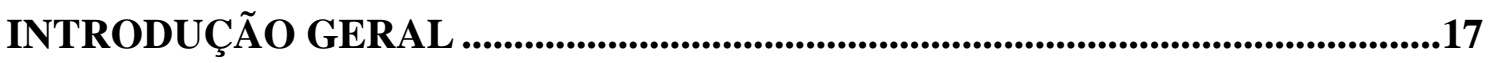

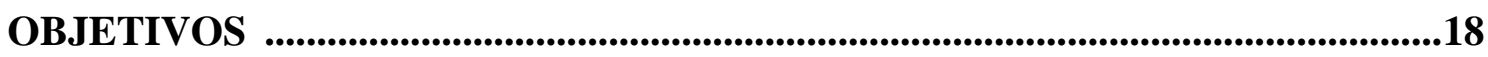

CAPÍTULO 1- ALTERAÇÕES DE UMA ESPÉCIE TOLERANTE À HIPÓXIA SOBRE O NÍVEL DE DANOS OXIDATIVOS

1. INTRODUÇÃ

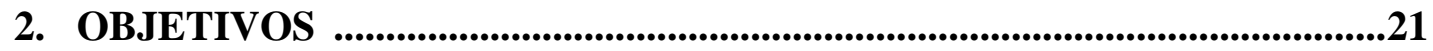

3. MATERIAIS E MÉTODOS ...........................................................................21

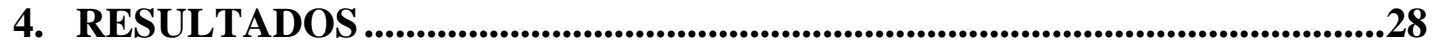

5. DISCUSSÃO E CONCLUSÃO ...............................................................................34

6. REFERÊNCIAS BIBLIOGRÁFICAS ....................................................................36

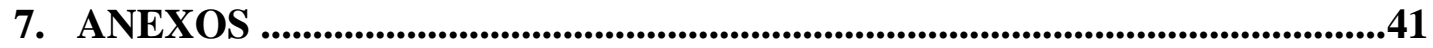

CAPÍTULO 2- RESISTÊNCIA À DIMINUIÇÃO DO PROVIMENTO SISTÊMICO DE OXIGÊNIO ADVINDO DA DESIDRATAÇÃO EM UM ANIMAL AQUÁTICO

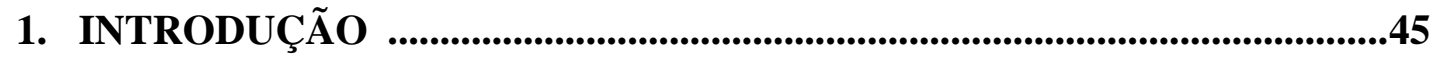

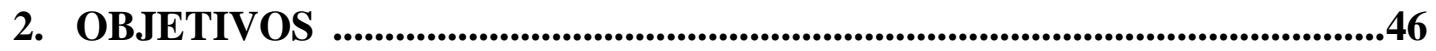

3. MATERIAIS E MÉTODOS .......................................................................................46

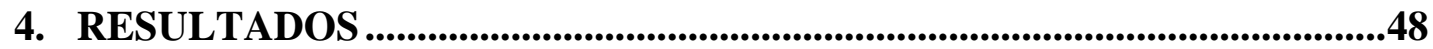

5. DISCUSSÃO E CONCLUSÃO ..............................................................51

6. REFERÊNCIAS BIBLIOGRÁFICAS ...............................................................53

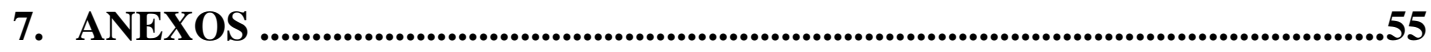

CAPÍTULO 3- CONTROLE DA TAXA METABÓLICA POR SUBSTRATOS DA CADEIA DE TRANSPORTE DE ELÉTRONS MITOCONDRIAL

1. INTRODUÇÃ

1.1. Taxa metabólica e restrição calórica …....................................................................57

1.2. Depressão metabólica: redução da taxa metabólica em animais ..................57

1.3. Alterações da taxa metabólica pela oferta de calorias .....................................58

1.4. Fatores que influênciam o Efeito Térmico dos Alimentos ..............................59

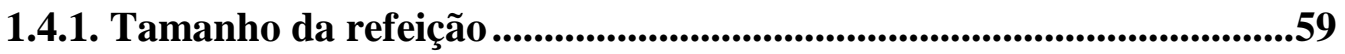

1.4.2. Composição do alimento ................................................................................60

1.4.3. Composição corporal do indivíduo ....................................................60

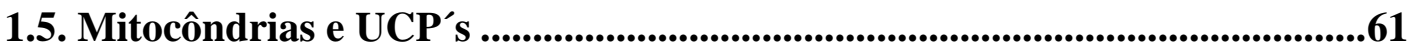

1.5.1. UCP'S e restrição alimentar .................................................................61

1.5.2. UCP'S e hormônios da tireóide ........................................................62 
1.5.3. UCP'S e hormônios da saciedade ........................................................62

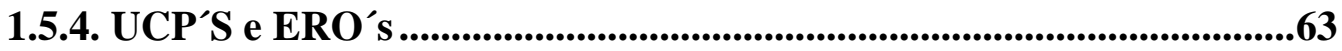

2. REVISÃO SISTEMÁTICA E ANÁLISE DE DADOS DA LITERATURA

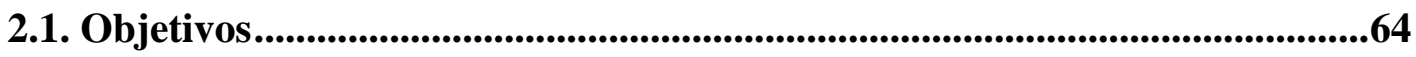

3. MÉTODOS.........................................................................................................64

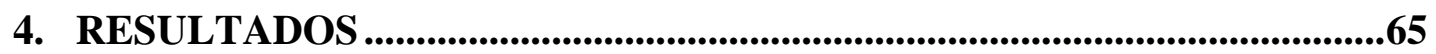

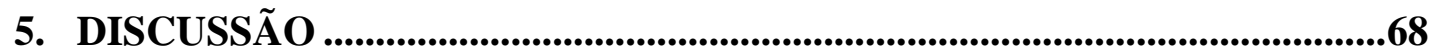

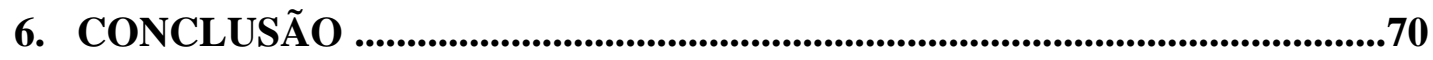

7. REFERÊNCIAS BIBLIOGRÁFICAS .............................................................71

CAPÍTULO 4- MANUSCRITO SUBMETIDO: METABOLIC ADAPTATION DUE TO CALORIC RESTRICTION MAY BE MINIMIZED BY INTERMITTENT INGESTION OF THERMOGENESIS-BOOSTING MEALS

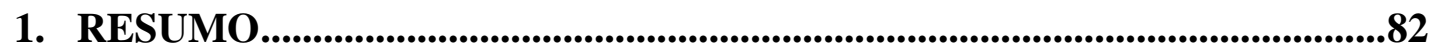

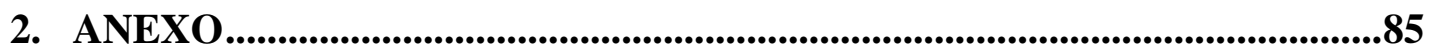

DISCUSSÃO GERAL E CONCLUSÕES............................................................89

REFERÊNCIAS BIBLIOGRÁFICAS .....................................................................91 


\section{LISTA DE FIGURAS}

\section{CAPÍTULO 1}

Figura 1. Desenho experimental (Experimento 1)

Figura 2. Concentração de lactato em músculo de cauda de girinos exposto ao ar ( hipóxia progressiva). Cada grupo com $\mathrm{n}=4$. Grupo com símbolo (*), apresenta média significativamente diferente do controle $(\mathrm{p}<0,05)$

Figura 3. Perda de peso de girinos exposto ao ar (hipóxia progressiva) sob a temperatura média de $26^{\circ} \mathrm{C} \pm 1$, experimento 2

Figura 4. Concentração de eq-GSH em fígado de grinos expostos a àgua com hipóxia severa $(0,3 \mathrm{mg} / \mathrm{L})$. Neste teste de sondagem, foi utilizado $\mathrm{n}=1$

Figura 5. Concentração de GSSG em fígado de grinos expostos a água com hipóxia severa $(0,3 \mathrm{mg} / \mathrm{L})$. Neste teste de sondagem, foi utilizado $n=1$ .32

Figura 6. Concentração de sulfidrilas totais em fígado de girinos exposto a água com hipóxia severa $(0,3 \mathrm{mg} / \mathrm{L})$. Cada grupo com $\mathrm{n}=6$. Não houve diferenças significativas 33

Figura 7. Concentração de TBARS em fígado de girinos expostos a águ com hipóxia severa $(0,3 \mathrm{mg} / \mathrm{L})$. Cada grupo com $\mathrm{n}=6$. Não houve diferenças significativas .33

\section{CAPÍTULO 2}

Figura 1. Perda de peso (g) por hora de desidratação. 49

Figura 2. Taxa de sobrevivência durante a desidratação .50

Figura 3. Ganho de peso (\%) ao longo da reidratação .51

\section{CAPÍTULO 3}

Figura 1. Correlação entre pico pós-prandial e o efeito térmico dos alimentos com diferentes nutrientes e quantidades $(\mathrm{p}<0,001)$. 


\section{LISTA DE TABELAS}

\section{CAPÍtULO 1}

Tabela 1. Condições experimentais às quais girinos Lithobates catesbeianus foram submetidos .25

Tabela 2. Condições de oxigênio antes e depois do experimento em cada aquário .31

\section{CAPÍTULO 3}

Tabela 1. Características das refeições dos artigos analisados .66

Tabela 2. Alterações da taxa metabólica em resposta a ingestão de nutrientes. .66 


\section{LISTA DE ANEXOS}

\section{CAPÍTULO 1}

ANEXO A- Criação de ovos de girinos, com criação de zooplâncton

ANEXO B- Criação de girinos, estágio I-VI (Taylor e Kollros, 1946), com temperatura de $25 \pm 1{ }^{\circ} \mathrm{C}, \mathrm{pH} 6$, amônia $0,000 \pm 0,008$, oxigenação controlada por meio de aeração, e com densidade de 1U/L, fotoperíodo 12:12

ANEXO C- Imagem do aquário utilizado para o experimento de hipóxia severa

ANEXO D- Comportamento dos animais, na superfície do aquário, durante hipóxia severa $(0,3 \mathrm{mg} / \mathrm{L})$

ANEXO E- Aumento da vascularização da cauda de girinos (cauda vermelha), na exposição ao ar.

\section{CAPÍTULO 2}

ANEXO A-Tabela 1. Determinação do conteúdo de água corporal em animal inteiro $(\mathrm{n}=10)$ em estufa à $90^{\circ} \mathrm{C}$ por 24 horas. Percentual de água (média e desvio padrão) e o conteúdo de água corporal animal inteiro $\left(\mathrm{g} \mathrm{H}_{2} \mathrm{O} / \mathrm{g}\right.$ peso) de Lithobates catesbeianus. 55 ANEXO B- Tabela 2. Determinação do conteúdo de água corporal no músculo de Lithobates catesbeianus $(\mathrm{n}=5)$ em estufa à $90^{\circ} \mathrm{C}$ por 12 horas. Percentual de água (média e desvio padrão) .55

ANEXO C- Tabela 3. Determinação do conteúdo de água corporal no fígado de Lithobates catesbeianus $(\mathrm{n}=10)$ em estufa à $90^{\circ} \mathrm{C}$ por 12 horas. Percentual de água (média e desvio padrão) .55

\section{CAPÍTULO 4}

ANEXO A- Normas da revista Medical Hypotheses, que o manuscrito foi submetido 
SÌMBOLOS E SIGLAS

$\mu \mathrm{L}$ - Microlitros

$\mu \mathrm{M}$ - Micromolar

2-VP- 2-vinilpiridina

ACGCL- Ácidos Graxos de Cadeia Longa

ADP- Adenosina Difosfato

AGCM- Àcidos Graxos de Cadeia Média

AGMI- Ácidos Graxos Monoinsaturados

AGPI- Ácidos Graxos Poliinsaturados

AGS- Ácidos Graxos Saturados

ATP- Adenosina Trifosfato

CEUA- Comissão de Ética no Uso Animal

$\mathrm{CO}_{2}$ - Dióxido de Carbono

DNA- Ácido Desoxirribonucleico

DNP- Dinitrofenol

DTNB- 5,5'-ditiobis-2-ácido nitrobenzóico

EDTA- Àcido Etilenodiamino Tetra-Acético (agente quelante)

ERO’s - Espécies Reativas de Oxigênio

g- Grama

GR- Glutationa Redutase

GSH- Glutationa reduzida 
GSSG- Glutationa oxidada

GSSG/GSH-eq -Razão glutationa oxidada e glutationa equivalente

h- Hora

$\mathrm{H}_{2} \mathrm{O}_{2}$ - Peróxido de Hidrogênio

Kcal- quilocalorias

LDH- Lactato Desidrogenase

MDA- Malondialdeído

$\mathrm{mg} / \mathrm{L}$ - Miligrama por litro

mL- Mililitros

$\mathrm{mL} / \mathrm{Kg} \cdot \mathrm{min}^{-1}-$ Mililitros por quilograma por minuto

mM- Milimolar

$\mathrm{N}_{2}$ - Nitrogênio

$\mathrm{NAD}^{+}$- Nicotinamida Adenina Dinucleotídeo oxidada

NADH- Nicotinamida Adenina Dinucleotídeo reduzido

NADPH- Nicotinamida Adenina Dinucleotídeo Fosfato

NAOH- Hidróxido de Sódio

nm- nanômetro

${ }^{\circ} \mathrm{C}$ - Grau Celsius

RL- Radicais Livres

T3- Triiodotironina

T4- Tiroxina

TBA- Àcido Tiobarbitúrico

TBA2-MDA- Aduto Àcido Tiobarbitúrico- Malondialdeído

TBARS- Substâncias Reativas ao Àcido Tiobarbitúrico 
TCA- Ácido Tricloracético

TMR- Taxa Metabólica de Repouso

TNB- 5-tio-2-ácido nitrobenzóico

U/L- Unidade por litro

U/mL- Unidade por mililitro

UCP’s- Uncoupled Protein 


\section{RESUMO}

A taxa metabólica basal é o principal componente no gasto energético total dos seres humanos e demais animais na maioria das situações. Devido a isso, em muitas situações desfavoráveis energeticamente, ocorre alterações da taxa metabólica, permitindo o sistema manter a homestasia. Os seres humanos, durante restrição calórica, reduzem a taxa metabólica, situação conhecida como adaptação metabólica. Essa adaptação também ocorre em muitos animais na natureza, devido a estresses ambientais, dentre eles a falta de disponibilidade de nutrientes e de água, levando-os à depressão metabólica. É conhecido que esses animais sofrem maior estresse oxidativo, devido à redução e o aumento abrupto da atividade mitocondrial, decorrente das condições desfavoráveis e favoráveis, respectivamente. No caso dos seres humanos, a depressão metabólica advinda da restrição calórica dificulta a perda de peso e contribui para a obesidade.O presente trabalho avaliou: (1) as alterações de uma espécie tolerante à hipóxia sobre o nível de danos oxidativos; (2) a resistência à diminuição do provimento sistêmico de oxigênio advindo da desidratação em um animal aquático ao estresse da desidratação; (3) o controle da taxa metabólica pela disponibilidade de substratos da cadeia de transporte de elétrons mitocondrial por meio de dados da literatura; (4) uma teoria (manuscrito/artigo submetido) que relaciona a disponibilidade de nutrientes com a taxa metabólica e uma estratégia que utilize tal relação para o combate da obesidade e doenças relacionadas

Palavras-chaves: Taxa metabólica, Adaptação metabólica, depressão metabólica, estresse oxidativo, atividade mitocondrial. 


\begin{abstract}
Basal metabolic rate is the main component in total energy expenditure of humans and other animals in most situations. Because of this, in many energetically unfavorable situations occurs changes in metabolic rate, allowing the system to maintain homestasia. During caloric restriction, humans reduces metabolic rate, a condition known as metabolic adaptation. This adaptation also occurs in many animals in nature, due to environmental stresses, including the lack of availability of nutrients and water, causing them to metabolic depression. It is known that these animals show increased oxidative stress due to the reduction and the abrupt increase in mitochondrial activity, due to the unfavorable conditions and favorable, respectively. In the case of human beings, arising metabolic depression of calorie restriction hinders weight loss and contributes to obesidade.This study evaluated: (1) changes of a tolerant species to hypoxia on the level of oxidative damage; (2) resistance to reduced systemic provision of oxygen arising from dehydration in an aquatic animal to the stress of dehydration; (3) the control metabolic rate by the availability of substrates of the mitochondrial electron transport chain through the literature; (4) a theory (manuscript / submitted article) relating to nutrient availability to the metabolic rate and a strategy that uses such a relationship to combat the obesity and related diseases
\end{abstract}

Key-words: Metabolic rate, metabolic adaptation, metabolic depression, oxidative stress, mitochondrial activity. 


\section{INTRODUÇÃO GERAL}

\section{Metabolismo: Taxa Metabólica de Repouso}

Para manter suas funções vitais, o corpo possui um gasto energético durante o repouso, a Taxa Metabólica de Repouso (TMR). Ela é um componente que possui a maior contribuição no gasto energético total diário na maioria das situações (Ravussin, 1986). A energia necessária para manter a maioria das funções é advinda do metabolismo aeróbico, o qual possibilita um maior aproveitamento da energia fornecida pelos alimentos, produzindo mais Adenosina Trifosfato (ATP), do que no metabolismo anaeróbico (Ramos et al., 2000). Porém, nesse processo de produção de energia realizado pelas mitocôndrias por meio de reações de oxidação-redução, o oxigênio, ao ser reduzido a água, leva a formação de radicais livres (Ramos et al., 2000)

\section{Espécies Reativas de Oxigênio e estresse oxidativo}

Os Radicais Livres (RL) são denominados por possuírem um ou mais elétrons desemparelhados com existência independente (Ramos et al., 2000). O oxigênio molecular é considerado uma espécie radicalar por sua característica de receber um átomo por vez, sendo capaz de gerar outras espécies radicalares e não-radicalares com alto potencial de ação danosa para o organismo (Gregory e Fridovich, 1973). O oxigênio ao ser reduzido na célula à água $\left(\mathrm{H}_{2} \mathrm{O}\right)$ possui uma pequena parte que é parcialmente reduzida, formando o radical superóxido que, ao sofrer dismutação espontânea realizada pela superóxido dismutase, produz o peróxido de hidrogênio $\left(\mathrm{H}_{2} \mathrm{O}_{2}\right)$. Este, ao reagir com ferro (II) ou outros metais, forma o radical hidroxil (Nohl e Hegner, 1978). A produção de Espécies Reativas de Oxigênio (ERO’s) mitocondrial é proveniente da fosforilação oxidativa que ocorre na cadeia respiratória, no complexo I e III (Andreyev, Kushnareva, Starkov, 2005).

O aumento de ERO’s leva a agressões celulares, como peroxidação dos lipídios de membrana, danos às proteínas dos tecidos, às enzimas, carboidratos e DNA. Essas lesões caracterizam o estresse oxidativo, ou seja, uma condição em que ocorre um desequilíbrio entre as concentrações de radicais e as defesas antioxidantes (Nohl e Hegner, 1978; Cini et al.,1994). 


\section{Adaptações metabólica e Estresse Oxidativo}

Há muitos animais que passam por estresses ambientais, como falta de nutrientes, de água, mudanças bruscas de temperatura, os sujeitando ao estresse oxidativo (HermesLima, 2004). Para sobreviver ao estresse, eles reduzem sua taxa metabólica (Storey e Storey, 2010). A depressão metabólica reduz a demanda de ATP diminuindo algumas vias, por exemplo a redução de síntese de proteína (Guppy et al., 1999). Sabe-se que a mitocôndria possui papel fundamental na produção de energia, ou seja, de ATP. Quando há falta de disponibilidade de nutrientes há redução na atividade mitocondrial e o contrário também ocorre (Brown, 1992).

Os seres humanos, durante restrição calórica, também passam por adaptação metabólica, caracterizada pela redução na taxa metabólica (Dullo e Jacquet, 1998), a longo prazo, isso causa resistência à perda de peso e facilita o reganho (Guppy, Fuery, Flanigan, 1994). Entender os fatores metabólicos que levam a adaptações nos humanos à restrição de nutrientes, relacionando com processos semelhantes enfrentados por animais na natureza, pode ajudar a elucidar os mecanismos de tais processos e propor possíveis soluções.

\section{OBJETIVOS}

Os objetivos deste trabalho são: (1) Avaliar as alterações de uma espécie tolerante à hipóxia sobre o nível de danos oxidativos; (2) Analisar a resistência à diminuição do provimento sistêmico de oxigênio advindo da desidratação em um animal aquático ao estresse da desidratação; (3) Investigar o controle da taxa metabólica pela disponibilidade de substratos da cadeia de transporte de elétrons mitocondrial através de dados da literatura; (4) Propor uma teoria (manuscrito/artigo submetido) que relaciona a disponibilidade de nutrientes com a taxa metabólica e uma estratégia que utilize tal relação para o combate da obesidade e doenças relacionadas:

O trabalho está divido em quatro capítulos, os quais abordarão os objetivos citados acima. 
Capítulo 1 - alterações de uma espécie TOLERANTE À HIPÓXIA SOBRE O NÍVEL DE DANOS OXIDATIVOS 


\section{ALTERAÇÕES DE UMA ESPÉCIE TOLERANTE À HIPÓXIA SOBRE O NÍVEL DE DANOS OXIDATIVOS}

\section{INTRODUÇÃO}

Os seres humanos são intolerantes a grandes flutuações na disponibilidade de oxigênio (Zweier, Flaherty e Weisfeldt, 1987). A isquemia gera uma diminuição da disponibilidade de oxigênio, causando hipóxia e anóxia nos tecidos. Esta condição ocorre em situações como transplante de órgãos (Meng et al., 2013; Ge et al., 2013), infarto do miocárdio (Forman et al., 1991), lesões na mucosa intestinal (Grisham, Hernandez e Granger, 1986; Ge et al., 2013), nos pulmões (Kennedy et al., 1989; Mühl et al., 2003) e pâncreas (Sanfey et al., 1985; Elgebalyet al., 2011). Com a reperfusão e o retorno do oxigênio, observa-se um aumento na formação de espécies reativas de oxigênio (ERO’s), que resultam em estresse oxidativo, danos a moléculas e lesões em tecidos (Gregory e Fridovich, 1973; Garlick et al., 1987; Maupoil e Rochete, 1988; Zweier et al., 1989). Este estresse ocorre pelo desbalanço entre as defesas antioxidantes e a produção de ERO’s, ou seja, o sistema antioxidante não é eficiente o suficiente para que os tecidos resistam à maior quantidade formada de ERO’s (Nohl e Hegner, 1978; Cini et al., 1994; Phelan e Lange, 1991).

Existem animais que passam por processo semelhante à isquemia e reperfusão em humanos, porém, ao contrário destes, eles sobrevivem e não apresentam prejuízos funcionais (Ramos-Vasconcelos e Hermes-Lima, 2003; Welker et al., 2013). Por exemplo, tais organismos enfrentam flutuações no consumo de oxigênio durante o estado de estivação, hibernação, desidratação, mergulho e privação alimentar (Hermes-Lima e Storey, 1998; Lushchak et al., 2001; Ferreira, Alencastro, Hermes-Lima, 2003). Para sobreviverem, eles apresentam adaptações metabólicas, por exemplo, reduzindo sua taxa metabólica e aumentando as enzimas antioxidantes (Hermes-Lima e Storey, 1998; Michaelidis, 2002; Ultsch, Reese e Stewart, 2004). Peixes com um importante antioxidante (catalase) suprimido apresentam aumento de GSSG/GSH-eq (indicador de desbalanço redox) durante a reoxigenação pós-hipóxia, o que indica que tal componente tem uma importância em conferir resistência ao estresse oxidativo (Welker et al., 2012). Porém, tal estudo submeteu os animais à hipóxia constante, o que possivelmente não 
revela o que ocorre na natureza ou durante a isquemia, quando a hipóxia se torna progressiva. A hipóxia também aumenta a produção de ERO’s (Duranteau et al., 1998), o nível de danos oxidativos (Møller et al, 2001; Chen et al., 2005) e das defesas antioxidantes (Lopes et al., 2013). Porém, tal fenômeno depende do grau de hipóxia, ou seja, há níveis de hipóxia que não aumentam a produção de ERO’s (Welker et al., 2013). A hipóxia progressiva, que se intensifica com o tempo e pode chegar à anóxia, é o que mais ocorre durante a isquemia e na natureza.

Para investigar o efeito da hipóxia progressiva e a hipóxia severa sobre o sistema antioxidante de um organismo, é importante que ele seja tolerante a tal situação. Dentre as espécies conhecidas, a rã Lithobates catesbeianus é de fauna estrangeira, disponível em ranários produtores de carne e um vertebrado, conhecida por ser resistente a variações

de oxigênio (Winmil, Chen, Hedrick, 2004; Hedrick, Fahlman, Bickler, 2005). Suas respostas podem servir para comparação com humanos e outros animais, o que o torna um modelo adequado a ser estudado. Desta forma, o presente estudo teve o objetivo de analisar á resistência ao efeito da hipóxia progressiva e a hipóxia severa em Lithobates catesbeianus, avaliando os danos oxidativos.

\section{OBJETIVOS}

Avaliar a resistência de um animal tolerante à anóxia, Lithobates catesbeianus, à redução sistêmica de oxigênio advinda do estresse da hipóxia progressiva e a hipóxia severa sobre o balanço redox no nível de danos oxidativos.

\section{MATERIAIS E MÉTODOS}

\section{Manutenção dos animais (ovos)}

Foram comprados girinos da fazenda Rander (www.rander.com.br), com cinco dias de eclodidos, fase escolhida por ainda se alimentarem do vitelo do ovo e não possuírem a necessidade de estarem imersos na água, evitando o estresse da troca de ração e mudança de hábitat - água do aquário que foram mantidos. Eles foram transportados em sacos plásticos com oxigênio até ao Biotério do Instituo de Biologia da Universidade de Brasília-UnB. Foram mantidos em aquários em temperatura de $24-25{ }^{\circ} \mathrm{C}, \mathrm{pH} 6$, 
oxigenação controlada por meio de aeração, com densidade de 1 U/L, fotoperíodo 12:12. Anteriormente a transferência dos girinos para o aquário, foi usado na água anti-cloro e um saco fechado com pequenos furos com esterco de carneiro curtido, anteriormente deixado de molho, para retirar excesso de sujeira e urina. O esterco foi usado para formação de zooplâncton (ANEXO A). O saco foi mantido durante uma semana. A limpeza da água ocorreu uma vez por semana, ou quando necessário, sifonando a sujeira do fundo. A água, para a reposição durante a limpeza, era usado anti-cloro uma gota por litro e mantida um dia antes com esterco de carneiro. Durante a troca, o esterco era retirado e a água colocada no aquário.

A partir do décimo dia de eclosão, em dias alternados, eles foram alimentados com ração $45 \%$ de proteína. Na primeira semana eles foram alimentados com $0,4 \mathrm{~g}$ de ração, na segunda semana com $0,8 \mathrm{~g}$, a cada semana a quantidade de ração era dobrada, observando sempre as necessidades, por meio dos excretos na água. Ao $25^{\circ}$ dia de eclosão, os girinos apresentaram taxa de mortalidade maior que $80 \%$, com a explosão do intestino, acredita-se que a ração oferecida com alto valor proteico, possa ter causado a morte, devido a alteração da qualidade da água com compostos nitrogenados (Seixa Filho et al, 2008).

\section{Aclimatação}

Com a alta mortalidade apresentada durante a criação dos ovos, foram comprados girinos da fazenda Rander (www.rander.com.br), no estágio desejado, com aproximadamente 65 dias de eclodidos, estágio I-VI (Taylor e Kollros 1946), com peso entre 5-7g, os quais ainda não possuem membros posteriores integralmente formados, e são totalmente dependentes da água (ANEXO B). Eles foram transportados em sacos plásticos com oxigênio até ao Biotério do Instituo de Biologia da Universidade de Brasília-UnB. Eles foram mantidos por uma semana em aquário. Na água, foi usado anticloro, temperatura de $25 \pm 1^{\circ} \mathrm{C}, \mathrm{pH}$, amônia $0,000 \pm 0,008$, oxigenação controlada por meio de aeração, e com densidade de 1U/L, fotoperíodo 12:12. Em dias alternados, os girinos foram alimentados com ração $55 \%$ de proteína. Este projeto foi avaliado e aprovado pela Comissão de Ética no Uso Animal (CEUA) do Instituto de Ciências Biológicas da Universidade de Brasília . 


\section{$\underline{\text { Experimento } 1}$}

\section{Exposição à hipóxia progressiva (exposição aérea)}

Para determinar o tempo máximo de sobrevivência de Lithobates castebeianus, à hipóxia progressiva, 22 girinos foram retirados da água, pesados e expostos ao ar, sem hidratação com temperatura média de $25^{\circ} \mathrm{C} \pm 1$, a umidade do ar não foi monitorada. A taxa de mortalidade foi verificada por meio da interrupção das funções vitais (movimento bucal, presença ou ausência de batimento cardíaco, resposta a estímulo externo - toque na cauda).

Para verificar se os animais estavam em hipóxia, após 3 h de experimento, 4 girinos foram mortos por decapitação, as amostras de músculo da cauda foram retirados e congelados à $-80{ }^{\circ} \mathrm{C}$ para posterior medição da concentração de lactato indicador do grau de hipóxia. O mesmo foi realizado às 6 h e 12 h de experimento (Fig 1).

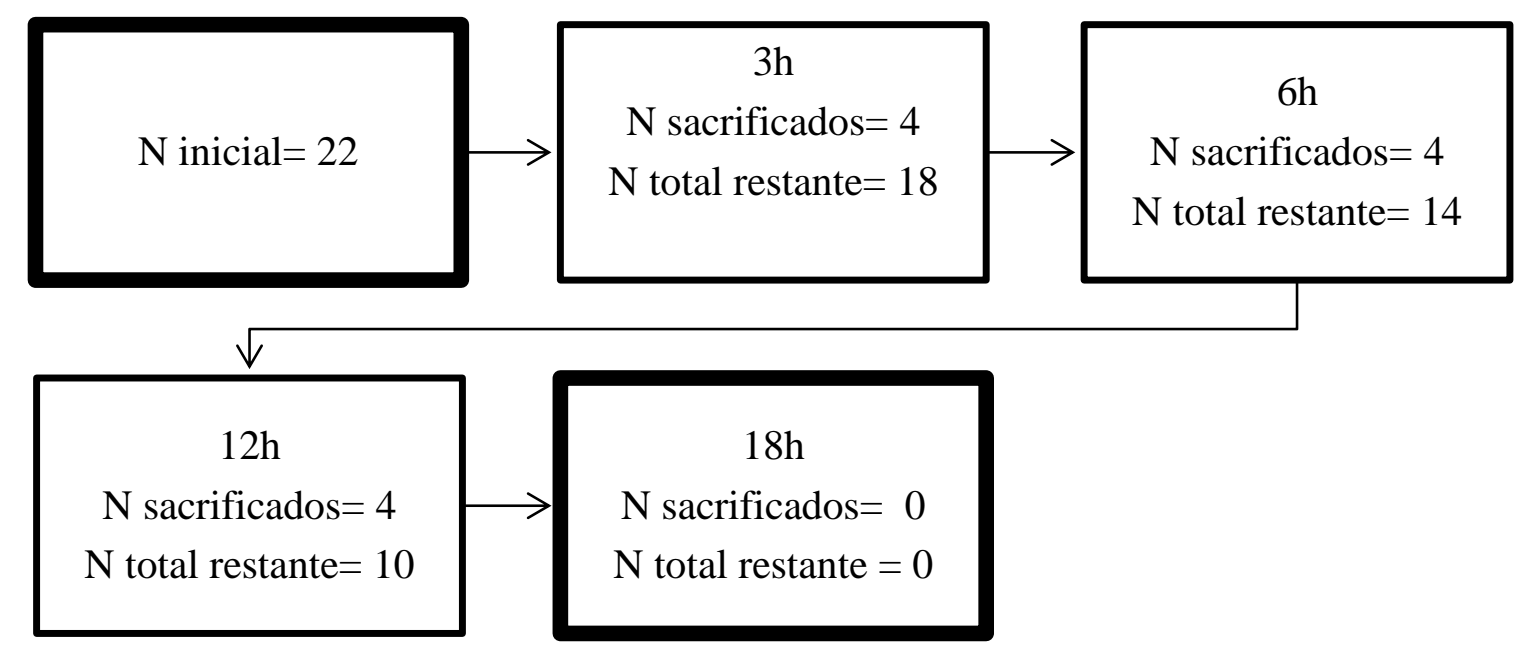

Fig 1. Desenho experimental (Experimento 1). 


\section{Medição de lactato}

\section{Prepração do tecido}

As amostras de músculo congeladas e pesadas foram homogenizadas em homogenizador de $3 \mathrm{~mL}$ (tubo e pistilo de vidro), estes eram sempre mantidos no gelo. $\mathrm{O}$ homogenato foi preparado com Ácido Tricloracético (TCA) $20 \%$. A concentração final do homogenato foi de 1:5. O homogenato era transferido para tubos Eppendorfes, centrigugado por $6 \mathrm{~min}$ a $10.000 \mathrm{xg}$ à $4^{\circ} \mathrm{C}$. Com o sobrenadante foi determinado a concentração de lactato.

\section{Medição de lactato por ensaio enzimático}

A concentração de lactato foi determinada, seguindo protocolo de Davidson (1978), a qual consiste na mensuração através da conversão de lactato a piruvato pela ação da lactato desidrogenase (LDH), com o consumo de $\mathrm{NAD}^{+}$, ocorrendo formação de NADH, a qual pode ser estimada espectrofotometricamente, através da variação da absorbância em $340 \mathrm{~nm}$. O ensaio foi realizado em microplaca, com volume final de $200 \mu 1$, e as concentrações do meio reacional: Tampão sulfato de hidrazina 0,4 M, glicina $1 \mathrm{M}$, EDTA 5,4 mM, NaOH 1,02 M, pH 9,0.

\section{Experimento 2}

Para determinar o fator predominante na morte dos girinos (hipóxia ou desidratação) do Experimento 1, foram realizados os seguintes experimentos:

\section{Exposição à hipóxia progressiva por exposição aérea}

Dez grinos foram retirados da água, pesados e expostos ao ar, sem hidratação com temperatura média de $26^{\circ} \mathrm{C} \pm 2$. Neste teste, a umidade do ar não foi monitorada. Nos tempos de 3, 6 e 12 horas, os animais foram pesados (Fig. 3) para verificar a taxa da perda de água e para determinar a taxa de mortalidade. Esta foi verificada através da interrupção das funções vitais (movimento bucal, presença ou ausência de batimento cardíaco, resposta a estímulo externo - toque na cauda). 


\section{Exposição à hipóxia severa por exposição a água quase anóxica (em aquário)}

Para eliminar o efeito da dessecação presente no experimento acima, a hipóxia severa também foi avaliada em animais submersos em água quase anóxica $(n=10)$, no qual os girinos foram acondicionados em aquário com capacidade para $5 \mathrm{~L}$, com tampa com dois pequenos furos $(1,2 \mathrm{~cm})$, um para entrada do gás nitrogênio e um para a saída de gases (ANEXO C), temperatura média de $26{ }^{\circ} \mathrm{C} \pm 1$. Antes de iniciar, foram adicionados dois frascos de $62 \mathrm{~mL}$ em cada aquário para a coleta de amostras para verificar concentração de oxigênio antes e após experimento, pelo método de Winkler (Carpenter, 1965). Os aquários foram vedados com vaselina sólida, por todo o espaço entre a tampa e o aquário. Após isto, o nitrogênio foi borbulhado durante $2 \mathrm{~h} 30 \mathrm{~min}$. As aberturas para a entrada e saída de gás também foram vedadas após borbulhar o nitrogênio. Os aquários foram abertos, um frasco com água era tampado e retirado do aquário, os animais eram imediatamente colocados no aquário e este era novamente fechado e vedado.

A saturação de oxigênio foi de $5 \%(0,3 \mathrm{mg} / \mathrm{L})$, condizendo com os valores encontrados na literatura de hipóxia severa (Routley et al, 2002; Fonseca et al, 2013; Huang et al, 2014).

\section{$\underline{\text { Experimento 3 }}$}

Com o tempo de sobrevivência determinado no experimento 2, durante exposição à hipóxia severa, foi realizado experimento com saturação de oxigênio de 5\% (0,3 mg/L) em 60 animais divididos conforme o quadro abaixo:

Tabela 1. Condições experimentais às quais girinos Lithobates catesbeianus foram submetidos.

\begin{tabular}{cl}
\hline Grupo & Condições experimentais \\
\hline 1. Controle & Animais mantidos em normóxia (tanque) \\
2. 15 min de exposição à hipóxia & Animais retirados dos tanques em normóxia e \\
& expostos a água hipóxia por 15 min. \\
3. $\mathbf{3 0}$ min de exposição à hipóxia & Animais retirados dos tanques em normóxia e \\
& expostos a água hipóxia por 30 min.
\end{tabular}




\section{4. $1 \mathrm{~h}$ de exposição à hipóxia Animais retirados dos tanques em normóxia e expostos a água hipóxia por $1 \mathrm{~h}$. \\ 5. 3 h de exposição à hipóxia Animais retirados dos tanques em normóxia e expostos a água hipóxia por $3 \mathrm{~h}$. \\ 6. $6 \mathrm{~h}$ de exposição à hipóxia Animais retirados dos tanques em normóxia e expostos a água hipóxia por $6 \mathrm{~h}$.}

Cada grupo foi composto por $\mathrm{n}=10$. Após borbulhar nitrogênio gasoso, os aquários foram vedados com vaselina sólida, por todo o espaço entre a tampa e o aquário. Ao final de cada tempo, exemplo 15 min, o aquário era aberto e retirado um animal por vez, o qual era sacrificado por decapitação. Amostras de cauda e fígado (lavadas em solução salina $0,78 \%$ ) foram armazenadas em freezer a $-80^{\circ} \mathrm{C}$. Depois, as amostras foram divididas em duas partes e pesadas para análises. Durante todo o procedimento, as amostras foram mantidas em nitrogênio líquido. A cada animal retirado, o aquário era novamente vedado.

\section{Medição de dano oxidativos}

\section{Preparação do tecido}

As amostras de fígado congeladas e pesadas foram homogenizadas em homogenizador de $3 \mathrm{~mL}$ (tubo e pistilo de vidro), estes eram sempre mantidos no gelo. $\mathrm{O}$ homogenato foi preparado com Ácido Tricloracético (TCA) $20 \%$. A concentração final do homogenato foi de 1:10. O homogenato era transferido para tubos Eppendorf e centrigugado por $6 \mathrm{~min}$ a $10.000 \mathrm{xg}$ à $4^{\circ} \mathrm{C}$. Com o sobrenadante, foi determinada a concentração dos indicativos de danos oxidativos.

\section{Medição de glutationa}

A concentração de glutationa (GSH) foi determinada seguindo protocolo de Welker (2009) (adaptado de Akerboom e Sies (1981) e Griffith (1980)). O método consiste na reação do grupo sulfidrila de duas moléculas de glutationa reduzida (GSH) com uma molécula de 5,5'-ditiobis-2-ácido nitrobenzóico (DTNB), produzindo duas moléculas 5-tio-2-ácido nitrobenzóico (TNB) e uma molécula de gluationa oxidada (GSSG). TNB absorve luz em $412 \mathrm{~nm}$. 
Esta reação permite medir a concentração de sulfidrilas não proteicas, como GSH e sulfidrilas proteicas, pois as proteínas são precipitadas (por ácido). A concentração de glutationa total é expressa como equivalentes de glutationa (eq-GSH), sendo que o GSSG já presente na amostra é reduzido a GSH pela presença de GR e NADPH.

Com os homogenatos preparados, foram separados dois tubos Eppendorf para GSH e dois tubos Eppendorf para GSSG. Nos tubos para medição de eq-GSH, foi colocado $25 \mu \mathrm{L}$ de homogenato, $75 \mu \mathrm{L}$ de Tampão fosfato $0,5 \mathrm{M}(\mathrm{pH} 7,0)$ e $5 \mu \mathrm{L}$ de etanol. Para medição de GSSG, foram colocados nos tubos $25 \mu \mathrm{L}$ de homogenato, $75 \mu \mathrm{Lde}$ Tampão fosfato 0,5 M pH 7,0, e $5 \mu \mathrm{L}$ de 2-vinilpiridina (2-VP). Depois os tubos foram agitados em 'vortex' e deixados no escuro por 1 hora.

Em microplacas, foi realizada uma curva padrão de eq-GSH e GSSG, com volume final de $200 \mu \mathrm{L}$, sendo as concentrações do meio reacional: Tampão fosfato $100 \mathrm{mM} \mathrm{pH}$ 7,0 EDTA 1 mM; TCA 0,238\%; GSH 0 a 1,5 $\mu \mathrm{M}$; NADPH 0,1 mM; DTNB 0,1 mM e GR 0,05 a 0,4 U/mL. Para a leitura das amostras, seguiu-se os mesmos passos, substituindo a GSH pela amostra.

\section{Medição de sulfidrilas totais}

O método permite determinar a concentração de sulfidrilas não proteicas, sendo um indicativo para a concentração de GSH. Foi feito o protocolo segundo Beutler, Duron, Kelly (1963), o qual consiste na reação do grupo sulfidrila -SH com uma molécula de 5,5'-ditiobis-2-ácido nitrobenzóico (DTNB), produzindo duas moléculas 5-tio-2-ácido nitrobenzóico (TNB), o qual absorve luz em $412 \mathrm{~nm}$. Em microplacas, foi realizada a curva padrão para com GSH, com volume final de $200 \mu \mathrm{L}$, sendo as concentrações do meio reacional: TCA $2 \%$ (para o branco); GSH 0 a $20 \mu \mathrm{M}$; Tampão fosfato $0,3 \mathrm{M}$ (pH 7,0); Tampão fosfato $100 \mathrm{mM}$ (pH 7,0)EDTA $1 \mathrm{mM}$; e DTNB 0,1 mM.

\section{Medição de TBARS}

Para determinar o grau de peroxidação lipídica, foi usado o teste de TBARS, seguindo protocolo de Buege e Aust (1978), modificado por Welker (2009). A peroxidação lipídica resulta na formação de aldeídos, como o malondialdeído (MDA), 
este reage com duas moléculas de ácido tiobarbitúrico (TBA), formando um aduto TBA2MDA. A leitura é feita em 532 e $600 \mathrm{~nm}$, onde $600 \mathrm{~nm}$ é para evitar diferenças de absorção de fundo

\section{Análise Estatística}

As análises estatísticas foram feitas no software Graphad Prism 7.0. Usou-se o teste de normalidade Shapiro-Wilk, antes de aplicar os teste paramétricos e nãoparámetricos, de ANOVA que foi usado para verificar diferenças existentes entre os grupos e havendo diferenças significativas, foi utilizado o teste $t$ de Student $(p<0,05)$. Os testes são apresentados com a média \pm erro padrão da média.

\section{RESULTADOS}

No Experimento 1, foi observada uma taxa de $100 \%$ de sobrevivência de $L$. catesbeinus até $12 \mathrm{~h}$ de exposição ao ar. Após $18 \mathrm{~h}$ de exposição ao ar, todos os animais estavam mortos. Não foi avaliado em que período entre 12-18 h, ocorreram as mortes.

A concentração de lactato não indicou diferenças entre o grupo controle e o grupo de $3 \mathrm{~h}$ e 6 h de exposição ao ar (e à hipóxia), enquanto que com 12 h de exposição, observou-se um aumento na concentração de lactato, com diferenças significativas em relação ao controle (Fig. 2). 


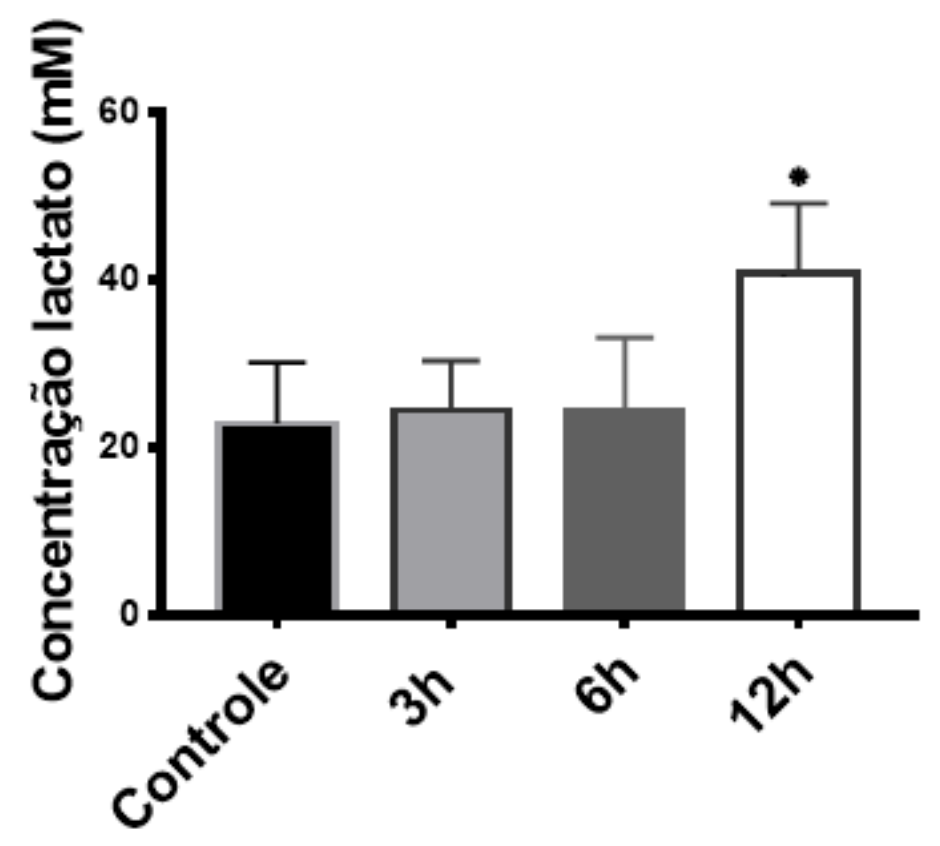

Figura 2. Concentração de lactato em músculo de cauda de girinos expostos expostos ao ar (hipóxia progressiva) sob a temperatura de $25^{\circ} \mathrm{C}$. Cada grupo com $n=4$. Grupo com símbolo (*), apresenta média significativamente diferente do controle $(\mathrm{p}<0,05)$.

Durante o experimento 1, foi observado dessecamento nos girinos. Para avaliar se o efeito da desidratação é maior do que a hipóxia ocasionada pela exposição ao ar, no experimento 2, os animais foram pesados nos tempos de 3, 6 e $12 \mathrm{~h}$. Com 3 horas de exposição ao estresse, os animais apresentavam uma perda de 34,52 \% de água corporal (Fig. 3) em relação ao baseline. Apesar de todos os animais já estarem mortos com $12 \mathrm{~h}$ de experimento, estes foram pesados para verificar a perda de água, o qual foi de 75,24 $\%$. No segundo experimento, os animais apresentaram $100 \%$ de sobrevivência até 6 horas de exposição. Com 12 horas, todos estavam mortos. 


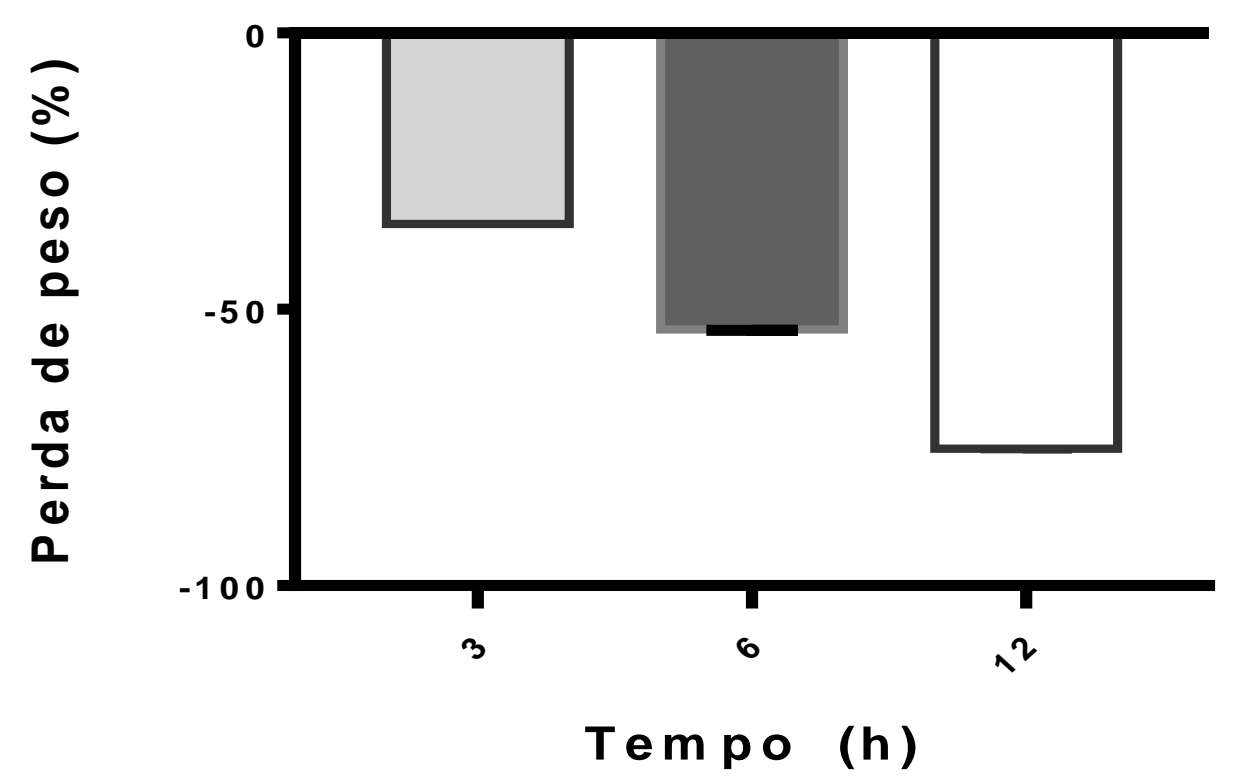

Figura 3. Perda de peso de girinos exposto ao ar (hipóxia progressiva) sob a temperatura de $26^{\circ} \mathrm{C}$, experimento 2

Os animais expostos à hipóxia severa submersa (experimento 2), no aquário, após $\cong 1$ hora de experimento apresentavam-se menos ativos, com redução no número de nados e ficavam na parte de cima do aquário, onde havia uma pequena coluna de ar (ANEXO D). Durante $12 \mathrm{~h}$ de experimento, $100 \%$ dos animais sobreviveram, com $13 \mathrm{~h}$ de experimento, 1 animal morreu. Após $18 \mathrm{~h}$ de exposição à água quase anóxica, $40 \%$ dos girinos estavam mortos.

Os animais no experimento 3 apresentaram 100\% de sobrevivência durante todo o experimento. Durante a hipóxia, a concentração de oxigênio variou, ou seja, não foi mantida constante até o final da retirada do último animal de cada aquário, nos tempos de 1 h, 3 h e 6 h (Tabela 1$)$. 
Tabela 2. Concentração de oxigênio antes e depois do experimento em cada aquário.

\begin{tabular}{lll}
\hline & Antes experimento & Pós-experimento \\
\hline Controle & $5,33 \mathrm{mg} / \mathrm{L}$ & $10,58 \mathrm{mg} / \mathrm{L}$ \\
$15 \mathrm{~min}$ & $0,36 \mathrm{mg} / \mathrm{L}$ & $0,26 \mathrm{mg} / \mathrm{L}$ \\
$30 \mathrm{~min}$ & $0,31 \mathrm{mg} / \mathrm{L}$ & $0,33 \mathrm{mg} / \mathrm{L}$ \\
$1 \mathrm{~h}$ & $0,41 \mathrm{mg} / \mathrm{L}$ & $1,14 \mathrm{mg} / \mathrm{L}$ \\
$3 \mathrm{~h}$ & $0,31 \mathrm{mg} / \mathrm{L}$ & $1,31 \mathrm{mg} / \mathrm{L}$ \\
$6 \mathrm{~h}$ & $0,36 \mathrm{mg} / \mathrm{L}$ & $1,57 \mathrm{mg} / \mathrm{L}$ \\
\hline
\end{tabular}

Assim, como no experimento 2, os animais apresentaram o comportamento de redução de nados e permaneciam na parte de cima do aquário. Grupos de animais foram eutanasiados nos tempos $3 \mathrm{~h}$ e $6 \mathrm{~h}$. Eles estavam menos agitados (apáticos) do que em situações de normóxia. Durante a dissecação dos animais, foi observado o surgimento de gotículas de gordura nos fígados. A temperatura da água dos aquários de hipóxia foi de $20^{\circ} \mathrm{C}$, exceto o de $6 \mathrm{~h}$, que estava no fim do experimento a $21,5^{\circ} \mathrm{C}$.

Foram medidos danos oxidativos nos animais controle e nos tempos iniciais de hipóxia, nos quais o grau de hipóxia permaneceu constante.

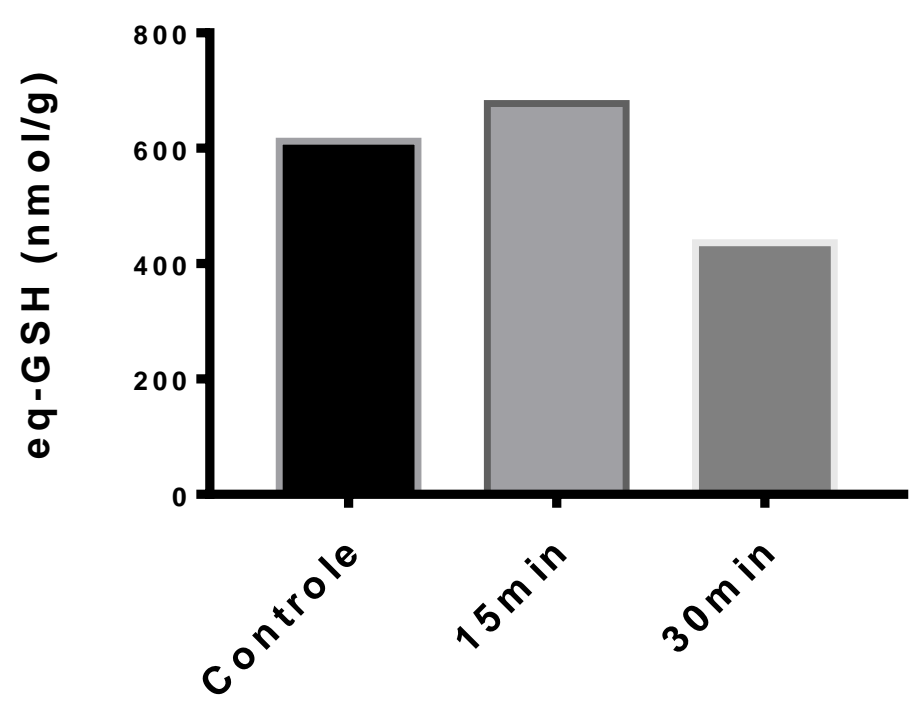

Figura 4. Concentração de eq-GSH em fígado de girinos expostos a água com hipóxia severa $(0,3 \mathrm{mg} / \mathrm{L})$. Neste teste de sondagem, foi utilizado $\mathrm{n}=1$. 
Animais em hipóxia de 15 e 30 minutos não mostraram alterações significativas na concentração de eq-GSH (Fig. 6), bem como GSSG (Fig. 7), sulfidrilas totais (Fig. 8) e TBARS (Fig. 9).

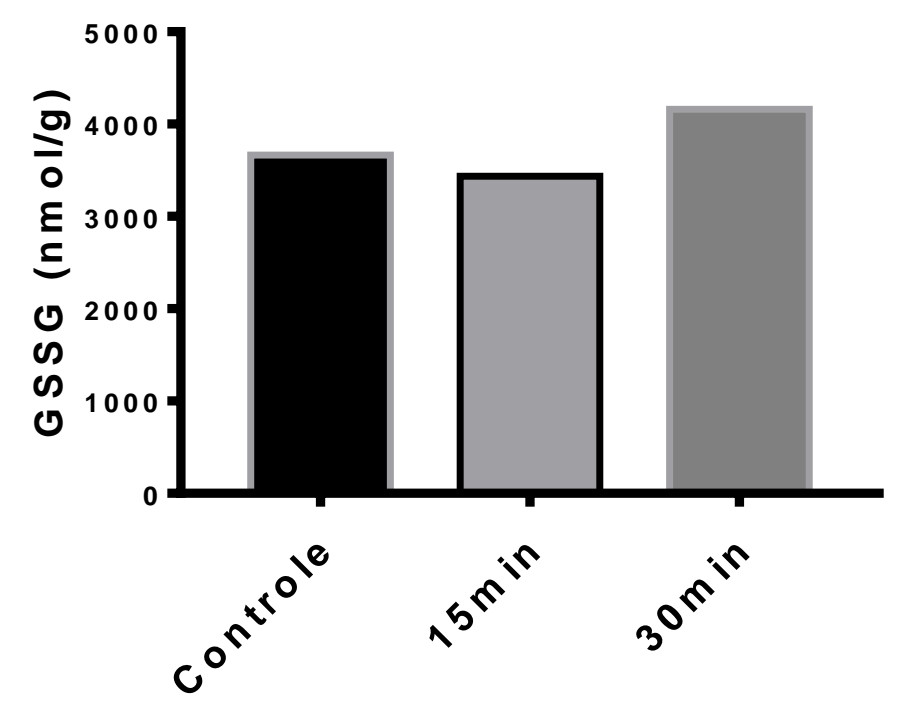

Figura 5. Concentração de GSSG em fígado de girinos expostos a água com hipóxia severa $(0,3 \mathrm{mg} / \mathrm{L})$. Neste teste de sondagem, foi utilizado $\mathrm{n}=1$. 


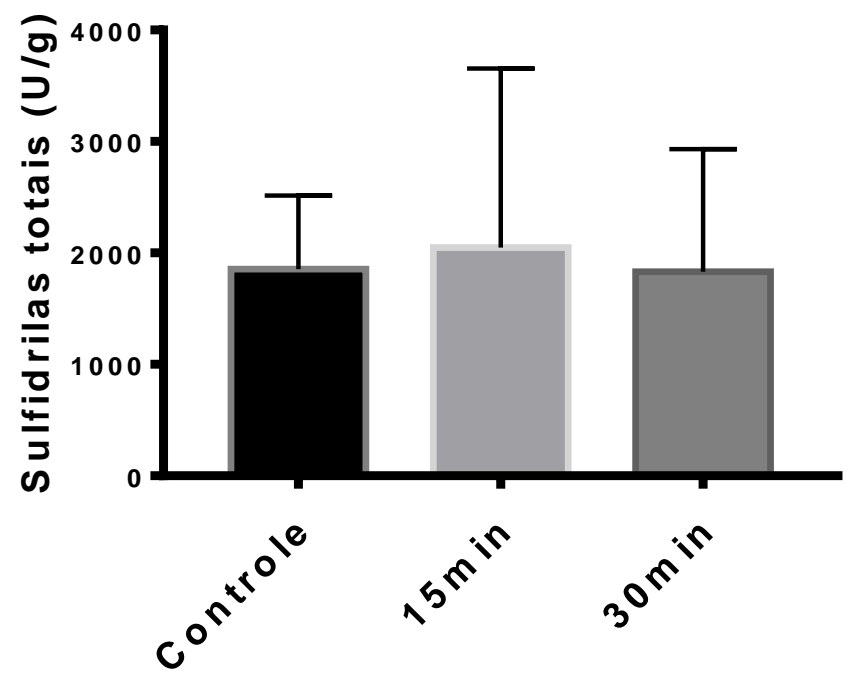

Figura 6. Concentração de sulfidrilas totais em fígado de girinos expostos a água com hipóxia severa $(0,3 \mathrm{mg} / \mathrm{L})$. . Cada grupo com $\mathrm{n}=6$. Não houve diferenças significativas.

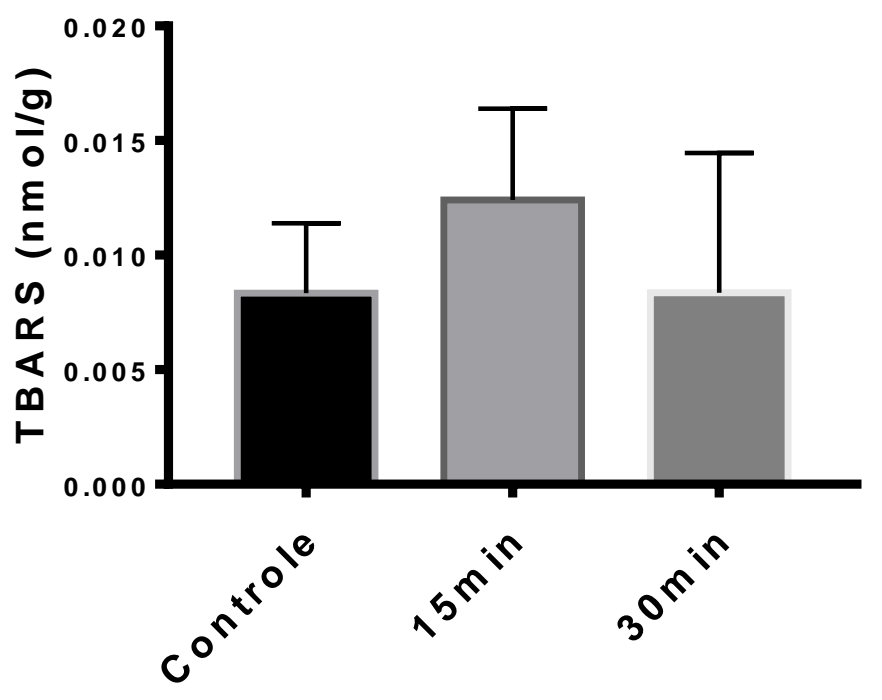

Figura 7. Concentração de TBARS em fígado de girinos expostos a água com hipóxia severa $(0,3 \mathrm{mg} / \mathrm{L})$. Cada grupo com $\mathrm{n}=6$. Não houve diferenças significativas 


\section{DISCUSSÃO E CONCLUSÃO}

A respiração cutânea de L. catesbeianus por difusão é limitada (Clemens, Feder, 1992), o que dificultaria a respiração durante exposição aérea, isto tende a gerar hipóxia - Apesar de ter sido observado um aumento na vascularização na cauda dos girinos (ANEXO E), o aumento na perfusão cutânea não compensa efetivamente a redução de oxigênio do ambiente (Clemens, Feder, 1992). Na fase de girino, anfíbios são conhecidos por apresentarem a maior parte da respiração, $60 \%$, por meio da respiração cutânea, porém, nesta fase, eles já apresentavam pulmões (Burggren, West, 1982). Que pode ter contribuído para a respiração, como observado na Fig. 2, a qual mostrou o aumento na concentração de lactato, indicativo de anaerobiose, com $12 \mathrm{~h}$ de exposição ao ar (à hipóxia). Além disso, girinos de L. catesbeinus, aumentam a frequência respiratória, tornando possível a manutenção da atividade respiratória $\left(98 \% \mathrm{~N}_{2} / 2 \% \mathrm{CO}_{2}\right)$ (Winmill, Chen, Hedrick, 2005). Apesar do estudo mostrar aumento no uso do metabolismo anaeróbico com $3 \mathrm{~h}$ de hipóxia em cérebros isolados de girinos $\left(\begin{array}{lllll}98 & \% & \mathrm{~N}_{2} / 2 & \% & \mathrm{CO}_{2}\end{array}\right)$ (Winmill, Chen, Hedrick, 2005), no corpo inteiro, a queda na concentração de oxigênio parece ser mais gradual, como observado no indicativo de anaerobiose, com $12 \mathrm{~h}$ de exposição. L. catesbeianus é conhecida por sobreviver a anóxia à baixas temperaturas (Wasser et al., 1993). Além disso, a temperatura utilizada nos experimentos 20-26 C, proporcionou o aumento no consumo de oxigênio que aumenta com uma maior temperatura (Rocha, Branco 1997), contribuindo para a morte dos grinos. Desta forma, uma maior temperatura contribui para maiores alterações induzidas pela hipóxia em $L$. catesbeinus (Rocha, Branco 1997). Como os animais não foram pesados no experimento 1 , não foi possível afirmar se o fator de estresse que gerou as mortes foi a desidratação.

No experimento 2 (Fig. 4), os girinos apresentaram uma alta perda de água. Sabese que anfíbios são susceptíveis à perda de água devido sua alta permeabilidade cutânea (Shoemaker, Nagy, 1977). A fim de sanar o problema da desidratação, foi realizado o experimento de hipóxia em ambiente aquático. Na hipóxia aquática, os animais apresentaram comportamento de inércia, com redução de nados e ficando na superfície do aquário, no qual havia uma pequena coluna de ar (necessária para o borbulhamento de nitrogênio gasoso). Esse comportamento condiz com o expressado por L.catesbeianus adultas, as quais suprimem a ventilação branquial e aumentam a respiração aérea (pulmões) (West, Burggren, 1983). Além disso, a redução de nados reduz o gasto de energia, sendo um indicativo da depressão metabólica, característico de animais que 
enfrentam flutuações no consumo de oxigênio (Storey, 1996). Isso deve ter permitido a total sobrevivência dos animais com $12 \mathrm{~h}$ de exposição (Fig. 5) à hipóxia severa de 0,3 mg/L (Welker et al., 2013).

Considerando 12 h o tempo máximo de resistência da espécie L. catesbeianus, à hipóxia, foi realizado o experimento de hipóxia severa em ambiente aquático por até o tempo de 6 h. Em células de mamíferos, com 15 min em hipóxia de 1-2\%, há aumento na produção de ERO's (Hernansanz-Agustín et al., 2014). No presente trabalho, foram realizadas medições de danos oxidativos nos tempos de 15 e 30 minutos de exposição a hipóxia de 5\%. Apesarde não ter sido observado alterações significativas no nível de danos oxidativos (Figs. 4-7), há uma tendência de aumento de GSH, sulfirilas e de TBARS no tempo de 15 minutos, enquanto com 30 minutos há uma redução. Espécies tolerantes a flutuações no consumo de oxigênio, como L. catesbeianus, são conhecidas por reduzirem sua taxa metabólica e aumentarem suas defesas antioxidantes (HermesLima e Storey, 1998; Welker et al., 2012), tornando-os resistentes ao estresse oxidativo. Há espécies que sobrevivem por dias em baixas concentrações de oxigênio (Ultsch, Reese, Stewart, 2004). Como não se conseguiu manter constante a concentração de oxigênio nos aquários de 1,3 e 6 h no experimento 3, não foi possível, tornar o protocolo reprodutível, para medições nestes tempos. 


\section{REFERÊNCIAS BIBLIOGRÁFICAS}

Akerboom TP, Sies H. Assay of glutathione, glutathione disulfide, and glutathione mixed disulfides in biological samples. Methods Enzymol. 1981; v. 77, p. 373382.

Beutler E, Duron O, Kelly BM Improved method for the determination of blood glutathione. J Lab Clin Med.1963; 61,882-888.

Buege JA, Aust SD. Microsomal lipid peroxidation. Methods Enzymol. 1978; v. 52, p. 302-310.

Burggren WW, West NH. Changing respiratory importance of gills, lungs and skin during metamorphosis in the bullfrog Rana catesbeiana. Respiration physiology. 1982; 47(2), 151-164

Carpenter JH. The accuracy of the Winkler method for dissolved oxygen. Limnol.; Oceanog. 1965; 10: 135-140.

Chen, L., Einbinder, E., Zhang, Q., Hasday, J., Balke, C.W., Scharf, S.M. Oxidative stress and left ventricular function with chronic intermittent hypoxia in rats. Am. J. Respir. Crit. Care Med. 2005; 172: 915-920.

Cini M, Fariello RG, Bianchetti A, Moretti A. Studies on lipid peroxidation in the rat brain. Neuro chemical research. 1994; 19(3): 283-288.

Clemens DT, Feder ME. Dependence of oxygen uptake on ambient PO 2 in isolated perfused frog skin. Journal of Comparative Physiology B. 1992; 162(7), 646-650.

Davidson DF. Analysis for lactate and pyruvate with the LKB 8600 reaction rate analyzer.Clinical Chemistry 1978; v. 24, p.512-3.

Duranteau J, Chandel NS, Kulisz A, Shao Z \& Schumacker PT. Intracellular signaling by reactive oxygen species during hypoxia in cardiomyocytes.J Biol Chem. 1998; 273:11619-11624.

Elgebaly MM, Ogbi S, LI W, Mezzetti EM, Prakash R, Johnson MH, Bruno A, Fargan B, Ergul A. Neurovascular injury in acute hyperglycemia and diabetes: a comparative analysis in experimental stroke. Translational stroke research. 2011; 2(3): 391-398.

Ferreira MVR, Alencastro ACR, Hermes-lima M. Role of antioxidante defenses during estivation and anoxia exposure in the fresh wate rsnail Biomphalaria tenagophila (Orbigny, 1835). Canadian journal of zoology. 2003; 81(7):12391248

Fonseca EM, Silva GSF, Fernandes M, Giusti H, Noronha-de-Souza CR, Glass ML, Bícego KC, Gargaglioni LH. The breathing pattern and the ventilatory response to aquatic and aerial hypoxia and hypercarbia in the frog Pipa carvalhoi. Comp Biochem and Physiol, Part A. 2012; v.162 p.281-287. 
Forman MB, Perry JM, Wilson BH, Verani MS, Kaplan PR., Shawl FA, Friesinger GC. Demostration of Myocardial Reperfusion Injury in Humans: Results of a Pilot Study Utilizing Acute Coronary Angioplasty whit Perfluorochemical in Anterior Myocardial Infarction. Journal of the American College of Cardiology. 1991; 18 (14): 911-918.

Garlick PB, Davies MJ, Hearse DJ ,Slater TF. Direct detection of free radicals in the reperfused rat heart using electron spin resonanc espectroscopy. Circulation research. 1987; 61(5):757-760.

Ge M, Chi X, Zhang A, Luo G, Sun G, Xie H, Hei Z. Intestinal NF-E2-related factor-2 expression and antioxidant activity changes in rats undergoing orthotopic liver autotransplantation. Oncology letters. 2013; 6(5):1307-1312.

Gregory EM, Fridovich I. Induction of superoxide dismutase by molecular oxygen. Journal of bacteriology.1973; 114(2): 543-548.

Griffith OW. Determination of glutathione and glutathione disulfide using glutathione reductase and 2-vinylpyridine. Anal Biochem. 1980; v. 106, p. 207212.

Grisham MB, Hernandez LA, Granger DN. Xanthine oxidase and neutrophil infiltration in intestinal ischemia. American Journal of PhysiologyGastrointestinal and Liver Physiology. 1986, 251(4): G567-G574.

Hedrick MS, Fahlman CS, Bickler PE. intracellular calcium and survival of tadpole forebrain cells in anoxia. Journal of experimental biology. 2005; 208(4): 681-686.

Hermes-lima M, Storey K. Role of antioxidant defenses in the tolerance of severe dehydration by anurans. The case of the leopard frog Rana pipiens.Molecular and Cellular Biochemistry. 1998; 189: 79-89.

Hernansanz-Agustín, P., Izquierdo-Álvarez, A., Sánchez-Gómez, F. J., Ramos, E., Villa-Piña, T., Lamas, S., Bogdanova, A. and Martínez-Ruiz, A. Acute hypoxia produces a superoxide burst in cells. Free Radic. Biol. Med. 2014; 71C, 146-156..

Huang CY, Lin HC, Lin HC. Effects of hypoxia on ionic regulation, glycogen utilization and antioxidative ability in the gills and liver of the aquatic airbreathingfish Trichogaster microlepis. Comp Biochem Physiol, Part A. 2015; v.179 p.25-34.

Kennedy TP, Rao NV, Hopkins C, Pennington L, Tolley E, Hoidal JR. Role of reactive oxygen species in reperfusion injury of the rabbit lung. Journal of Clinical Investigation. 1989; 83(4): 1326.

Lopes, AR, Trübenbach K., Teixeira T, Lopes VM, Pires V, Baptista M., Repolho T, Calado R, Diniz M, Rosa R. Oxidative stress in deep scattering layers: Heat shock response and antioxidant enzymes activities of myctophid fishes thriving in 
oxygen minimum zones. Deep Sea Research Part I: Oceanographic Research Papers. 2013;82:10-16.

Lushchak VI, Lushchak LP, Mota AA, Hermes-Lima M. Oxidative stress and antioxidant defenses in goldfish Carassius auratus during anoxia and reoxygenation.Am J Physiol Regulatory Integrative Comp Physiol. 2001; 280:100-107

Maupoil V, Rochette L. Evaluation of free radical and lipid peroxide formation during global ischemia and reperfusion in isolated perfused rat heart. Cardiovascular Drugs and Therapy. 1988; 2(5) :615-621.

Meng Z, Cao R, Wang Y, Cao H, Liu T, Yang Z, Wang X. Suppression of renal TRPM7 may alleviate kidney injury in the renal transplantation. World Journal of Urology. 2013: 1-9.

Michaelidis B. Studies on the extra- and intracellular acid-base status and its role on metabolic depression in the land snail Helix lucorum (L.) during estivation. J Comp PhysiolB. 2002; 172: 347-354.

Møller P, Loft S, Lundby C,Olsen N V. Acute hypoxia and hypoxic exercise induce DNA strand breaks and oxidative DNA damage in humans. The FASEB Journal. 2001; 15(7)1181-1186.

Mühl D, Füredi R, Cristofari J, Ghosh S, Bogár L, Borsiczki B Z, Gasz B Z, Rőth E, Lantos J. Evaluation of oxidative stress in the thrombolysis of pulmonary embolism.J. Throm. Thrombolysis. 2006; 22 :221-228.

Nohl H, Hegner D. Do mitochondria produce oxygen radicals in vivo? European Journal of Biochemistry. 1978; 82( 2): 563-567.

Phelan AM, Lange DG. Ischemia/reperfusion-induced changes im membrane fluidity characteristics of brain capillary endothelial cells and its prevention by liposomal-incorporated superoxide dismutase.Biochimicaet Biophysica Acta. 1991; 1067: 97-102.

Ramos-vasconcelos GR, Hermes-lima M. Hypometabolism, antioxidant defenses and free radical metabolism in the pulmonateland snail Helix aspersa. $\mathrm{J}$ ExpBiol. 2003; 206: 675-685.

Rocha PL, Branco LGS. Cardiovascular, respiratory and metabolic responses to temperature and hypoxia of the winter frog Rana catesbeiana. Brazilian journal of medical and biological research, 1997; 30, 125-131.

Routley MH, Nilsson GE, Renshaw GMC. Exposure to hypoxia primes the respiratory and metabolic responses of the epaulette shark to progressive hypoxia. Comparative Biochem Physiol Part A. 2002; v.131 p.313-321. 
Sanfey H, Bulkley Gregory B, Cameron J L. The pathogenesis of acute pancreatitis. The source and role of oxygen-derived free radicals in three different experimental models. Annals of surgery. 1985; 201(5): 63.

Seixas Filho JT, Gomes LH, Aguiar DVC, et al.. Avaliação histológica do intestino médio, do fígado e do pâncreas de girinos de rã-touro alimentados com rações comerciais formuladas com três níveis de proteína bruta. Revista Brasileira de Zootecnia. 2008; 37(12), 2090-2096.

Shoemaker V, Nagy KA. Osmoregulation in amphibians and reptiles. Annual Review of Physiology. 1977; 39(1), 449-471.

Storey KB. Oxidative stress: animal adaptations in nature. Braz. J. Med. Biol. Res. 29. 1996; 1715-1733.

Taylor AC, Kollros JJ. Stages in the normal development of Rana pipiens larvae. The Anatomical Record. 1946; 94(1), 7-23.

Ultsch GR, Reese SA, Stewart E. Physiology of hibernation in Rana pipiens:

Metabolic rate, critical oxygen tension, and the effects of hypoxia on several plasma variables. J of Experimental Zoology Part A: Comparative Experimental Biology. 2004; 301(2):169-176.

Ultsch GR, Reese SA, Stewart E. Physiology of hibernation in Rana pipiens: metabolic rate, critical oxygen tension, and the effects of hypoxia on several plasma variables. Journal of Experimental Zoology Part A: Comparative Experimental Biology. 2004; 301(2), 169-176.

Wasser JS, Jackson DC, Chang SY, Warburton SJ. Maintenance of high extracellular $\mathrm{pH}$ does not influence cell $\mathrm{pH}$ or metabolism in submerged anoxic bullfrogs. Journal of Experimental Zoology. 1993; 265(6), 619-626.

Welker AF. Efeitos da flutuação da disponibilidade de oxigênio e da privação alimentar sobre o metabolismo de radicais livres. Universidade de São Paulo 2009, Brasil.

Welker AF, Campos EG, Cardoso LA, Hermes-lima M. Role of catalase on the hypoxia/reoxygenation stress in the hypoxia-tolerant Nile tilapia. Am J Physiol Regul Integr Comp Physiol. 2012; 302:1111-1118.

Welker AF, Moreira DC, Campos EG, Hermes-Lima M. Role of redox metabolism for adaptation of aquatic animals to drastic changes in oxygen availability. Comp Biochem Physiol A Mol Integr Physiol. 2013 Apr 12. In press.

West NH, Burggren WW. Reflex interactions between aerial and aquatic gas exchange organs in larval bullfrogs. American Journal of Physiology-Regulatory, Integrative and Comparative Physiology. 1983; 244(6), R770-R777. 
Winmill RE, Chen AK, Hedrick MS. Development of the respiratory response to hypoxia in the isolated brain stem of the bullfrog Rana catesbeiana. Journal of experimental biology. 2005; 208(2): 213-222.

Zweier JL, Flaherty JT, Weisfeldt, ML. Direct measurement of free radical generation following reperfusion of ischemic myocardium.Proc.Nati. Acad. Sci. USA. 1987 ; 84(84): 1404-1407.

Zweier JL, Kuppusamy P, Williams R, Rayburn BK, Smith D, Weisfeldt ML, Flaherty JT. Measurement and characterization of postischemic free radical generation in the isolated perfused heart. Journal of Biological Chemistry. $1989 ; 264(32): 8890-18895$. 


\section{ANEXOS}

ANEXO A- Criação ovos de grinos, com esterco, para criação de zooplâncton.

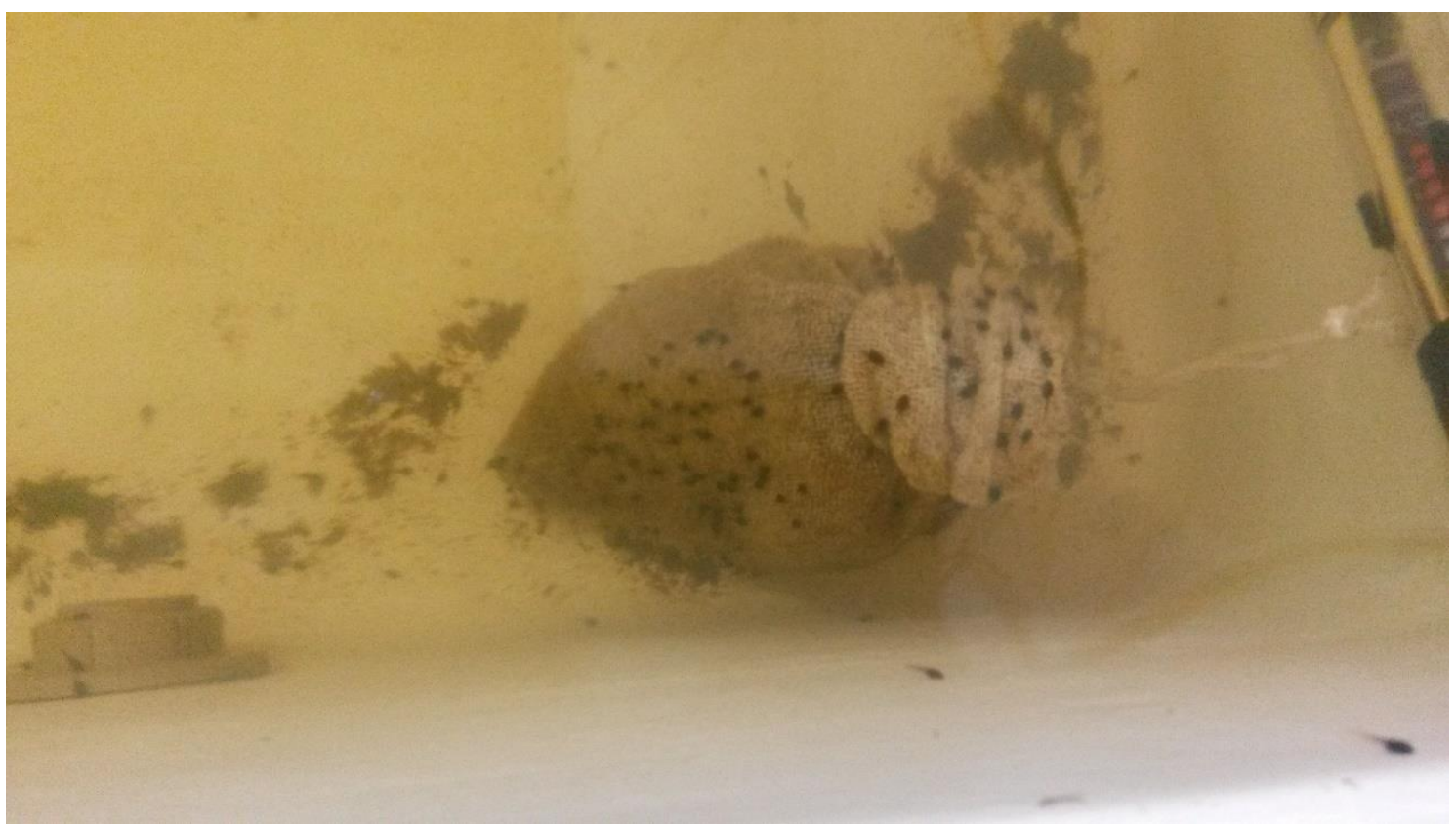

ANEXO B - Criação de girinos, estágio I-VI (Taylor e Kollros 1946), com temperatura de $25 \pm 1^{\circ} \mathrm{C}$, pH 6, amônia $0,000 \pm 0,008$, oxigenação controlada por meio de aeração, e com densidade de $1 \mathrm{U} / \mathrm{L}$, fotoperíodo 12:12.

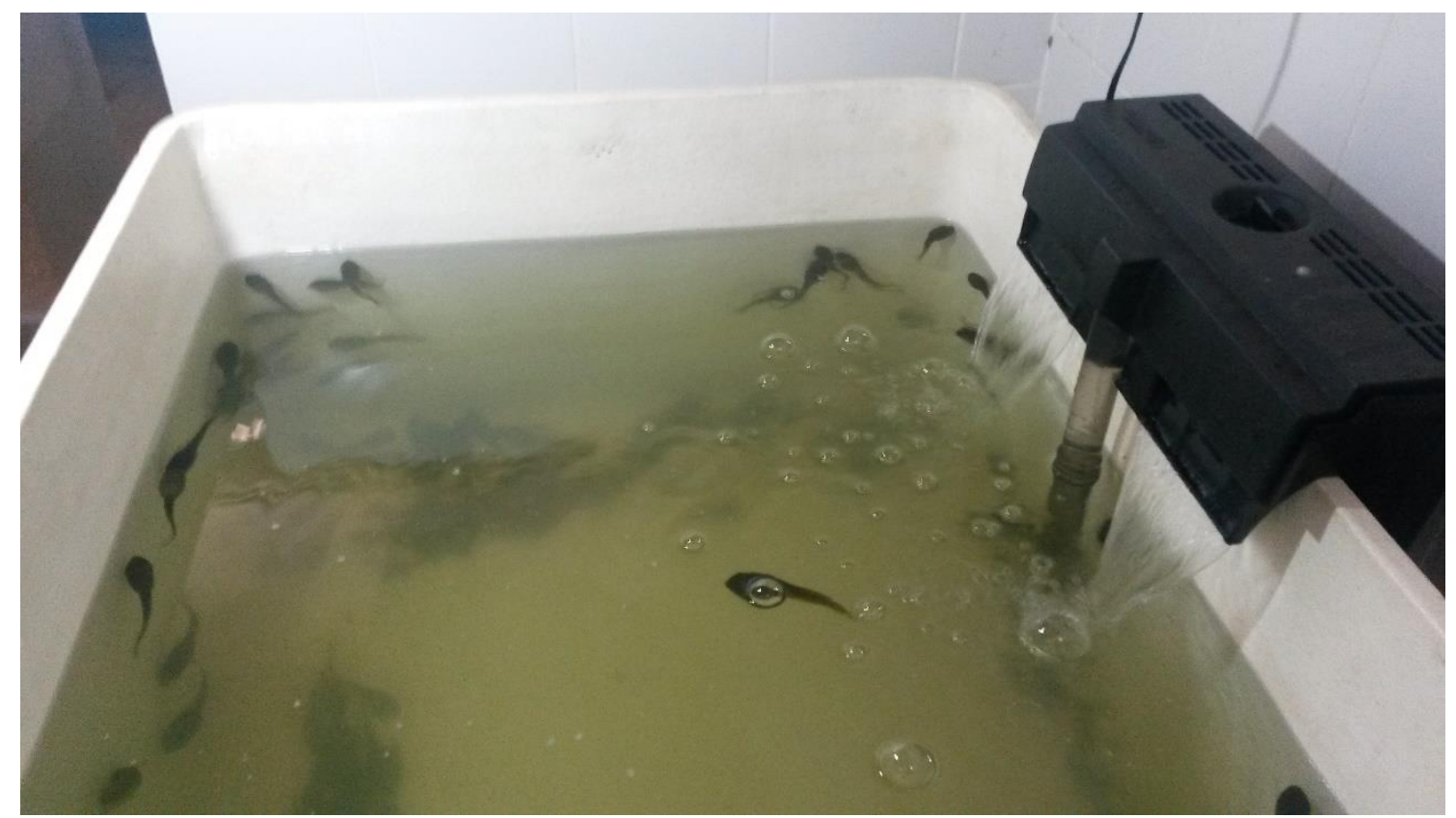


ANEXO C - Imagem do aquário utilizado para o experimento de hipóxia severa.

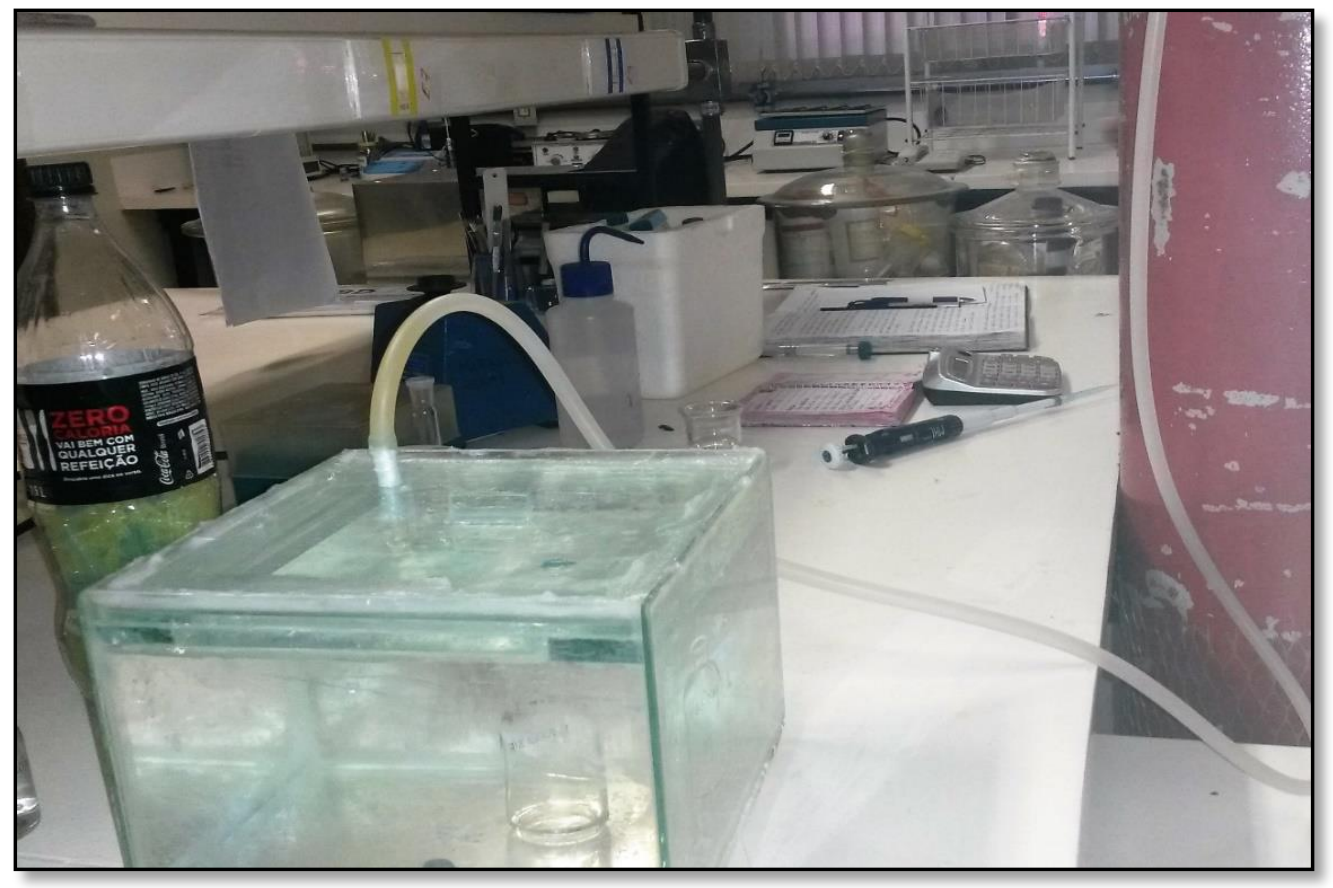

ANEXO D- Comportamento dos animais, na superfície do aquário, durante hipóxia severa $(0,3 \mathrm{mg} / \mathrm{L})$.

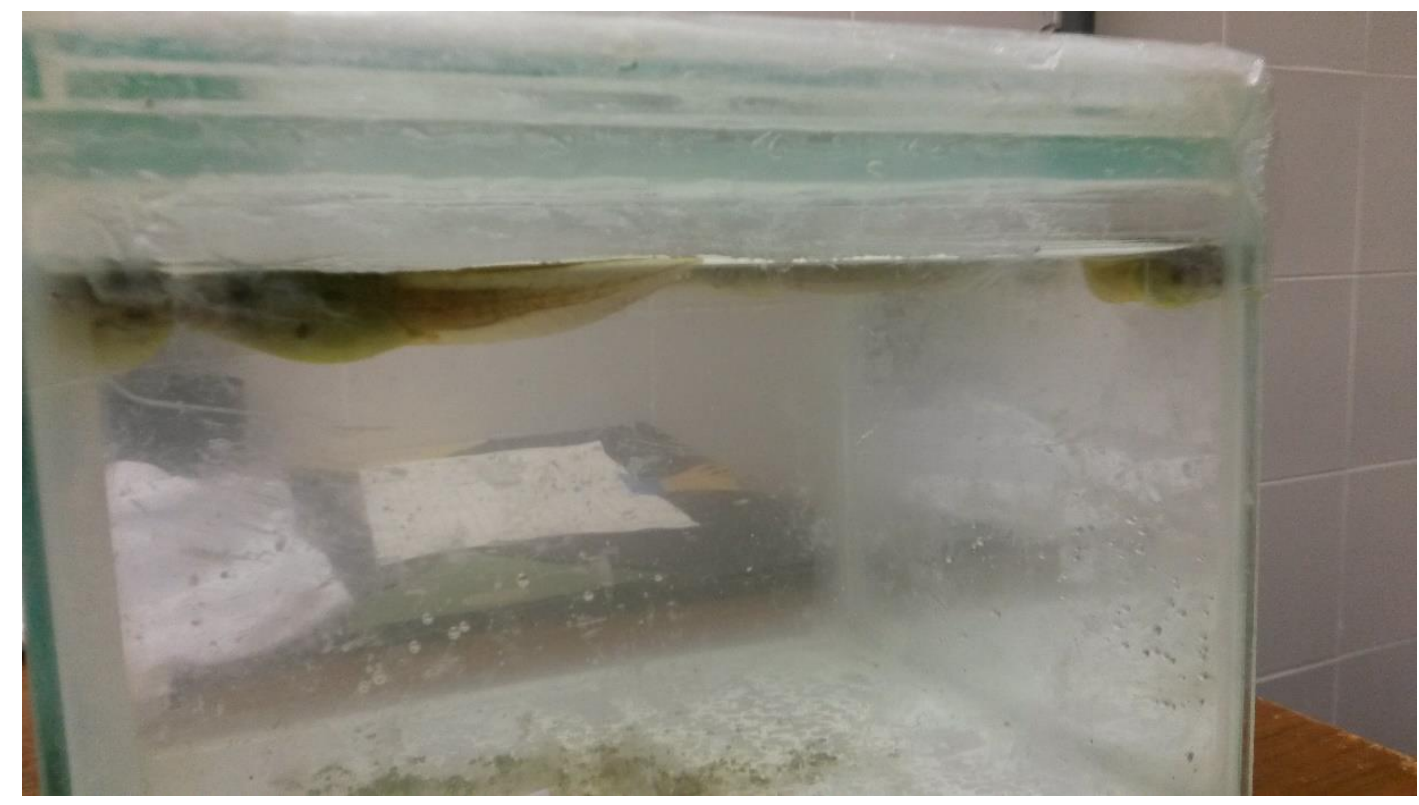


ANEXO E Aumento da vascularização da cauda de girinos (cauda vermelha), na exposição ao ar.

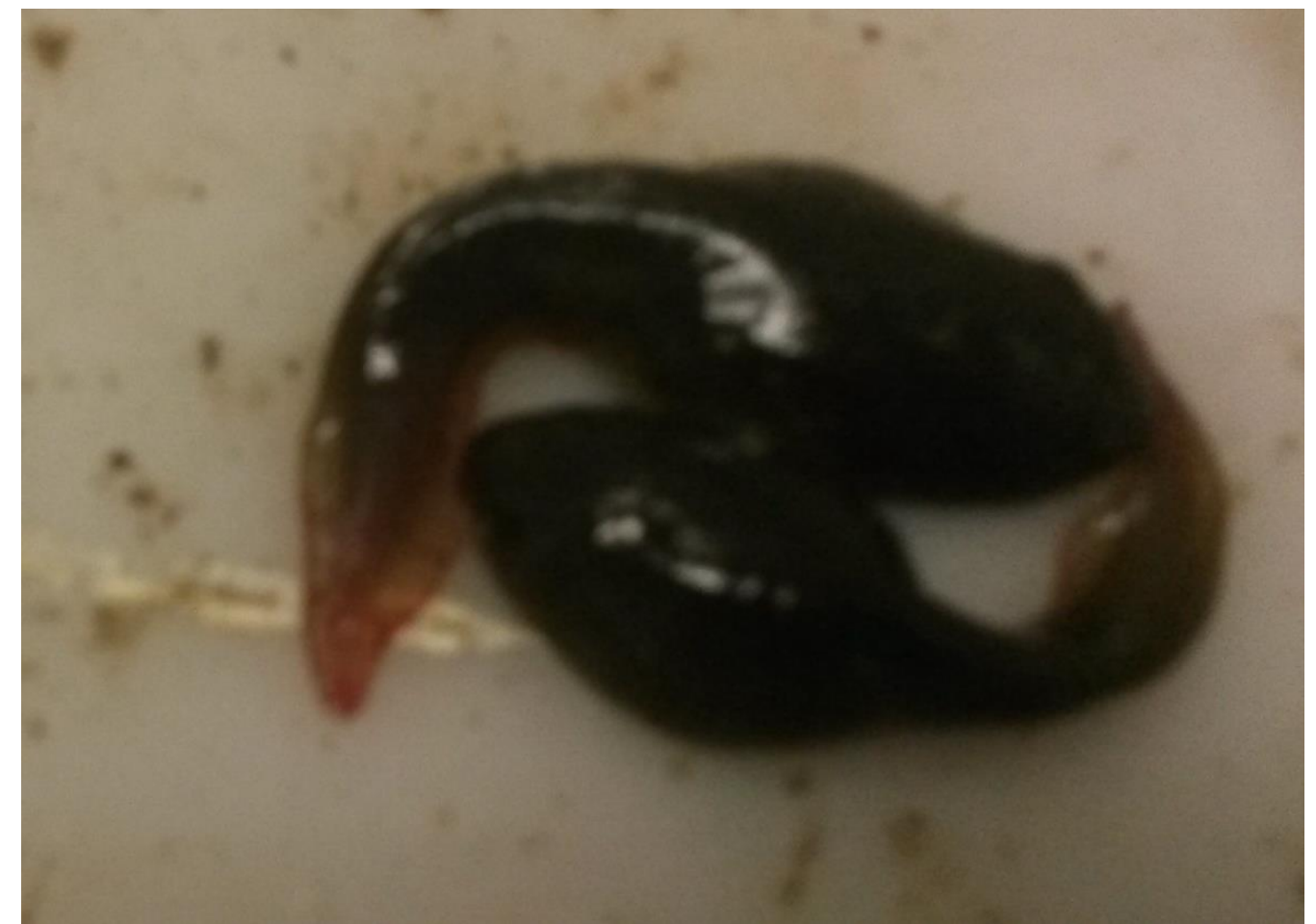




\section{Capítulo 2 - resistênCIA À DiminUiÇão do PROVIMENTO SISTÊMICO DE OXIGÊNIO ADVINDO DA DESIDRATAÇÃO EM UM ANIMAL AQUÁTICO}




\section{RESISTÊNCIA À DIMINUIÇÃO DO PROVIMENTO SISTÊMICO DE OXIGÊNIO ADVINDO DA DESIDRATAÇÃO EM UM ANIMAL AQUÁTICO}

\section{INTRODUÇÃO}

$\mathrm{Na}$ natureza, há muitos animais que passam por estresses ambientais, como estivação, hibernação e desidratação, que levam a flutuações no consumo de oxigênio. Para sobreviverem, os animais apresentam adaptações metabólicas que os tornam tolerantes ao estresse (Zhang et al., 2012; Hermes-Lima, Zenteno-Savin, 2002).

Anfíbios, devido à sua pele altamente permeável, são susceptíveis à perda de água decorrente da baixa umidade do ar, sendo o tamanho corporal um dos principais determinantes para a taxa de evaporação (Shoemaker, Nagy, 1977). A tolerância à desidratação em anfíbios depende de diversos fatores, como a velocidade da perda de água, a temperatura e as condições gerais dos animais (Bentley, 1966). Eles podem tolerar uma perda de cerca de $60 \%$ de peso de água corporal (Shoemaker, Nagy, 1977; HermesLima, Storey, 1998). Para tolerar a desidratação, eles entram no estado de hipometabolismo, suprimindo vias que tenham um alto gasto energético (Roufayel, Biggar, Storey, 2011, Hillman 1978), modulam o metabolismo, aumentando os níveis de glicose sanguínea e tecidual, os níveis de lactato e ativando kinases (Churchill, Storey, 1995; Holden, Storey, 1997; Malik, Storey, 2009). Além disso, a desidratação aumenta a osmolaridade sanguínea, diminui a entrega de oxigênio sanguíneo causando hipóxia e ou anóxia, causando danos ao DNA (Andrew, 1991) e diminuindo a taxa de sobrevivência (Hermes-Lima, Storey, 1998).

Humanos são pouco tolerantes à desidratação, com perda de $10 \%$ apresentam vários problemas clínico (Andrew, 1991). Quando desidratados, os mamíferos, aumentam o risco à isquemia causada pela hiperosmolaridade, aumentando a produção de Espécies Reativas de Oxigênio (ERO’s) e causando disfunção cerebral (Faraco et al., 2014). Esses danos a moléculas e lesões em tecidos ocorrem devido ao desbalanço entre as defesas antioxidantes e a produção de ERO's, ou seja, o sistema antioxidante não é eficiente o suficiente para que os tecidos resistam à maior quantidade formada de ERO’s (Cini et al., 
1994; Phelan e Lange, 1991; Maupoil e Rochete, 1988; Zweier et al., 1989), contrário ao que ocorre em espécies resistentes ao estresse, tornando importante o seu estudo.

Desta forma, este estudo pretendeu investigar a resistência de uma espécie de anfíbio à diminuição do provimento sistêmico de oxigênio ocasionado pela desidratação .

\section{OBJETIVOS}

Analisar a resistência da espécie Lithobates catesbeianus à redução sistêmica de oxigênio advinda do estresse de hipóxia e desidratação.

\section{MATERIAIS E MÉTODOS}

\section{Aclimatação}

Foram comprados girinos da fazenda Rander (www.rander.com.br), com aproximadamente 65 dias de eclodidos, estágio I-VI (Taylor ,Kollros, 1946), com peso entre 5-7 g, os quais ainda não possuem membros posteriores integralmente formados, e são totalmente dependentes da água. Eles foram transportados em sacos plásticos com oxigênio até ao Biotério do Instituo de Biologia da Universidade de Brasília-UnB. Eles foram mantidos por uma semana em aquário. Na água, foi usado anti-cloro, temperatura de $25 \pm 1^{\circ} \mathrm{C}, \mathrm{pH}$, amônia $0,000 \pm 0,008$, oxigenação controlada por meio de aeração, e com densidade de $1 \mathrm{U} / \mathrm{L}$, fotoperíodo 12:12. Em dias alternados, os girinos foram alimentados com ração $55 \%$ de proteína. Este projeto foi avaliado e aprovado pela Comissão de Ética no Uso Animal (CEUA) do Instituto de Ciências Biológicas da Universidade de Brasília.

\section{Determinação do conteúdo de água corporal e dos tecidos}

Para determinar a quantidade de água corporal de L. catesbeianus, foram usados dez girinos (5-7 g). Seguindo protocolo Churchill e Storey (1993), os girinos foram pesados e colocados em estufa à $90{ }^{\circ} \mathrm{C}$ por 24 horas. Após verificar que o peso deles estavam constante, foi possível determinar o conteúdo de água do animal $\left(\mathrm{g} \mathrm{H}_{2} \mathrm{O} / \mathrm{g}\right.$ de peso) pela perda de peso observada.. 
A quantidade de água no fígado $(n=10)$ e no músculo da cauda $(n=5)$ foi determinada seguindo o mesmo procedimento descrito acima, em estufa à $90{ }^{\circ} \mathrm{C}$ por 12 horas.

\section{$\underline{\text { Experimento 1 }}$}

\section{Desidratação: taxa de perda de água e mortalidade}

No primeiro experimento, 60 girinos foram retirados da água, pesados e expostos ao ar sem hidratação, em temperatura média de $25^{\circ} \mathrm{C} \pm 0,1$ e umidade de $67,7 \% \pm 4$, a qual foi medida e monitorada com higrômetro e mantida com umidificador de ar. O umidificador foi mantido distante dos animais e permitiu uma taxa de perda de água controlada. A cada hora os animais foram pesados (Fig. 1) para verificar a taxa da perda de água e para determinar a taxa de mortalidade. Esta foi verificada através da interrupção das funções vitais (movimento bucal, presença ou ausência de batimento cardíaco, resposta a estímulo externo - toque na cauda).

\section{Reidratação e mortalidade}

Após a desidratação por $8 \mathrm{~h}(\mathrm{n}=20), 10 \mathrm{~h}(\mathrm{n}=20)$ e $12 \mathrm{~h}(\mathrm{n}=20)$, grupos de animais foram retornados à água e mantidos nela por 24 h para verificar a sobrevivência.

\section{$\underline{\text { Experimento 2 }}$}

\section{Desidratação: taxa de perda de água e mortalidade}

Foram utilizados 44 girinos, os quais foram expostos ao ar sem hidratação, temperatura média de $23{ }^{\circ} \mathrm{C} \pm 0,2$ e umidade de $88,4 \% \pm 2$, a qual foi medida e monitorada com higrômetro e mantida com umidificador de ar. O umidificador foi mantido distante dos animais e permitiu uma taxa de perda de água controlada . Conforme o primeiro experimento, a cada hora os animais foram pesados para verificar a taxa da perda de água e para determinar a taxa de mortalidade.

\section{Reidratação e mortalidade}

Após a desidratação, foram adicionados $40 \mathrm{~mL}$ de água, quantidade suficiente para cobrir os aniamis, sem cloro no recipiente de cada girino. Após 1 h $(n=11)$ e 3 h de 
reidratação $(n=11)$, os demais animais foram retornados ao tanque de água para avaliar sobrevivência por $24 \mathrm{~h}$.

\section{Análise Estatística}

Para determinar o conteúdo de água ( $\mathrm{g} \mathrm{H}_{2} \mathrm{O} / \mathrm{g}$ de peso) de cada animal durante a desidratação, foi utilizada a fórmula (Churchill, Storey, 1993):

$$
\frac{(\mathrm{Pi}-\mathrm{Pf})}{(\mathrm{Pi}-\mathrm{Bwc})} \times 100, \text { onde }
$$

Pi: Peso inicial

Pf: Peso final

Bwc: conteúdo de g de água por g de peso

As análises estatísticas descritivas foram feitas no software Graphad Prism 7.0.

\section{RESULTADOS}

Os girinos de Lithobates catesbeianus apresentaram $85 \%$ de água corporal (ANEXO A). O músculo (cauda) possui 70,41 \% de água (ANEXO B) e o fígado 29,53 $\%$ (ANEXO C).

No primeiro experimento de desidratação, os girinos tiveram em média uma taxa de perda de água de 3,5\%/h (Fig. 1). Após 7 h de experimento, um girino morreu. Com 8h, os animais já haviam desidratado 36,68 \%, com isso 19 girinos foram devolvidos à água (porque um havia morrido). 


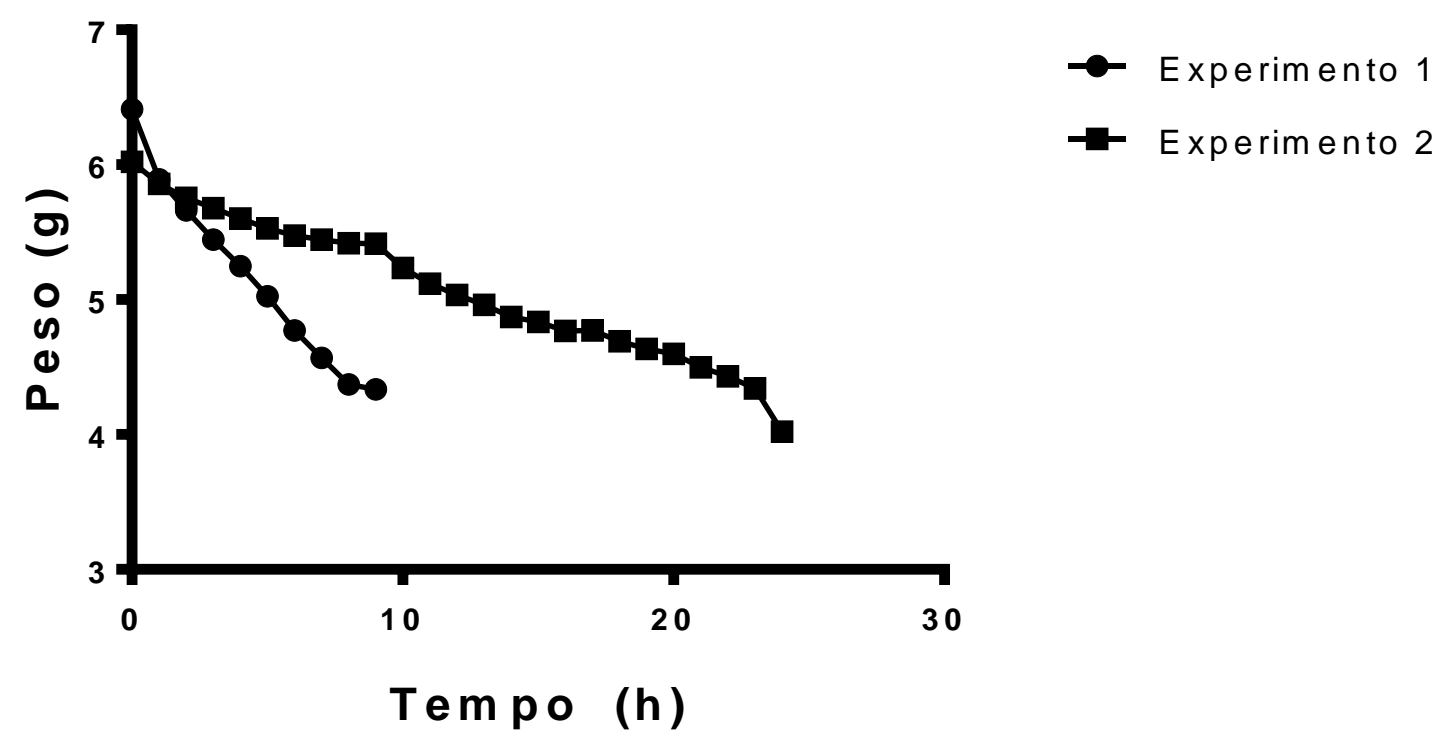

Figura 1. Perda de peso (g) por hora de desidratação.

Às $10 \mathrm{~h}$ de desidratação, com uma média de perda de peso de água de 37,33\%, já haviam morrido 36,66 \% de animais. Não foi avaliada a desidratação até 12 h, devido as mortes ocorridas e por apresentarem letargia. No segundo experimento, foi verificada uma taxa de perda de água de 1,5\%/h. Após 24 h de desidratação, com uma média de perda de peso de água de 38,69 \%, apenas um animal havia morrido (Fig. 2). 


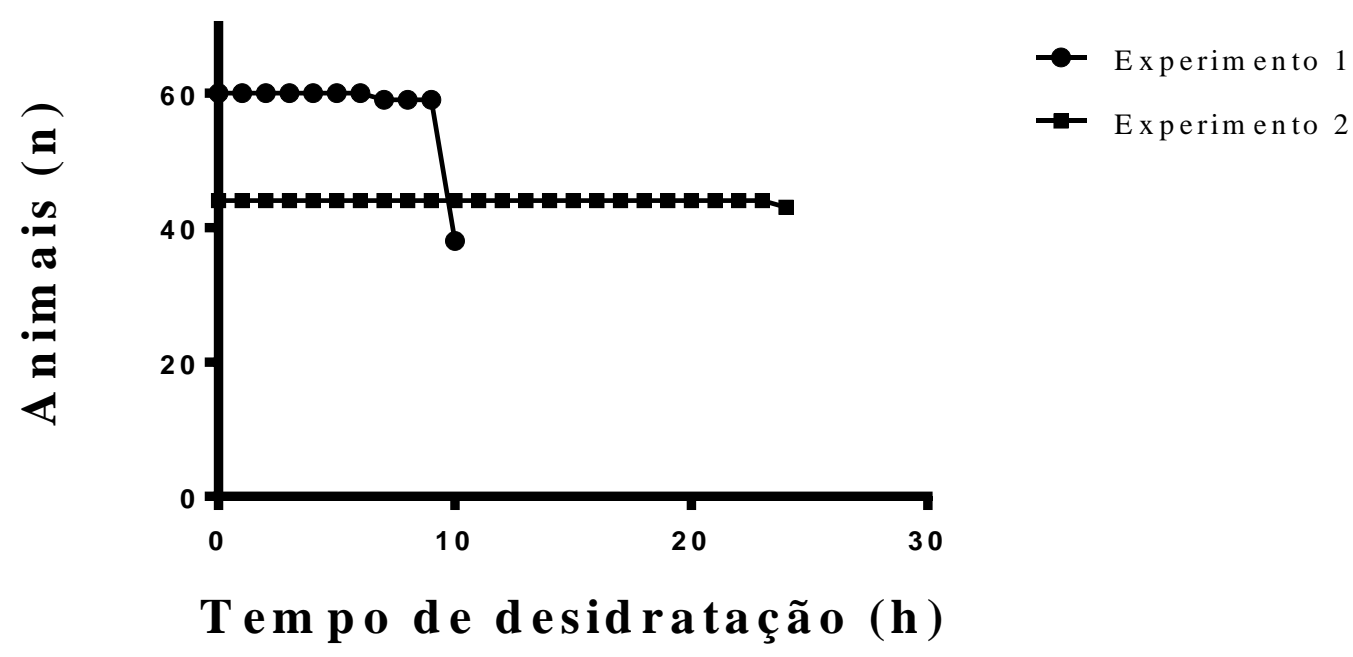

Figura 2. Taxa de sobrevivência durante a desidratação.

Todos os animais restantes do primeiro experimento foram colocados em aquários e sua sobrevivência avaliada por 48 h, os quais apresentaram 81,5\% de morte. Alguns animais foram pesados aleatoriamente, para verificar o ganho de peso por hora. Com $4 \mathrm{~h}$, os animais começaram a morrer, então só foi observado o ganho até $3 \mathrm{~h}$ de reidratação. No segundo experimento, entre 1 h e 1h30min, 8 animais dos 11 que foram selecionados para pesagem pós reidratação, ganharam uma média de 7,9 \% de água (Fig. 3). O segundo a ser analisado após 3 h de reidratação, só restaram 3 vivos de 11 animais, este grupo não foi pesado. Então, durante a reidratação dos animais, 4,54 \% morreram no decorrer de 2 h submersos a água, enquanto após 4h de reidratação, 68 \% já apresentaram morte. 


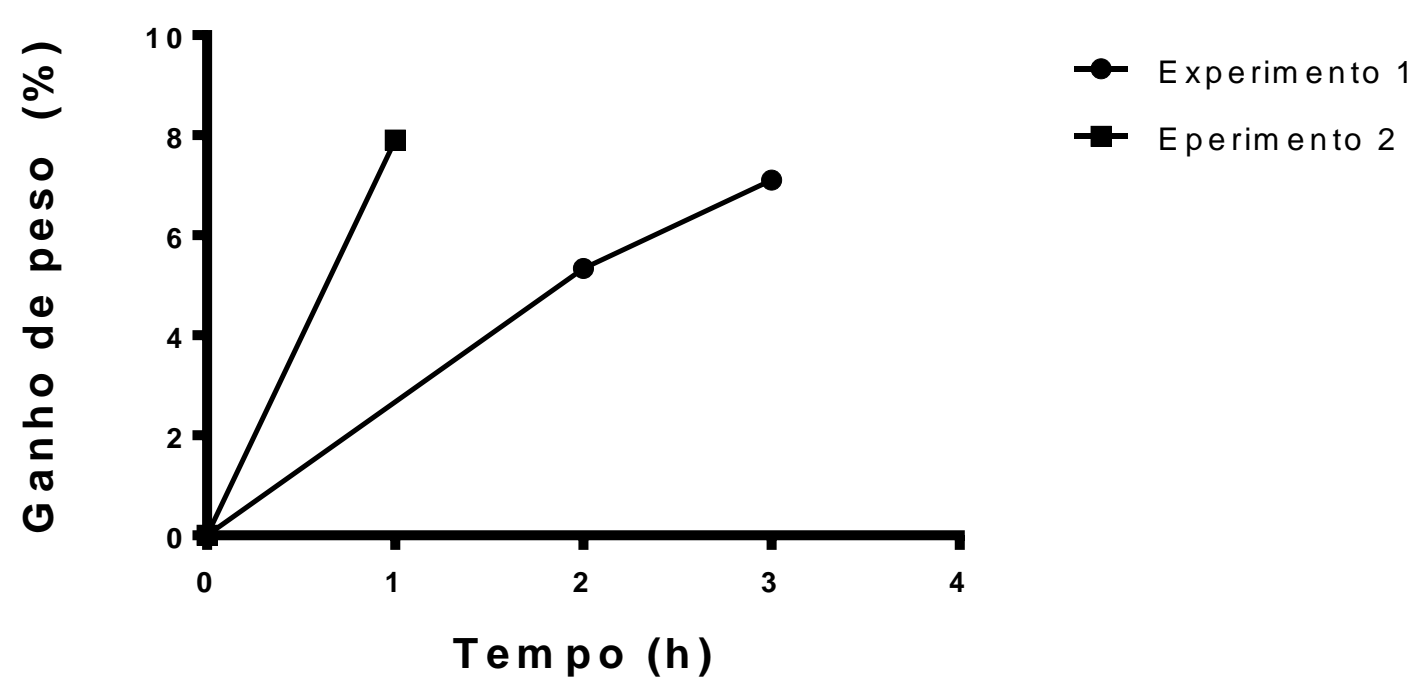

Figura 3. Ganho de peso (\%) ao longo da reidratação.

No decorrer dos dois experimentos de desidratação, as caudas dos girinos apresentaram-se vermelhas, com alta vascularização, logo no início à exposição, cerca de 3h (ANEXO E)

\section{DISCUSSÃO E CONCLUSÃo}

A espécie estudada mostrou pouca tolerância ao estresse de desidratação, pois houve uma alta taxa de mortalidade com uma média de $37 \%$ de perda de água corporal nos dois experimentos. Outra espécie, Xenopus laevis, também apresenta pouca tolerância, não suporta desidratação acima de 30 \% (Malik e Storey, 2009). Diferente de outras espécies, Rana pipiens sobrevive a uma desidratação de 50 \% (Hermes-Lima e Storey, 1998). Uma diferença do protocolo deste artigo em relação ao presente estudo foi que o primeiro teve taxa de evaporação de $0,56 \%$ /hora, enquanto que neste presente trabalho, a diferença na taxa de perda de água de $L$. catesbeianus foi de 3,5\%/hora no primeiro experimento e de 1,5\%/hora no segundo. Uma menor taxa de perda de água, 1,5\%/hora, reduziu a mortalidade durante a desidratação, porém na reidratação, houve uma alta taxa de mortalidade de $81,5 \%$ no primeiro experimento e $68 \%$ no segundo experimento. 
A temperatura utilizada neste experimento foi de $23 \pm 2{ }^{\circ} \mathrm{C}$, enquanto em outros trabalhos a temperatura usada foi menor, $5^{\circ} \mathrm{C}$, para R.sylvatica e $R$. pipiens (Churchill, Storey, 1993; Holden, Storey, 1997; Hermes-Lima , Storey, 1998; Katzenback et al., 2014). É provável que a menor taxa metabólica do animal resultante da menor temperatura tenha contribuído para a alta resistência destes animais. Porém, o relato de que outra espécie de anfíbio (X. laevis) apresenta resistência à desidratação a uma temperatura de $22^{\circ} \mathrm{C}$ (Luu, Storey, 2015) corrobora a conclusão de que L. catesbeianus é uma espécie sensível à desidratação.

Espécies resistentes a desidratação apresentam adaptações como aumento da osmolaridade sanguinea, aumento da concentração de glicose plasmática, aceleração do desenvolvimento, aumento da atividade de enzimas antioxidantes, e aumento da expressão de fator de transcrição (Malik, Storey, 2009; Malik, Storey, 2011; GomezMestre, Kulkarni, Buchholz, 2013). Neste trabalho, não foi possível avaliar as adaptações bioquímicas previstas no projeto original de mestrado, pois a espécie mostrou-se pouco tolerante ao estresse. Porém, os experimentos realizados permitiram se chegar à conclusão de que a morte de girinos L. catesbeianus submetidos à exposição ao ar se deve à desidratação e não à hipóxia, uma vez que eles resistem várias horas de hipóxia severa quando mantidos submersos em água quase anóxica. Portanto, neste animal, a exposição ao ar não é um protocolo adequado para se investigar as respostas bioquímicas à hipóxia/anóxia. 


\section{REFERÊNCIAS BIBLIOGRÁFICAS}

Andrew RD. Seizure and acute osmotic change: clinical and neurophysiological aspects. Journal of the neurological sciences. 1991; 101(1), 7-18.

Bentley PJ. Adaptations of amphibia to arid environments. Science. 1966; 152(3722), 619-623.

Churchill TA, Storey KB. Dehydration tolerance in wood frogs: a new perspective on development of amphibian freeze tolerance. American Journal of PhysiologyRegulatory, Integrative and Comparative Physiology. 1993; 265(6), R1324-R1332.

Churchill TA, Storey KB. Metabolic effects of dehydration on an aquatic frog, Rana pipiens. The Journal of experimental biology. 1995; 198(1), 147-154.

Cini M, Fariello RG, Bianchetti A, Moretti, A. Studies on lipid peroxidation in the rat brain. Neurochemical research. 1994; 19(3), 283-288.

Faraco G, Wijasa TS, Park L, Moore J, Anrather J, Iadecola C. Water deprivation induces neurovascular and cognitive dysfunction through vasopressin-induced oxidative stress. Journal of Cerebral Blood Flow \& Metabolism. 2014; 34(5), 852860.

Gomez-Mestre I, Kulkarni, S, Buchholz DR. Mechanisms and consequences of developmental acceleration in tadpoles responding to pond drying. PloS one. 2013; 8(12), e84266.

Hermes-Lima M, Storey KB. Role of antioxidant defenses in the tolerance of severe dehydration by anurans. The case of the leopard frog Rana pipiens. Molecular and cellular biochemistry. 1998; 189(1-2), 79-89.

Hermes-Lima M, Zenteno-Savin T. Animal response to drastic changes in oxygen availability and physiological oxidative stress.Comparative Biochemistry and Physiology Part C: Toxicology \& Pharmacology. 2002; 133(4), 537-556.

Hillman SS. The roles of oxygen delivery and electrolyte levels in the dehydrational death of Xenopus laevis. Journal of comparative physiology. 1978; 128(2), 169-175.

Holden CP, Storey, K. B. Second messenger and cAMP-dependent protein kinase responses to dehydration and anoxia stresses in frogs. Journal of Comparative Physiology B. 1997; 167(4), 305-312.

Katzenback BA, Holden HA, Falardeau J, Childers C, Hadj-Moussa H, Avis TJ, Storey KB. Regulation of the Rana sylvatica brevinin-1SY antimicrobial peptide during development and in dorsal and ventral skin in response to freezing, anoxia and dehydration. Journal of Experimental Biology. 2014; 217(8), 1392-1401.

Luu BE, Storey KB. Dehydration triggers differential microRNA expression in Xenopus laevis brain. Gene. 2015; 573(1), 64-69. 
Malik AI, Storey KB. Transcriptional regulation of antioxidant enzymes by FoxO1 under dehydration stress. Gene. 2011; 485(2), 114-119.

Malik AI, Storey KB. Activation of extracellular signal-regulated kinases during dehydration in the African clawed frog, Xenopus laevis. Journal of Experimental Biology. 2009; 212(16), 2595-2603.

Maupoil V, Rochette L. Evaluation of free radical and lipid peroxide formation during global ischemia and reperfusion in isolated perfused rat heart. Cardiovascular Drugs and Therapy. 1988; 2 (5), p. 615-621.

Phelan AM, Lange DG. Ischemia/reperfusion-induced changes im membrane fluidity characteristics of brain capillary endothelial cells and its prevention by liposomalincorporated superoxide dismutase. Biochimica et Biophysica Acta. 1991; 1067, p.97-102.

Roufayel R, Biggar KK, Storey KB. Regulation of cell cycle components during exposure to anoxia or dehydration stress in the wood frog, Rana sylvatica. Journal of Experimental Zoology Part A: Ecological Genetics and Physiology. 2011; 315(8), 487-494.

Shoemaker V, Nagy KA. Osmoregulation in amphibians and reptiles. Annual Review of Physiology. 1977; 39(1), 449-471.

Taylor AC, Kollros JJ. Stages in the normal development of Rana pipiens larvae. The Anatomical Record. 1946; 94(1), 7-23.

Zhang G, Fang X, Guo X, Li L, Luo R, Xu F, Yang P, Zhang L, Wang X, Qi H, Xiong Z, Que H, Xie Y, Holland PWH, Paps J, Zhu Y, Wu F, Chen Y, Wang J, Peng C, Meng J, Yang L, Liu J, Wen B, Zhang N et al. The oyster genome reveals stress adaptation and complexity of shell formation. Nature. 2012; 490(7418), 49-54.

Zweier JL,Kuppusamy P, Williams R, Rayburn BK, Smith D, Weisfeldt ML, Flaherty JT. Measurement and characterization of post ischemic free radical generation in the isolated perfused heart. Journal of Biological Chemistry. 1989; 264(32), p.889018895. 


\section{ANEXOS}

ANEXO A - Tabela 1. Determinação do conteúdo de água corporal em animal inteiro $(\mathrm{n}=10)$ em estufa à $90^{\circ} \mathrm{C}$ por 24 horas. Percentual de água (média e desvio padrão) e o conteúdo de água corporal $\left(\mathrm{g} \mathrm{H}_{2} \mathrm{O} / \mathrm{g}\right.$ peso) de Lithobates catesbeianus.

\begin{tabular}{ccccc}
\hline $\begin{array}{c}\text { Animal inteiro } \\
\begin{array}{c}\text { Peso inicial } \\
(\mathbf{g})\end{array}\end{array}$ & $\begin{array}{c}\text { Peso final } \\
(\mathbf{g})\end{array}$ & $\begin{array}{c}\text { Perda de peso } \\
\left(\mathbf{H}_{2} \mathbf{O} \mathbf{g}\right)\end{array}$ & $\begin{array}{c}\text { \% de peso que } \\
\text { restou }\end{array}$ & $\begin{array}{c}\text { \% de água do } \\
\text { animal }\end{array}$ \\
\hline $6,73 \pm 1,43$ & $1,01 \pm 0,21$ & $5,73 \pm 1,24$ & $15,00 \pm 1,46$ & $85,00 \pm 1,46$ \\
Conteúdo de água corporal & 0,85 & & \\
\hline
\end{tabular}

ANEXO B- Tabela 2. Determinação do conteúdo de água corporal no músculo de Lithobates catesbeianus $(\mathrm{n}=5)$ em estufa à $90^{\circ} \mathrm{C}$ por 12 horas. Percentual de água (média e desvio padrão)

\begin{tabular}{ccccc}
\hline Músculo & & & \\
\hline $\begin{array}{c}\text { Peso inicial } \\
(\mathbf{g})\end{array}$ & $\begin{array}{c}\text { Peso final } \\
(\mathbf{g})\end{array}$ & $\begin{array}{c}\text { Perda de peso } \\
\left(\mathbf{H}_{2} \mathbf{O} \text { g) }\right.\end{array}$ & $\begin{array}{c}\text { \% de peso que } \\
\text { restou }\end{array}$ & $\begin{array}{c}\text { \% de água no } \\
\text { músculo }\end{array}$ \\
\hline $1,32 \pm 0,20$ & $0,4 \pm 0,17$ & $0,91 \pm 0,04$ & $29,58 \pm 7,58$ & $70,41 \pm 7,58$ \\
\hline
\end{tabular}

ANEXO C- Tabela 3. Determinação do conteúdo de água corporal no fígado de Lithobates catesbeianus $(\mathrm{n}=10)$ em estufa à $90^{\circ} \mathrm{C}$ por 12 horas. Percentual de água (média e desvio padrão)

Fígado

\begin{tabular}{ccccc}
\hline $\begin{array}{c}\text { Peso inicial } \\
(\mathbf{g})\end{array}$ & $\begin{array}{c}\text { Peso final } \\
(\mathbf{g})\end{array}$ & $\begin{array}{c}\text { Perda de peso } \\
\left(\mathbf{H}_{2} \mathbf{O} \mathbf{~ g}\right)\end{array}$ & $\begin{array}{c}\text { \% de peso que } \\
\text { restou }\end{array}$ & $\begin{array}{c}\text { \% de água no } \\
\text { fígado }\end{array}$ \\
\hline $0,22 \pm 0,09$ & $0,15 \pm 0,05$ & $0,07 \pm 0,03$ & $70,47 \pm 5,51$ & $29,53 \pm 5,51$ \\
\hline
\end{tabular}


Capítulo 3 - controle da TAXA Metabolló POR SUBSTRATOS DA CADEIA DE TRANSPORTE DE ELÉTRONS MITOCONDRIAL 


\section{CONTROLE DA TAXA METABÓLICA POR SUBSTRATOS DA CADEIA DE TRANSPORTE DE ELÉTRONS MITOCONDRIAL}

\section{INTRODUÇÃO}

\subsection{Taxa metabólica de repouso e restrição calórica}

A restrição calórica causa muitas mudanças, hormonais, bioquímicas, comportamentais e de composição corporal. Ela leva a redução de peso, tanto de massa gorda e quanto de massa magra (Knuth et al., 2015), diminui os níveis de glicose sanguinea, de insulina, dos hormônios tireoidianos, de leptina, da atividade do sistema nervoso simpático, da termogênese (Dullo e Jacquet, 1998; MacLean, 2006; Müller et al., 2015), diminuição da pressão sanguínea, do quociente respiratório (Müller et al., 2015; Leibel, Rousebaum, Hirsch, 1995) e queda da taxa de vazamento de prótons na mitocôndria (Hagopian et al., 2004). Além disso, a mudança de uma alimentação normocalórica para uma restrição calórica também causa diminuição da taxa metabólica de repouso (Dullo e Jacquet, 1998; MacLean, 2006), a qual é estimada pela queda no consumo de oxigênio (Ravussin et al., 1986).

A taxa metabólica repouso (TMR) possui a maior contribuição, no gasto energético total diário, representando cerca de 60-70\%, o restante do gasto provém do efeito térmico dos alimentos que representa entre 14-20\% e atividade termogênica sem exercício,-representando cerca de 20 a 40\% do gasto energético total diário (Ravussin et al., 1986; Levine, Schleusner, Jensen, 2000; Levine, 2004). O fenômeno da diminuição da taxa metabólica em resposta à restrição de alimentos e de energia em humanos é chamado de adaptação metabólica (Rosenbaum et al., 2008), enquanto que, em outros animais, é comumente chamada de depressão metabólica (Ehrhardt, Heldmaier, Exner, 2005; Storey e Storey, 2010).

\subsection{Depressão metabólica: redução da taxa metabólica em animais}

Muitos organismos em situações de estresses ambientais, como mudança brusca de temperatura, falta de água, de alimento, entram em um estado de hipometabolismo, ou 
seja, diminuem sua taxa metabólica de repouso, o que contribui para a sua sobrevivência (Ortmann et al., 2000; Secor, 2005; Frick et al., 2008; OelKrug, Heldmaier, Meyer, 2011; Franco et al., 2012; Welker et al. 2013) Há espécies que podem diminuir entre 70-85 \% da taxa metabólica basal (Brustovetsky et al., 1990; Kayer, Cramps, Franklin, 2009; Reylli et al., 2014). Por exemplo, lagartos teiús têm um consumo de oxigênio no início do outono de $0.0627 \pm 0.0057\left(\mathrm{ml} \mathrm{O}_{2} \mathrm{~h}^{-1} \mathrm{~g}^{-1}\right)$, e cai para $0.0119 \pm 0.0013\left(\mathrm{ml} \mathrm{O}_{2} \mathrm{~h}^{-1} \mathrm{~g}^{-1}\right)$ no inverno (Souza et al., 2004). Hamsters em temperatura ambiental de $16{ }^{\circ} \mathrm{C}$ reduzem a taxa metabólica de $2,4 \mathrm{ml} \mathrm{O}_{2} \mathrm{~h}^{-1} \mathrm{~g}^{-1}$ para $0,6 \mathrm{ml} \mathrm{O}_{2} \mathrm{~h}^{-1} \mathrm{~g}^{-1}$ ao entrar em torpor em uma temperatura de $5{ }^{\circ} \mathrm{C}$ (Heldmaier e Ruf, 1992).

A queda na taxa metabólica desses animais está correlacionada com a redução da massa de órgãos (Souza et al., 2004; Naya et al., 2009) e com redução na sua atividade mitocondrial, como em caramujos e cobras em estivação, esquilos hibernantes (Stuart et al., 1998; Brustovetsky et al., 1990; Brown e Staples, 2014). Na hibernação de esquilos, a queda na taxa de respiração mitocondrial relaciona-se com a diminuição na temperatura corporal (Chung et al., 2011). Durante estivação e hibernação, há mudanças na composição da membrana das mitocôndrias (Stuart et al., 1998, Chung et al., 2011), essa mudança pode levar a perda de função de citocromo $\mathrm{C}$ oxidase, sendo tecido-específico (Frick et al., 2010). Em caramujos, a diminuição da taxa metabólica, também ocorre pela menor oxidação de substrato, que representa $75 \%$ da taxa respiratória mitocondrial, enquanto os $25 \%$ é do turnover de ATP (Bishop, Pierre, Brand, 2002). Hamsters durante torpor reduzem a taxa respiratória até $70 \%$, utilizando glutamato como substrato para a mitocôndria (Brown, Gerson, Staples, 2007). Ou seja, no hipometabolismo, há alterações da atividade mitocondrial advindas da diminuição da disponibilidade de substrato.

\subsection{Alterações da taxa metabólica pela oferta de calorias}

Assim como animais em depressão metabólica, a adaptação metabólica em humanos é caracterizada pela redução da taxa metabólica. A adaptação metabólica causada pela restrição calórica pode persistir depois da perda de peso, o que dificulta a manutenção e facilita o reganho de peso. Quanto maior é tal restrição calórica, mais intensa é a adaptação (Leibel, Rousebaum, Hirsch, 1995; Guppy, Fuery, Flanigan, 2004). Por exemplo, obesos possuem redução da taxa metabólica de $1984 \pm 342$ kcal para 1581 $\pm 348 \mathrm{Kcal}$, pós-redução de $20 \%$ de perda de peso, sendo tal queda indubitavelmente 
significante $(\mathrm{p} \leq$ 0,001) (Leibel, Rosenbaum, Hirsch, 1995). Mulheres com anorexia nervosa, que se caracterizam pela perda de peso por uma severa restrição calórica, apresentam menor taxa metabólica basal, 3,810 $\pm 937 \mathrm{~kJ} / \mathrm{dia}$, comparadas com grupo controle, 5,576 $\pm 209 \mathrm{~kJ} / \mathrm{dia}$ (Bossu et al., 2007). Com o tratamento de uma alimentação adequada, há o aumento na taxa metabólica e na massa gorda, e um aumento inicialmente pouco expressivo de massa magra (Polito et al., 1998; Agüera et al., 2015). Indivíduos em restrição calórica durante 12 e 24 semanas apresentam queda da taxa metabólica basal de $\approx 20$ e $25 \%$ respectivamente, e durante 12 semanas de realimentação há um aumento de $\approx 10 \%$ (Dullo e Jacquet, 1998), ou seja, a TMR está positivamente relacionada com a oferta de nutrientes/calorias.

De forma similar à relação positiva entre a TMR e a oferta de nutrientes/calorias durante situações de restrição calórica, a taxa metabólica aumenta por várias horas, em resposta à ingestão de alimentos (Tataranni et al., 1995), fenômeno chamado de Efeito Térmico dos Alimentos ou Termogênese Pós-Prandial. A Termogênese Pós-Prandial é atribuída à digestão, absorção e estoque energético (D`Alessio et al., 1988; Levine, 2004).

\subsection{Fatores que Influênciam o Efeito Térmico dos alimentos}

A quantidade de calorias da refeição e a sua composição possuem influências no efeito térmico dos alimentos (Tai, Catillo, Pi-Sunyer, 1991; Suen et al., 2003).

\subsubsection{Tamanho da refeição}

Quanto maior a ingestão alimentar, maior o aumento da taxa metabólica (Caudwell et al., 2013). Um estudo mostrou que uma refeição com 3138 kJ apresenta um maior efeito térmico $(241,00 \pm 34,56$; total $\mathrm{kJ} / 5 \mathrm{~h})$ do que seis refeições de $523 \mathrm{~kJ}(174,47 \pm$ 25,10; total kJ/5h) (Tai et al., 1991). Os ácidos graxos de cadeia média (AGCM), os quais são absorvidos mais rapidamente, aumentam o efeito térmico pós-prandial mais do que ácidos graxos de cadeia longa (Scalfi, Coltorti, Contaldo, 1991; Ogawa et al., 2007; Clegg e Golsorkhi, Henry, 2013). Frutose é uma molécula que não é utilizada pelos tecidos extra-hepáticos, possui um maior efeito térmico do que glicose (Schwarz et al., 1989; Tappy e Jéquier, 1993; Blaak e Saris, 1996; Cox et al.,2012). Isso corrobora a explicação de que o maior aumento do efeito pós-prandial ocorre quando há uma maior oferta de substratos na mitocôndria. 


\subsubsection{Composição do alimento}

A composição do alimento também interfere no efeito térmico (Westertep, 2004). Por exemplo, mulheres obesas e mulheres magras, ao receberam refeições isocaloricas (2026 kJ) com diferença na composição, uma rica em proteína (18,3 g carboidrato, 0,16 g de gordura, e 102,4 g de proteína), e outra rica em gordura (39,4 g de gordura, 19,9 g de carboidrato, e 11,8 g de proteína), apresentam um maior efeito térmico quando ingerem uma dieta rica em proteínas $(356,8 \pm 129$ e $348,8 \pm 171,3 \mathrm{~kJ} / \mathrm{h}$, respectivamente) em comparação com uma dieta rica em gordura $(125,2 \pm 93,4$ e 145,6 $\pm 117,8 \mathrm{~kJ} / \mathrm{h}$, respectivamente) (Tentolouris et al., 2008). Outro estudo com indivíduos que receberam dietas isocalóricas ( $2331 \pm 36 \mathrm{~kJ}$ por cada refeição), com diferença na composição, uma rica em proteína com $68 \%$, outra rica em carboidrato, $69 \%$, e outra em gordura, $70 \%$, apresentaram efeito térmico de $261 \pm 59,92 \pm 67$ e $97 \pm 71 \mathrm{~kJ}$, respectivamente, mostrando um aumento significativo em resposta à refeição rica em proteína $(\mathrm{P}<0.001)$ (Crovetti et al., 1997)

\subsubsection{Composição corporal do indivíduo}

O efeito térmico dos alimentos também é dependente do indivíduo, por exemplo, indivíduos com capacidade de oxigênio máxima alta, de $62 \mathrm{~mL} / \mathrm{kg} \cdot \mathrm{min}^{-1}$, possuem maior efeito pós-prandial (correlacionado por análise de regressão; $\mathrm{p} \leq 0,05$ ), do que indivíduos com capacidade de oxigênio máxima baixa, de $43 \mathrm{~mL} / \mathrm{kg} \cdot \mathrm{min}^{-1}$ (Hill et al., 1984). Há estudos que mostram que indivíduos obesos apresentam o efeito térmico dos alimentos pós-prandial menor do que indivíduos não obesos (Pittet et al., 1976; Shetty et al., 1981; D’Alessio et al., 1988). Por exemplo, obesos têm um aumento do efeito térmico de $31 \pm$ $3 \mathrm{kcal} / 3 \mathrm{~h}$ enquanto não obesos tem um gasto de $69 \pm 4 \mathrm{kcal} / 3 \mathrm{~h}$, após uma refeição mista liquida de $720 \mathrm{kcal}$ (Segal et al., 1990), apresentando menor aumento da taxa metabólica basal pós-prandial (Wang, Strouse 1924; Nelson et al., 1992). Alguns estudos não mostram diferenças no aumento do efeito térmico dos alimentos ente obesos e magros (Felig et al., 1983; Tentolouris et al., 2008). Obesos e magros, após refeição rica em gordura, não apresentaram diferenças significativas no efeito térmico, $100 \mathrm{kcal} \mathrm{e} 140 \mathrm{kcal}$, respectivamente (Imbeault et al., 2001). Porém, indivíduos obesos com diferente distribuição de gordura corporal apresentam diferenças no efeito térmico dos alimentos. As diferenças não são claras entre obesos e não obesos, mas em relação à distribuição da 
gordura corporal. O aumento percentual da taxa metabólica pós-prandial não muda entre os grupos: glúteo-femoral $(13,2 \pm 1,3)$, intermediários $(13,9 \pm 0,9)$, abdominal (11,3 \pm $1,0)$ e controle $(12,1 \pm 2,6)$ (Westrate et al., 1990). Nestes estudos, indivíduos obesos e magros não possuem diferenças significativas na quantidade de massa magra, a qual relaciona-se com um maior efeito térmico e da taxa metabólica, por exemplo, indivíduos com uma maior quantidade de massa magra correlacionam positivamente com um maior aumento da taxa metabólica pós-prandial $\left(\mathrm{r}^{2}=0,39 \mathrm{p}=0,001\right)$ (Reed e Hill, 1996). Apesar das controvérsias, há muitas evidências do menor efeito térmico dos alimentos em obesos (Jonee et al., 1997). Aparentemente, a divergência dos resultados e conclusões dos diferentes estudos se deve à diferença na metodologia utilizada.

\subsection{Mitocôndrias e proteínas desacopladoras (UCP's)}

$\mathrm{Na}$ mitocôndria, parte dos prótons bombeados no espaço intermembrana é desacoplada da ATP sintase (Rolfe, Brand, 1997) por meio das proteínas desacopladoras (UCP's), as quais se encontram na membrana interna da mitocôndria de diferentes tecidos (Nicohlls 2006; Brand, Esteves, 2005). Dentre as atividades que elas estão envolvidas estão a termogênese e a diminuição da produção de radicais livres (Brand, Esteves, 2005).

\subsubsection{UCP's e restrição alimentar}

As proteínas desacopladoras estão envolvidas na restrição alimentar, por exemplo, ratos durante restrição alimentar possuem menor expressão de mRNA de UCP's quando comparados com o estado de realimentação, relacionando positivamente com o menor gasto energético e maior eficiência energética (Samec, Seydoux, Dullo, 1998). Pessoas com resistência à perda de peso expressam menos UCP3 e apresentam menor vazamento de prótons do que pessoas com facilidade a perda de peso (Harper et al., 2002). Mulheres obesas, durante restrição calórica, possuem maior queda na taxa metabólica basal, de 7,62 $\pm 0,67$ para 6,97 $\pm 0,52$ após a perda de peso. Esta maior queda da taxa metabólica é observado em mulheres com alta termogênese adaptativa (alta adaptação a conservação de energia), o que não foi observado em mulheres com baixa termogênese adaptativa (baixa adaptação a conservação de energia), de 7,03 \pm 0,38 para 7,09 \pm 0,39 (BosyWestphal et al., 2009). Indivíduos que sofreram queimaduras, que possuem dificuldades 
no ganho de peso, apresentam uma alta taxa metabólica basal e um alto desacoplamento mitocondrial no músculo esquelético (Porter et al., 2014).

Mulheres com anorexia nervosa podem apresentar hipotermia (Croxson et al., 1977; Smith et al., 1983; Madden et al., 2015) que pode estar envolvida com a UCP-2 e UCP-3, Por exemplo, em pessoas com anorexia nervosa, há uma maior frequência dos alelos D11S911 (UCP-3) em relação ao controle (Campbell et al., 1999). Enquanto outro estudo com três polimorfismo nos genes UCP2 e 3, não encontrou relação com anorexia nervosa (Ando et al., 2004). Ainda não é claro se há relação de UCP’s com anorexia nervosa, mas sabe-se que UCP’s possuem relação com taxa metabólica (Bouchard et al., 1997).

\subsubsection{UCP's e hormônios da tireoide}

A expressão das UCP's e a taxa metabólica aumentam em resposta ao hormônio da tireoide, T3 (Lange et al., 2001; Lange et al., 2007; Lanni et al., 1997), além disso, as UCP’s estão envolvidas no metabolismo de ácidos graxos (Brand e Esteves, 2005). A superexpressão de UCP3 leva a um menor ganho de massa gorda com uma dieta rica em gordura (Costford et al., 2008).A secreção de hormônios tireoidianos é reduzida em pessoas com hipotireoidismo (Akbaba et al., 2015), os quais apresentam metabolismo lento. Apesar de não existir um consenso sobre os níveis circulantes dos hormônios da tireoide em obesos (Tagliaferri et al., 2001; Knudsen et al., 2005; Pearce, 2012), eles têm um mario consumo de oxigênio e este possue relação intrínseca com as UCP's.

\subsubsection{UCP's e hormônios da saciedade}

Leptina, outro hormônio envolvido no balanço de energia, é alterado em indivíduos obesos, os quais possuem alta concentração, porém são resistentes a sua ação (Considine et al., 1996, Ritze et al., 2016). Há estudo que mostra uma maior concentração em pacientes com hipotireoidismo do que pacientes com hipertireoidismo (Hsieh et al. 2002), mas, há controvérsias sobre a relação da leptina no hipotireoidismo e hipertireoidismo (Sreenan, Caro, Refettof 1997; Pinkney et al., 1998; Akbaba et al., 2015). Em camundongos, leptina pode ter envolvimento no controle alimentar associado com UCP1. Camundongos com expressão de UCP1 apresentam menor ingestão alimentar 
quando são injetados com leptina, em comparação com camundongos sem UCP1 (Okamatsu et al., 2011). Camundongos obesos possuem menor expressão de UCP1 e essa expressão aumenta quando se injeta leptina (Commins et al., 1991). Também se observa um aumento na produção de calor, na expressão de UCP 2, 3, e na taxa de vazamento de prótons em camundongos injetados com leptina (Henry, 2011), aumento do gasto energético, redução e manutenção de perda por mais tempo em camundongos injetados com leptina (Gullicksen et al., 2011).

\subsubsection{UCP's e ERO'S}

Proteínas desacopladoras também são citadas por contribuírem na queda da produção de RL (Criscuolo et al., 2006, Brand et al., 2002). Há muitas correlações que evidenciam essa função, por exemplo, em estudo sobre longevidade, a ingestão do desacoplador mitocondrial DNP diminui a produção de ERO's, com uma redução de $80 \%$ no fígado, além de aumentar a taxa metabólica e a longevidade em camundongos (Caldeira da Silva et al., 2008). Diferenças em camundongos com alta e baixa taxa metabólica também foram observadas. Aqueles com alta taxa possuem maior desacoplamento mitocondrial (200 nmol O/min/mg proteína) e maior longevidade (641 dias) vs com baixa taxa (150 $\mathrm{nmol} \mathrm{O/min/mg} \mathrm{proteína)} \mathrm{e} \mathrm{menor} \mathrm{longevidade} \mathrm{(472} \mathrm{dias)}$ (Speakman et al., 2004). Girinos de rã expostos ao DNPtêm aumento da taxa metabólica e aumento na síntese de ATP, demostrando um alto custo de energia, queda na produção de peróxido de hidrogênio e de danos lipídicos (Salin et al., 2012). No peixe truta, alta taxa metabólica apresentou baixa concentração de peroxido de hidrogênio (Salin et al., 2015)

\section{REVISÃO SISTEMÁTICA E ANÁLISE DE DADOS DA LITERATURA}

Os dados na literatura mostram que há alterações da taxa metabólica com restrição calórica ou superalimentação. Dados in vitro também relacionam a disponibilidade de substrato com uma maior atividade mitocondrial. Tais relações conduzem à hipótese de que um aumento na ingestão de alimentos geraria um maior aumento da taxa metabólica por causa da maior disponibilidade (pico de concentração) de substrato pós-prandial. Porém, ainda não há na literatura um estudo que investigasse tal relação com clareza. 


\subsection{Objetivo}

Assim, esse estudo propôs avaliar se o aumento do pico de concentração de substratos pós-prandial se correlaciona com um maior aumento da taxa metabólica através de dados da literatura.

\section{MÉTODOS}

O estudo realizou um levantamento bibliográfico do aumento da taxa metabólica de repouso pós-prandial. Para isso foi utilizado os bancos de dados Pubmed e Web of science. As palavras chaves utilizadas foram: Thermic effect food; Thermic effect food in the metabolic rate.

Critérios de inclusão:

1. Dietas ricas em carboidrato, em lipidios ou proteínas

2. Dietas liquidas não isoladas (apenas um macronutriente)

3. Dietas com kcal especificada

4. Artigos com resultado da mensuração da taxa metabólica

5. Resultado da mensuração da taxa metabólica com tempo, o qual foi mensurado

6. Resultados dos grupos considerados normais/controle

Critérios de exclusão:

1. Estudo com crianças ou somente com idosos

2. Mulheres em pré-menopausa ou em menopausa

3. Dietas liquidas isoladas (apenas um macronutriente)

4. Resultados com grupos não considerados normais/controle

Foram encontrados aproximadamente 79 artigos, com as palavras chaves usadas, destes, foram selecionados 20 artigos incluídos nos critérios citados acima. Os dados dos artigos selecionados foram dispostos em tabela.

Para a análise, os seguintes dados foram coletados:

- características da dieta, 
- tempo de jejum antes da refeição,

- tempo de mensuração do aumento da taxa metabólica,

- quociente respiratório,

- pico do efeito térmico dos alimentos em minuto,

- percentual de aumento acima da baseline,

- e o percentual de aumento da taxa metabólica em relação a kcal do alimento ingerido.

Para extrair os dados expostos em gráficos, foi utilizado o software g3data 1.5. Para o aumento da taxa metabólica em relação a kcal do alimentos, foi utilizado o cálculo abaixo (Schallenberg, 1974) :

$$
\text { DIT }=\frac{(\text { Pós prandial }- \text { Pré prandial }) \text { x tempo de mensuração }(\text { min })}{\text { Conteúdo de energia do alimento }(\text { Kcal })} \times 100,
$$

onde DIT é o valor que se refere a termogênese induzida por dieta.

Após a elaboração da tabela, foi realizado o teste de normalidade de Shapiro-Wilk, a qual não revelou distribuição normal. Assim foi realizado o teste de correlação não parámetrico de Spearman entre o pico de aumento da taxa metabólica pós-prandial e o aumento total (nas horas subsequentes à refeição) da taxa metabólica pós-prandial. Foi realizado o teste utilizando o programa SPSS.

\section{RESULTADOS}

Dos 20 artigos analisados, 15 apresentaram as refeições na forma sólida, enquanto cinco estavam no estado líquido, considerando que, dentre as cinco refeições líquidas, um também apresentou uma refeição no estado sólido. 
Tabela 1. Características das refeições dos artigos analisados.

Características das refeições

Hiperglicidica Hiperlipidica Hiperprotéica Hipolipídica

Quantidade de refeições

14

14

2

2

analisadas

Carboidrato Lipídios Proteínas Lipídios

Média da quantidade do principal macronutriente em abundância/reduzido

105,4

57,4

97,5

12,0

(g)

A média do tempo de jejum anterior às refeições foi de 11,8 horas. A média de aumento do pico foi de $16,77 \%$ em relação à baseline, enquanto que o aumento da taxa metabólica relativo à quantidade de nutrientes foi de $8,49 \%$.

Tabela 2. Alterações da taxa metabólica em resposta a ingestão de nutrientes.

\begin{tabular}{|c|c|c|c|c|c|c|c|c|c|c|c|}
\hline Autores & $\begin{array}{c}\text { Características } \\
\text { da dieta }\end{array}$ & Kcal & $\begin{array}{l}\text { Prot. } \\
\text { (g) }\end{array}$ & $\begin{array}{c}\text { Carb. } \\
(\mathrm{g})\end{array}$ & $\begin{array}{l}\text { Lipid. } \\
\text { (g) }\end{array}$ & $\begin{array}{l}\text { Jejum } \\
\text { (h) }\end{array}$ & $\begin{array}{c}\text { Pico } \\
\text { de } \\
\text { TEF } \\
(\text { min })\end{array}$ & $\begin{array}{c}\text { Pico de } \\
\text { TEF ( \% } \\
\text { baseline) }\end{array}$ & $\begin{array}{c}\text { Aumento } \\
\text { da taxa } \\
\text { metabólica } \\
\text { relativo a } \\
\text { kcal }(\%) \\
\end{array}$ & $\begin{array}{c}\text { Tempo de } \\
\text { mensuração } \\
\text { (h) }\end{array}$ & $\begin{array}{l}\text { QR } \\
(\%)\end{array}$ \\
\hline \multirow{4}{*}{$\begin{array}{l}\text { Flatt et al,, } 1985 \\
\text { (56) }\end{array}$} & Hipolipidica & 482 & 32,25 & 75 & 5,88 & 12 & 75 & 17 & 15,8 & 9 & 2,4 \\
\hline & Hiperlipidica & & & & & & & & & & \\
\hline & AGCL * & 858 & 32,5 & 75,25 & 47,44 & 12 & 75 & 20 & 11,2 & 9 & 0,66 \\
\hline & AGCM $* *$ & 856 & 32,25 & 75 & 47,44 & 12 & 75 & 22 & 12,3 & 9 & 0,09 \\
\hline \multirow[b]{2}{*}{$\begin{array}{l}\text { Seaton et al., } \\
1986(57)\end{array}$} & $\mathrm{AGCM} * *$ & 400 & - & - & 48 & $\begin{array}{l}\text { Durante } \\
\text { a noite }\end{array}$ & $\begin{array}{l}90- \\
120 \\
\end{array}$ & 16 & 12,1 & 6 & -6 \\
\hline & AGCL * & 400 & - & - & 45 & $\begin{array}{l}\text { Durante } \\
\text { a noite }\end{array}$ & $\begin{array}{l}150- \\
180 \\
\end{array}$ & 9 & 3,7 & 6 & -10 \\
\hline \multirow{4}{*}{$\begin{array}{l}\text { Kinabo } \\
\text { Durnin, } \\
\text { (38) }\end{array}$} & Hiperglicidica & 600 & 16,5 & 105 & 12,66 & 12 & 180 & 1,16 & 9,5 & 5 & - \\
\hline & \begin{tabular}{|l|} 
Hiperlipidica \\
\end{tabular} & 600 & 16,5 & 36 & 43,33 & 12 & 90 & 1,62 & 9,5 & 5 & - \\
\hline & Hiperglicidica & 1200 & 33 & 210 & 25,33 & 12 & 130 & 56,4 & 15 & 5 & - \\
\hline & Hiperlipidica & 1200 & 33 & 72 & 86,66 & 12 & 200 & 59,2 & 14,5 & 5 & - \\
\hline $\begin{array}{l}\text { Segal et al., } \\
1990(58)\end{array}$ & $\begin{array}{l}\text { Refeição mista } \\
\text { líquida } \\
\end{array}$ & 720 & 43,2 & 99 & 16,8 & 12 & 95 & 36 & 9,9 & 3 & - \\
\hline $\begin{array}{lll}\text { Segal et al., } \\
1992 \text { (59) }\end{array}$ & \begin{tabular}{|l|} 
Refeição mista \\
líquida \\
\end{tabular} & 720 & 43,2 & 99 & 16,8 & - & 60 & 14,5 & 4,7 & 3 & 8,7 \\
\hline $\begin{array}{lrl}\text { Segal et } & \text { al., } \\
1992 b(60) & \\
\end{array}$ & $\begin{array}{l}\text { Refeição mista } \\
\text { líquida } \\
\end{array}$ & 720 & 43,2 & 99 & 16,8 & 12 & $80-90$ & 13,4 & 5,11 & 3 & 8,1 \\
\hline
\end{tabular}




\begin{tabular}{|c|c|c|c|c|c|c|c|c|c|c|c|}
\hline $\begin{array}{l}\text { Hibbert et al., } \\
1994(61)\end{array}$ & $\begin{array}{l}\text { Refeição mista } \\
\text { líquida }\end{array}$ & 600 & 21 & 82,5 & 21,33 & 13 & - & - & 5,8 & 5 & - \\
\hline \multirow{2}{*}{$\begin{array}{l}\text { Labayen , Forga, } \\
\text {, Martínez, } 1999 \\
\text { (62) }\end{array}$} & Hiperglicidica & 495 & 21,75 & 99,25 & 1,22 & 12 & 30 & 9,8 & 6 & 3,5 & 9,9 \\
\hline & Hiperlipidica & 496 & 21,5 & 18,75 & $44,11 * *$ & 12 & 30 & 6,5 & 5,4 & 3,5 & 5,5 \\
\hline \multirow{5}{*}{$\begin{array}{l}\text { Brondel } \\
\text { Fricker, Fantino, } \\
1999 \text { (63) }\end{array}$} & Hiperlipidica & 129,12 & - & - & 108,46 & - & 7 & 3,71 & 1 & 0,01 & $-2,3$ \\
\hline & Hiperprotéica & 198,94 & 45,75 & - & - & - & 22 & 7,07 & 3,66 & 0,16 & $-5,9$ \\
\hline & Hiperglicídica & 161,16 & - & 103,14 & - & - & 32 & 11,44 & 7,73 & 0,33 & $-5,5$ \\
\hline & \multirow{2}{*}{$\begin{array}{l}\text { Após todos os } \\
\text { alimentos }\end{array}$} & \multirow{2}{*}{128,16} & \multirow[b]{2}{*}{-} & \multirow{2}{*}{94,83} & \multirow{2}{*}{-} & \multirow{2}{*}{-} & 42 & 14,27 & 13,03 & 0,5 & $-5,9$ \\
\hline & & & & & & & 85 & 12,92 & 2,39 & 1,8 & 0,72 \\
\hline $\begin{array}{l}\text { Armellini et al., } \\
2000(64)\end{array}$ & Formula líquida & 461,97 & 19,63 & 61,21 & 15,4 & 12 & - & - & 14 & 6 & - \\
\hline $\begin{array}{l}\text { Sawaya et al., } \\
2001(65)\end{array}$ & Refeição mista & 700 & 21 & 113,75 & 17,88 & overnight & $30-90$ & 23 & 8,8 & 6 & 6,5 \\
\hline $\begin{array}{l}\text { Faraj et al., } 2001 \\
(66)\end{array}$ & Hiperlípidica & 1062 & 31,9 & 55,8 & 80 & 12 & - & - & 5,2 & 8 & - \\
\hline \multirow{2}{*}{$\begin{array}{l}\text { Blundell } \\
\text { Cooling, King, } \\
2002 \text { (67) } \\
\end{array}$} & Hiperglícidica & 530 & 10,4 & 120,5 & 0,7 & 12 & 60-80 & 19,4 & 7,8 & 3 & 8,4 \\
\hline & Hiperlípidica & 507 & 1,6 & 26,6 & 43,8 & 12 & $40-60$ & 14,7 & 6 & 3 & 1,4 \\
\hline \multirow{3}{*}{$\begin{array}{l}\text { Piers et al., } 2002 \\
(68)\end{array}$} & Hiperlípidica & & & & & & & & & & \\
\hline & $\mathrm{AGS} * * *$ & 597,8 & 22,41 & 62,77 & 28,56 & $12-14$ & - & - & 5,9 & 5 & 4 \\
\hline & AGMI**** & 597,8 & 22,41 & 62,77 & 28,56 & $12-14$ & - & - & 5,7 & 5 & 5,5 \\
\hline \multirow{2}{*}{$\begin{array}{l}\text { Tentolouris et } \\
\text { al., } 2003(69)\end{array}$} & Hiperglicídica & 546 & 6,1 & 130 & 0,26 & $12-14$ & - & - & 4,3 & 3 & 11,7 \\
\hline & Hiperlípidica & 532 & 11 & 5 & 52 & $12-14$ & - & - & 3 & 3 & $-4,4$ \\
\hline \multirow{2}{*}{$\begin{array}{l}\text { Nagai, Sakane, } \\
\text { Moritani, } 2005 . \\
\text { (70) }\end{array}$} & Hipolípidica & 778,57 & 18,9 & 136,2 & 18,2 & 10 & 60 & 15,6 & 5 & 3,5 & 7,5 \\
\hline & Hiperlípidica & 778,33 & 20,3 & 37,6 & 60,6 & 10 & 30 & 12 & 3,9 & 3,5 & $-1,5$ \\
\hline $\begin{array}{l}\text { Marrades, } \\
\text { Martinez, } \\
\text { Moreno-Aliaga, } \\
2007 \text { (71) } \\
\end{array}$ & Hiperlípidica & 888,9 & 5,2854 & 6,3865 & 92,7 & 12 & - & - & 5 & 3 & - \\
\hline \multirow{5}{*}{$\begin{array}{l}\text { Acheson et al., } \\
2011(72)\end{array}$} & Hiperglicídica & 459 & 1,37 & 109,6 & 1,68 & $\begin{array}{l}\text { Durante } \\
\text { a noite }\end{array}$ & $\begin{array}{l}100- \\
120 \\
\end{array}$ & 12 & 10,5 & 5,5 & - \\
\hline & Hiperprotéica & & & & & & & & & & \\
\hline & Whey & 459 & 57,375 & 45,9 & 5,1 & $\begin{array}{l}\text { Durante } \\
\text { a noite }\end{array}$ & $\begin{array}{l}130- \\
160\end{array}$ & 25,1 & 20 & 5,5 & - \\
\hline & Caseina & 459 & 57,375 & 45,9 & 5,1 & $\begin{array}{l}\text { Durante } \\
\text { a noite }\end{array}$ & $\begin{array}{l}100- \\
120 \\
\end{array}$ & 19,6 & 17,7 & 5,5 & - \\
\hline & Soja & 459 & 229,5 & 183,6 & 45,9 & $\begin{array}{l}\text { Durante } \\
\text { a noite }\end{array}$ & $\begin{array}{l}130- \\
160\end{array}$ & 17,8 & 17,7 & 5,5 & - \\
\hline \multirow{4}{*}{$\begin{array}{l}\text { Clevenger, } \\
\text { Stevenson, } \\
\text { Cooper, } 2015 \\
(73)\end{array}$} & $\begin{array}{l}\text { Refeição } \\
\text { liquída } \\
\text { hiperlipídica }\end{array}$ & & & & & & & & & & \\
\hline & AGS $* * *$ & 748,5 & 9 & 43 & 58,2 & $8-12$ & $30-60$ & 13,3 & 13,1 & 5 & 3,2 \\
\hline & AGMI**** & 726,7 & 9 & 43 & 52,9 & $8-12$ & $30-61$ & 13,4 & 13 & 5 & 2,6 \\
\hline & AGPI***** & 732,3 & 9 & 43 & 52,9 & $8-12$ & $30-62$ & 13 & 12,6 & 5 & 3,6 \\
\hline \multirow{2}{*}{$\begin{array}{l}\text { Gepner et al., } \\
2015(74)\end{array}$} & Hiperglicídica & 370 & 18,45 & 44,4 & 13,3 & 8 & 10 & 8,7 & 1 & 0,6 & $-4,8$ \\
\hline & Hiperlipídica & 380 & 8 & 8 & 36 & 8 & 3 & 0,7 & $-0,1$ & 0,6 & $-4,8$ \\
\hline
\end{tabular}

*AGCL- Ácidos Graxos de Cadeia Longa, **AGCM- Ácidos Graxos de Cadeia Média, ***AGS- Ácidos Graxos

Saturados, ****AGMI- Ácidos Graxos Monoinsaturados, *****AGPI- Ácidos Graxos Poliinsaturados.

Quanto ao pico pós-prandial e o aumento da taxa metabólica nas horas subsequentes às refeições, foi observado uma correlação positiva (Fig. 1). 


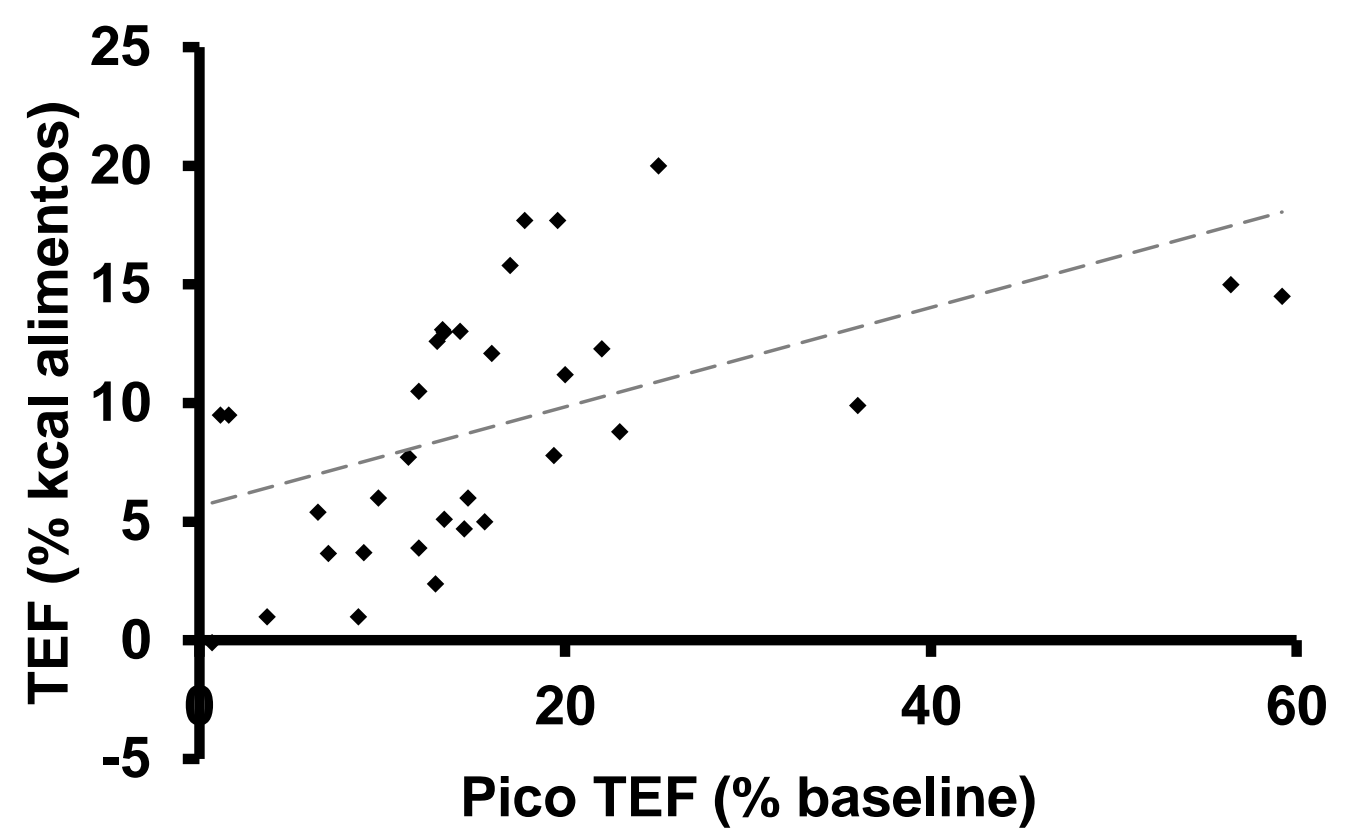

Figura 1. Correlação entre pico pós-prandial e o efeito térmico dos alimentos com diferentes nutrientes e quantidades $(\mathrm{p}<0.001)$. Com $\mathrm{r}=0,647$.

\section{DISCUSSÃO}

Os dados mostraram uma correlação entre o pico do efeito térmico dos alimentos e o aumento da taxa metabólica. Sabe-se que a atividade mitocondrial é influenciada pela disponibilidade de substratos (Brown, 1992). Ou seja, uma maior oferta de susbtrato gera um maior aumento da taxa metabólica. Estudos in vitro mostram que mitocôndrias de células isoladas têm maior atividade mitocondrial quando aumentam a captação de metabólitos em resposta à adição de ADP, que simula situação de depleção nos níveis de ATP (Nicolae et al., 2015). Nos estudos que avaliaram o efeito térmico dos alimentos, os indivíduos passaram por um período de jejum entre 10-12 h. O jejum prolongado antecedendo refeições, tornam o aumento do efeito térmico dos alimentos muito mais proeminente, devido ao baixo estoque de glicogênio. Por exemplo, estoques baixos de glicogênio causados por uma restrição calórica, acompanhado com uma grande refeição de carboidratos não causa lipogênese ‘de novo' significativa (Hellerstein et al., 1991), mas aumenta muito a taxa metabólica (Felber et al, 1981, Acheson et al., 1988), isso corrobora o aumento da TMR em favorecimento da disponibilidade de substrato. 
Além disso, essa correlação indica que um maior pico permite uma maior duração do aumento da taxa metabólica, como observado devido ao tempo de mensuração dos artigos (Tabela 2). Isso pode ocorrer devido o aumento da expressão de UCP's, as quais permitem o vazamento de prótons e a termogênese. Com o aumento da atividade mitocondrial, há geralmente um aumento da produção de ERO'S. Assim, como evidenciado em animais em estado de hipometabolismo, os quais apresentam uma pequena produção de ERO's que induz fatores de transcrição que estão envolvidos na defesa antioxidante. No retorno das condições favoravéis, no qual há o aumento da taxa metabólica basal, eles apresentam alta produção de ERO’s (Welker et al., 2013). Um exemplo são espécies de anfíbios, que passaram por privação alimentar, quando retornam a se alimentar apresentam um aumento entre 200-1000 \% do consumo de oxigênio em 24 h (Secor 2005). Outro fato é que animais que estão em estivação/hibernação têm queda na oxidação de substrato, como succinato (Frick et al., 2008; Chung et al., 2011), mostrando a redução da atividade mitocondrial durante depressão metabólica. Esquilos árticos Citellus parryi, durante hibernação, também possuem queda na taxa respiratória de mitocôndrias de fígado e na oxidação de substratos independente do substrato oxidado, e.g. piruvato/malato, succinato, chegando a uma queda de até $81 \%$ (Fedotcheva et al., 1985).

Dados in vitro também mostram que o aumento da atividade na cadeia fosforilativa aumenta a produção de ERO's, os quais induzem respostas, como o aumento de UCP's e antioxidantes. Células endoteliais, quando em meio com alta concentração de glicose, aumentam a produção de ERO’s e a expressão de UCP’s (Koziel, Sobieraj, Jamuszkiewicz, 2015).

A análise de correlação entre pico de TEF e TEF total mostrou que alguns dados destoaram da linha de tendência. Dentre eles, o artigo de Kinabo et al. (1990), que apresentou TEF abaixo da linha, foi o único que utilizou uma refeição com um teor calórico muito maior que os demais, com 1200 Kcal . Gepner et al. (2015) que também mostraram TEF abaixo do esperado, utilizaram uma medição de TEF por somente 36 minutos, com uma refeição rica em carboidratos. Além disso, o artigo de Acheson et al. (2011), o qual analisou a fonte protéica whey, apresentou TEF acima da linha de tendência. É necessário considerar que refeições de alto teor calórico (Kinabo e Dunin, 1990), alimentos de rápida absorção e o trânsito gastrointestinal dos alimentos podem 
aumentar ou diminuir o efeito térmico dos alimentos (Baker, 2015), consequentemente o aumento e duração da taxa metabólica.

\section{CONCLUSÕES}

O aumento do pico pós-prandial correlaciona-se com um maior aumento da taxa metabólica nas horas subsequentes às refeições. Este aumento corrobora o fato que as alterações da taxa metabólica estão relacionadas com um aumento na disponibilidade de substratos para a mitocôndria. $\mathrm{O}$ aumento de substrato gera maior aumento da atividade mitocondrial. Como observado na natureza, em animais que passam por depressão metabólica. Estes animais reduzem a produção de ERO’s, durante a depressão metabólica e aumentam abruptamente, quando há o retorno de sua taxa metabólica basal, as condições normais. Outra evidência é o fato que ERO's ativam UCP’S, as quais elevam a taxa metabólica basal. Desta forma, o uso de refeições que induzem um maior efeito térmico podem ser utilizadas estrategicamente para aumentar a taxa metabólica de repouso entre períodos de restrição calórica. O uso dessas refeições que aumentam o efeito térmico, o momento que devem ser utilizadas e a composição, devem ser esclarecidas. 


\section{REFÊNCIAS BIBLIOGRÁFICAS}

Acheson KJ, Schutz Y, Bessard T, Anantharaman K, Flatt JP, Jequier E. Glycogen storage capacity and de novo lipogenesis during massive carbohydrate overfeeding in man. The American journal of clinical nutrition. 1988; 48(2), 240-247.

Agüera, Z., Romero, X., Arcelus, J., Sánchez, I., Riesco, N., Jiménez-Murcia, S., ... \& Tárrega, S. Changes in Body Composition in Anorexia Nervosa: Predictors of Recovery and Treatment Outcome. PloS one. 2015; 10(11).

Akbaba G, Tuna MM, Koparal S, Vural M, Topcuoglu C, Guler S. Changes in the before and after thyroxine treatment levels of adipose tissue, leptin, and resistin in subclinical hypothyroid patients. Wiener klinische Wochenschrift. 2015;1-7.

Akbaba G, Tuna MM, Koparal S, Vural M, Topcuoglu C, Guler, S. Changes in the before and after thyroxine treatment levels of adipose tissue, leptin, and resistin in subclinical hypothyroid patients. Wiener klinische Wochenschrift. 2015; 1-7.

Ali SS, Marcondes MCG, Bajova H, Dugan LL, Conti B. Metabolic depression and increased reactive oxygen species production by isolated mitochondria at moderately lower temperatures. Journal of Biological Chemistry. 2010; 285(42), 32522-32528.

Ando T, Kodama N, Ishikawa T, Naruo T, Tachikawa N, Nozaki T, Okabe K, Takeuchi K, Masuda A,Kawamura N, Komaki G. Uncoupling protein-2/uncoupling protein-3 gene polymorphism is not associated with anorexia nervosa. Psychiatric genetics. 2004; 14(4), 215-218.

Bishop T, St-Pierre J, Brand MD. Primary causes of decreased mitochondrial oxygen consumption during metabolic depression in snail cells. American Journal of Physiology-Regulatory, Integrative and Comparative Physiology. 2002; 282(2), R372-R382.

Blaak EE, Saris WHM. Postprandial thermogenesis and substrate utilization after ingestion of different dietary carbohydrates.Metabolism. 1996; 45(10), 1235-1242.

Bossu C, Galusca B, Normand S, Germain N, Collet P, Frere D, Lang F, Laville M, Estour B. Energy expenditure adjusted for body composition differentiates constitutional thinness from both normal subjects and anorexia nervosa. American Journal of Physiology-Endocrinology and Metabolism. 2007; 292(1), E132-E137.

Bosy-Westphal A, Kossel E, Goele K, Later W, Hitze B, Settler U, Heller M, Glüer CC, Heymsfield SB, Müller MJ. Contribution of individual organ mass loss to weight loss-associated decline in resting energy expenditure. The American journal of clinical nutrition. 2009; 90(4), 993-1001.

Bouchar C, Pérusse L, Chagnon YC, Warden C, Ricquier D. Linkage between markers in the vicinity of the uncoupling protein 2 gene and resting metabolic rate in humans. Human molecular genetics. 1997; 6(11), 1887-1889. 
Brand M, Pamplona R, Portero-Otín M, Requena J, Roebuck S, Buckingham J,Clapham JC, Cadenas, S. Oxidative damage and phospholipid fatty acyl composition in skeletal muscle mitochondria from mice underexpressing or overexpressing uncoupling protein 3. Biochem. J, 2002; 368, 597-603.

Brand MD, Affourtit C, Esteves TC, Green K, Lambert AJ, Miwa S, Pakay JL, Parker, N. Mitochondrial superoxide: production, biological effects, and activation of uncoupling proteins. Free Radical Biology and Medicine. 2004; 37(6), 755-767.

Brand MD, Esteves TC. Physiological functions of the mitochondrial uncoupling proteins UCP2 and UCP3. Cell metabolism. 2005; 2(2), 85-93.

Brown GC, Brand MD. Changes in permeability to protons and other cations at high proton motive force in rat liver mitochondria. Biochemical Journal. 1986; 234(1), 7581.

Brown GC. Control of respiration and ATP synthesis in mammalian mitochondria and cells. Biochem. J. 1992; 284, 1-13.

Brown JC, Gerson AR, Staples JF. Mitochondrial metabolism during daily torpor in the dwarf Siberian hamster: role of active regulated changes and passive thermal effects. American Journal of Physiology-Regulatory, Integrative and Comparative Physiology. 2007; 293(5), R1833-R1845.

Brown JC, Staples JF. Substrate-specific changes in mitochondrial respiration in skeletal and cardiac muscle of hibernating thirteen-lined ground squirrels. Journal of Comparative Physiology B. 2014; 184(3), 401-414.

Brustovetsky NN, Amerkhanov ZG, Popova EY, Konstantinov AA. Reversible inhibition of electron transfer in the ubiquinol: cytochrome $\mathrm{c}$ reductase segment of the mitochondrial respiratory chain in hibernating ground squirrels. FEBS letters. 1990; 263(1), 73-76.

Caldeira da Silva CC, Cerqueira FM, Barbosa LF, Medeiros MH, Kowaltowski AJ. Mild mitochondrial uncoupling in mice affects energy metabolism, redox balance and longevity. Aging cell. 2008; 7(4), 552-56

Campbell DA, Sundaramurthy D, Gordon D, Markham AF, Pieri LF. Association between a marker in the UCP-2/UCP-3 gene cluster and genetic susceptibility to anorexia nervosa. Molecular psychiatry. 1999; 4(1), 68-70.

Caudwell P, Finlayson G, Gibbons C, Hopkins M, King N, Näslund E, Blundell JE. Resting metabolic rate is associated with hunger, self-determined meal size, and daily energy intake and may represent a marker for appetite. The American journal of clinical nutrition. 2013; 97(1), 7-14.

Chung D, Lloyd GP, Thomas RH, Guglielmo CG, Staples, JF. Mitochondrial respiration and succinate dehydrogenase are suppressed early during entrance into a 
hibernation bout, but membrane remodeling is only transient. Journal of Comparative Physiology B. 2011; 181(5), 699-711.

Clegg ME, Golsorkhi, M, Henry CJ. Combined medium-chain triglyceride and chilli feeding increases diet-induced thermogenesis in normal-weight humans. European journal of nutrition. 2013; 52(6), 1579-1585.

Commins SP, Watson PM, Padgett MA, Dudley A, Argyropoulos G, Gettys, TW. Induction of Uncoupling Protein Expression in Brown and White Adipose Tissue by Leptin 1. Endocrinology. 1999; 140(1), 292-300.

Considine RV, Sinha MK, Heiman ML, Kriauciunas A, Stephens TW, Nyce MR, Ohannesian JP, Marco CC, McKee LJ, Bauer TL, Caro JF. Serum immunoreactiveleptin concentrations in normal-weight and obese humans. New England Journal of Medicine. 1996; 334(5), 292-295.

Costford SR, Chaudhry SN, Crawford SA, Salkhordeh M, Harper ME. Long-term high-fat feeding induces greater fat storage in mice lacking UCP3. American Journal of Physiology-Endocrinology and Metabolism. 2008; 295(5), E1018-E1024.

Cox CL, Stanhope KL, Schwarz JM, Graham JL, Hatcher B, Griffen SC, Bremer AA, Berglund L, McGahan JP, Havel PJ, Keim, N. L. Consumption of fructose-sweetened beverages for 10 weeks reduces net fat oxidation and energy expenditure in overweight/obese men and women. European journal of clinical nutrition. 2012; 66(2), 201-208.

Criscuolo F, Mozo J, Hurtaud C, Nübel T, Bouillaud F. UCP2, UCP3, avUCP, what do they do when proton transport is not stimulated? Possible relevance to pyruvate and glutamine metabolism. Biochimica et Biophysica Acta (BBA)-Bioenergetics. 1996; 1757(9), 1284-1291.

Crovetti R, Porrini M, Santangelo A, Testolin G. The influence of thermic effect of food on satiety. European journal of clinical nutrition. 1998; 52(7), 482-488.

Croxson MS, Ibbertson HK. Low serum triiodothyronine (T3) and hypothyroidism in anorexia nervosa. The Journal of Clinical Endocrinology \& Metabolism. 1977; 44(1), 167-174.

D'Alessio DA, Kavle EC, Mozzoli MA, Smalley KJ, Polansky M, Kendrick ZV, Owen, O. E. Thermic effect of food in lean and obese men. Journal of Clinical Investigation. 1988; 81(6), 1781.

de Lange P, Feola A, Ragni M, Senese R, Moreno M, Lombardi A, Silvestri E, Amat R, Villaroya F, Goglia F, Lanni A. Differential 3, 5, 3'-triiodothyronine-mediated regulation of uncoupling protein 3 transcription: role of fatty acids. Endocrinology. 2007; 148(8), 4064-4072. 
de Lange P, Lanni A, Beneduce L, Moreno M, Lombardi A, Silvestri E, Goglia F. Uncoupling protein-3 is a molecular determinant for the regulation of resting metabolic rate by thyroid hormone. Endocrinology. 2001; 142(8), 3414-3420.

de Souza SCR, de Carvalho JE, Abe AS, Bicudo JEP, Bianconcini, MS. Seasonal metabolic depression, substrate utilisation and changes in scaling patterns during the first year cycle of tegu lizards (Tupinambis merianae). Journal of Experimental Biology. 2004; 207(2), 307-318.

Dulloo AG, Jacquet J. Adaptive reduction in basal metabolic rate in response to food deprivation in humans: a role for feedback signals from fat stores. The American journal of clinical nutrition. 1998; 68(3), 599-606.

Ehrhardt N, Heldmaier, G, Exner C. Adaptive mechanisms during food restriction in Acomys russatus: the use of torpor for desert survival. Journal of Comparative Physiology B. 2005; 175(3), 193-200.

Fedotcheva NJ, Sharyshev AA, Mironova GD, Kondrashova MN. Inhibition of succinate oxidation and $\mathrm{K}+$ transport in mitochondria during hibernation. Comparative Biochemistry and Physiology Part B: Comparative Biochemistry. 1985; 82(1), 191-195.

Felber JP, Meyer HU, Curchod B, Iselin HU, Rousselle J, Maeder E, Pahud P, Jequier E. Glucose storage and oxidation in different degrees of human obesity measured by continuous indirect calorimetry.Diabetologia. 1981; 20(1), 39-44.

Felig P, Cunningham J, Levit M, Hendler R, Nadel E. Energy expenditure in obesity in fasting and postprandial state. American Journal of Physiology-Endocrinology and Metabolism. 1983; 244(1), E45-E51.

Franco M, Contreras C, Cortés P, Chappell MA, Soto-Gamboa M, Nespolo RF. Aerobic power, huddling and the efficiency of torpor in the South American marsupial, Dromiciops gliroides. Biology open. 2012; 1(12), 1178-1184.

Frick NT, Bystriansky JS, Ip YK, Chew SF, Ballantyne JS. Carbohydrate and amino acid metabolism in fasting and aestivating African lungfish (Protopterus dolloi). Comparative Biochemistry and Physiology Part A: Molecular \& Integrative Physiology. 2008; 151(1), 85-92.

Frick NT, Bystriansky JS, Ip YK, Chew S F, Ballantyne JS. Cytochrome c oxidase is regulated by modulations in protein expression and mitochondrial membrane phospholipid composition in estivating African lungfish. American Journal of Physiology-Regulatory, Integrative and Comparative Physiology. 2010; 298(3), R608-R616.

Gullicksen PS, Flatt WP, Dean RG, Hartzell DL, Baile CA. Energy metabolism and expression of uncoupling proteins 1,2, and 3 after 21 days of recovery from 
intracerebroventricular mouse leptin in rats. Physiology \& behavior. 2002; 75(4), 473-482.

Guppy M, Fuery CJ, Flanigan JE. Biochemical principles of metabolic depression. Comparative Biochemistry and Physiology Part B: Comparative Biochemistry. 1994; 109(2), 175-189.

Hagopian K, Harper ME, Ram JJ, Humble SJ, Weindruch R, Ramsey JJ. Long-term calorie restriction reduces proton leak and hydrogen peroxide production in liver mitochondria. American Journal of Physiology-Endocrinology and Metabolism. 2005; 288(4), E674-E684.

Harper ME, Dent R, Monemdjou S, Bézaire V, Van Wyck L, Wells G, Kavaslar GN, Gauthier A, Tesson F, McPherson R. Decreased mitochondrial proton leak and reduced expression of uncoupling protein 3 in skeletal muscle of obese diet-resistant women. Diabetes. 2002; 51(8), 2459-2466.

Heldmaier G, Ruf T. Body temperature and metabolic rate during natural hypothermia in endotherms. Journal of Comparative Physiology B. 1992; 162(8), 696-706.

Hellerstein MK, Christiansen M, Kaempfer S, et al. Measurement of de novo hepatic lipogenesis in humans using stable isotopes. Journal of Clinical Investigation. 1991; 87(5), 1841.

Henry BA, Andrews ZB, Rao A, Clarke IJ. Central leptin activates mitochondrial function and increases heat production in skeletal muscle. Endocrinology. 2011; 152(7), 2609-2618.

Hill JO, Heymsfield SB, McMannus C, DiGirolamo M. Meal size and thermic response to food in male subjects as a function of maximum aerobic capacity. Metabolism. 1984; 33(8), 743-749.

Hsieh CJ, Wang PW, Wang ST, Liu RT, Tung SC, Chien WY, Lu YC, Chen JF, Chen $\mathrm{CH}, \&$ Kuo MC. Serum leptin concentrations of patients with sequential thyroid function changes. Clinical endocrinology. 2002; 57(1), 29-34.

Imbeault P, Doucet E, Mauriege P, St-Pierre S, Couillard C, Almeras N, Després JP, Tremblay A. Difference in leptin response to a high-fat meal between lean and obese men. Clinical Science. 2001; 101(4), 359-365.

Kinabo JL, Durnin JVGA. Thermic effect of food in man: effect of meal composition, and energy content. British Journal of Nutrition. 1990; 64(01), 37-44.

Knudsen N, Laurberg P, Rasmussen LB, Bülow I, Perrild H, Ovesen L, Jørgensen, T. Small differences in thyroid function may be important for body mass index and the occurrence of obesity in the population. The Journal of Clinical Endocrinology \& Metabolism. 2005; 90(7), 4019-4024. 
Knuth ND, Johannsen DL, Tamboli RA, Marks-Shulman PA, Huizenga R, Chen KY, Amburad NN, Ravussin E, Hall KD. Metabolic adaptation following massive weight loss is related to the degree of energy imbalance and changes in circulating leptin. Obesity. 2014; 22(12), 2563-2569.

Koziel A, Sobieraj I, Jarmuszkiewicz W. Increased activity of mitochondrial uncoupling protein 2 improves stress resistance in cultured endothelial cells exposed in vitro to high glucose levels. American Journal of Physiology-Heart and Circulatory Physiology. 2015; 00759.

Lanni A, De Felice M, Lombardi A, Moreno M, Fleury C, Ricquier D, Goglia F. Induction of UCP 2 mRNA by thyroid hormones in rat heart. FEBS letters. 1997; 418(1), 171-174.

Leibel RL, Rosenbaum M, Hirsch J. Changes in energy expenditure resulting from altered body weight. New England Journal of Medicine. 1995; 332(10), 621-628.

Levine JA, Schleusner SJ, Jensen MD. Energy expenditure of nonexercise activity. The American journal of clinical nutrition. 2000; 72(6), 1451-1454.

Levine JA. Nonexercise activity thermogenesis (NEAT): environment and biology. American Journal of Physiology-Endocrinology And Metabolism. 2004; 286(5), E675-E685.

MacLean PS, Higgins, JA, Jackman MR, Johnson GC, Fleming-Elder BK, Wyatt HR, Melanson E, Hill JO. Peripheral metabolic responses to prolonged weight reduction that promote rapid, efficient regain in obesity-prone rats. American Journal of Physiology-Regulatory, Integrative and Comparative Physiology. 2006;290(6), R1577-R1588.

Madden S, Miskovic-Wheatley J, Clarke S, Touyz, S, Hay P, Kohn, MR. Outcomes of a rapid refeeding protocol in Adolescent Anorexia Nervosa. Journal of eating disorders. 2015; 3(1), 8 .

Müller MJ, Enderle J, Pourhassan M, Braun W, Eggeling B, Lagerpusch M, Glüe CC, Kehayias JJ, Kiosz D, Bosy-Westphal A. Metabolic adaptation to caloric restriction and subsequent refeeding: the Minnesota Starvation Experiment revisited. The American Journal of Clinical Nutrition. 2015; 102(4), 807-819.

Murphy MP, Echtay KS, Blaikie FH, Asin-Cayuela J, Cochemé HM, Green K, Buckingam JÁ, Taylor ER, Hunrrel F, Hughess G, Miwa S, Cooper CE, Svistunenko DA, Smith RAJ, Brand MD. Superoxide Activates Uncoupling Proteins by Generating Carbon-centered Radicals and Initiating Lipid Peroxidation Studies Using a mitochondria-targeted spin trap derived from $\alpha$-phenyl-n-tert-butylnitrone. Journal of Biological Chemistry. 2003; 278(49), 48534-48545. 
Naya DE, Veloso C, Sabat P, Bozinovic F. The effect of short-and long-term fasting on digestive and metabolic flexibility in the Andean toad, Bufo spinulosus. Journal of Experimental Biology. 2009; 212(14), 2167-2175.

Nelson KM, Weinsier RL, James LD, Darnell B, Hunter G, Long CL. Effect of weight reduction on resting energy expenditure, substrate utilization, and the thermic effect of food in moderately obese women. The American journal of clinical nutrition. $1992 ; 55(5), 924-933$

Nicholls DG. The physiological regulation of uncoupling proteins.Biochimica et Biophysica Acta (BBA)-Bioenergetics. 2006; 1757(5), 459-466.

Nicolae A, Wahrheit J, Nonnenmacher Y, Weyler C, Heinzle E. Identification of active elementary flux modes in mitochondria using selectively permeabilized $\mathrm{CHO}$ cells. Metabolic engineering. 2015; 32, 95-105.

Oelkrug R, Heldmaier G, Meyer CW. Torpor patterns, arousal rates, and temporal organization of torpor entry in wildtype and UCP1-ablated mice. Journal of Comparative Physiology B. 2011; 181(1), 137-145.

Ogawa A, Nosaka N, Kasai M, Aoyama T, Okazaki M, Igarashi O, Kondo, K. Dietary medium-and long-chain triacylglycerols accelerate diet-induced thermogenesis in humans. Journal of oleo science. 2007; 56(6), 283-287.

Okamatsu-Ogura Y, Nio-Kobayashi J, Iwanaga T, Terao A, Kimura K, Saito M. Possible involvement of uncoupling protein 1 in appetite control by leptin. Experimental biology and medicine. 2011; 236(11), 1274-1281.

Ortmann S, Heldmaier G. Regulation of body temperature and energy requirements of hibernating Alpine marmots (Marmota marmota).American Journal of PhysiologyRegulatory, Integrative and Comparative Physiology. 2000; 278(3), R698-R704.

Parker N, Affourtit C, Vidal-Puig A, Brand MD. Energization-dependent endogenous activation of proton conductance in skeletal muscle mitochondria. Biochemical Journal. 2008; 412(1), 131-139.

Pearce EN. Thyroid hormone and obesity. Current Opinion in Endocrinology, Diabetes and Obesity. 2013; 19(5), 408-413.

Pinkney JH, Goodrick SJ, Katz J, Johnson AB, Lightman SL, Coppack SW, Mohamed-Ali V. Leptin and the pituitary-thyroid axis: a comparative study in lean, obese, hypothyroid and hyperthyroid subjects. Clinical endocrinology. 1998; 49(5), 583-588.

Pittet PH, Chappuis PH, Acheson K, De Techtermann F, Jequier E. Thermic effect of glucose in obese subjects studied by direct and indirect calorimetry. British Journal of Nutrition. 1976; 35(02), 281-292. 
Polito A, Cuzzolaro M, Raguzzini A, Censi L, Ferro-Luzzi, A. Body composition changes in anorexia nervosa. European journal of clinical nutrition. 1998; 52(9), 655662.

Porter C, Herndon DN, Børsheim E, Chao T, Reidy PT., Borack MS, Rasmussen BB, Chondronikola M, Saraf MK, Sidossis LS. Uncoupled skeletal muscle mitochondria contribute to hypermetabolism in severely burned adults. American Journal of Physiology-Endocrinology and Metabolism. 2014; 307(5), E462-E467.

Ravussin E, Lillioja S, Anderson TE, Christin L, Bogardus, C. Determinants of 24hour energy expenditure in man. Methods and results using a respiratory chamber. Journal of Clinical Investigation. 1986; 78(6), 1568.

Reed GW, Hill JO. Measuring the thermic effect of food. The American journal of clinical nutrition. 1996; 63(2), 164-169.

Ritze Y, Schollenberger A, Hamze SM, et al. Gastric ghrelin, GOAT, leptin, and leptinR expression as well as peripheral serotonin are dysregulated in humans with obesity. Neurogastroenterology and motility: the official journal of the European Gastrointestinal Motility Society. 2016 [ABSTRACT]

Rolfe D, Brand M. The physiological significance of mitochondrial proton leak in animal cells and tissues. Bioscience reports. 1997; 17, 9-16.

Rosenbaum M, Hirsch J, Gallagher DA, Leibel RL. Long-term persistence of adaptive thermogenesis in subjects who have maintained a reduced body weight. The American journal of clinical nutrition. 2008; 88(4), 906-912.

Salin K, Auer SK, Rudolf AM, Anderson GJ, Cairns AG, Mullen W, Hartley RC, Selman C Metcalfe NB. Individuals with higher metabolic rates have lower levels of reactive oxygen species in vivo. Biology letters. 2015; 11(9), 20150538.

Salin K, Luquet E, Rey B, Roussel D, VoituronY. Alteration of mitochondrial efficiency affects oxidative balance, development and growth in frog (Rana temporaria) tadpoles. The Journal of experimental biology. 2012; 215(5), 863-869.

Samec S, Seydoux J, Dulloo AG. Role of UCP homologues in skeletal muscles and brown adipose tissue: mediators of thermogenesis or regulators of lipids as fuel substrate?. The FASEB Journal. 1998; 12(9), 715-724.

Scalfi L, Coltorti A, Contaldo F. Postprandial thermogenesis in lean and obese subjects after meals supplemented with medium-chain and long-chain triglycerides. The American journal of clinical nutrition. 1991; 53(5), 1130-1133

Shallenberger RS. Occurrence of various sugars in foods. Sugars in Nutrition. HL Sipple \& KW McNutt, eds. 1974; 67-80. 
Schwarz JM, Schutz Y, Froidevaux F, Acheson KJ, Jeanprêtre N, Schneider H, Felber JP Jéquier E. Thermogenesis in men and women induced by fructose vs glucose added to a meal. The American journal of clinical nutrition. 1989; 49(4), 667-674.

Secor SM. Physiological responses to feeding, fasting and estivation for anurans. Journal of experimental biology. 2005; 208(13), 2595-2609.

Segal KR, Edano A, Blando L, Pi-Sunyer F. Comparison of thermic effects of constant and relative caloric loads in lean and obese men. The American journal of clinical nutrition. 1990; 51(1), 14-21.

Shetty PS, Jung RT, James WPT, Barrand MA, Callingham, BA. Postprandial thermogenesis in obesity. Clin Sci, 1981; 60, 519-525.

Smith DK, Ovesen L, Chu R, Sackel S, Howard L. Hypothermia in a patient with anorexia nervosa. Metabolism. 1983; 32(12), 1151-1154.

Speakman JR, Talbot DA, Selman C, Snart S, McLaren JS, Redman P, Krol E, Jackson DM, Johnson MS, Brand MD. Uncoupled and surviving: individual mice with high metabolism have greater mitochondrial uncoupling and live longer. Aging cell. 2004; 3(3), 87-95.

Sreenan S, Caro JF, Refetoff S. Thyroid dysfunction is not associated with alterations in serum leptin levels. Thyroid. 1997; 7(3), 407-409.

Storey, KB, Storey JM. Metabolic rate depression: the biochemistry of mammalian hibernation. Advances in clinical chemistry. 2010; 52, 78.

Stuart JA, Gillis TE, Ballantyne JS. Compositional correlates of metabolic depression in the mitochondrial membranes of estivating snails. American Journal of Physiology-Regulatory, Integrative and Comparative Physiology. 1998; 275(6), R1977-R1982.

Suen VMM, Silva GA, Tannus AF, Unamuno MRDL, Marchini JS. Effect of hypocaloric meals with different macronutrient compositions on energy metabolism and lung function in obese women. Nutrition. 2003; 19(9), 703-707.

Tagliaferri M, Berselli ME, Calo G, Minocci A, Savia G, Petroni ML, Viberti GC, Liuzzi, A. Subclinical hypothyroidism in obese patients: relation to resting energy expenditure, serum leptin, body composition, and lipid profile. Obesity research. 2001; 9(3), 196-201.

Tai MM, Castillo P, Pi-Sunyer FX. Meal size and frequency: effect on the thermic effect of food. The American journal of clinical nutrition. 1991; 54(5), 783-787.

Tappy L, Jéquier E. Fructose and dietary thermogenesis. The American journal of clinical nutrition. 1993; 58(5), 766S-770S. 
Tataranni PA, Larson DE, Snitker S, Ravussin E. Thermic effect of food in humans: methods and results from use of a respiratory chamber. The American journal of clinical nutrition. 1995; 61(5), 1013-1019.

Tentolouris N, Pavlatos S, Kokkinos A, Perrea D, Pagoni S, Katsilambros N. Dietinduced thermogenesis and substrate oxidation are not different between lean and obese women after two different isocaloric meals, one rich in protein and one rich in fat. Metabolism. 2008, 57(3), 313-320.

Wang CC, Strouse S. Studies on the Metabolism of Obesity: III. The Specific Dynamic Action of Food. Archives of Internal Medicine. 1924; 34(4), 573-583.

Welker AF, Moreira DC, Campos ÉG, Hermes-Lima, M. Role of redox metabolism for adaptation of aquatic animals to drastic changes in oxygen availability. Comparative Biochemistry and Physiology Part A: Molecular \& Integrative Physiology. 2013; 165(4), 384-404.

Westerterp KR . Diet induced thermogenesis. Nutrition \& metabolism. 2004; 1(1), 5.

Weststrate JA, Dekker J, Stoel M, Begheijn L, Deurenberg P,Hautvast JG. Resting energy expenditure in women: impact of obesity and body-fat distribution. Metabolism. 1990; 39(1), 11-17. 
Capítulo 4 - manuscrito submetido: METABOLIC ADAPTATION DUE TO CALORIC RESTRICTION MAY BE MINIMIZED BY INTERMITTENT INGESTION OF THERMOGENESIS-BOOSTING MEALS 
Metabolic adaptation due to caloric restriction may be minimized by including intermittent ingestion of thermogenesis-boosting meals to low calorie diets

Hylane Luiz Damascena1*, Alexis Fonseca Welker1

1Programa de Pós-Graduação em Ciências e Tecnologias em Saúde, Universidade de Brasília, DF, 72220-900, Brazil. 


\section{ABSTRACT}

The frequent failure of caloric restriction to treat obesity is partly attributed to the resultant fall in metabolic rate that is greater than predicted by changes in body composition. The present work shows evidence from diverse research fields which support the hypothesis that meals providing high peaks of substrates availability in the cell/mitochondria milieu would raise and lengthen postprandial proton leak and thermogenesis. Therefore, the inclusion of intermittent thermogenesis-boosting meals to low calorie diets could potentially minimize the metabolic adaptation observed with underfeeding. In order to raise metabolic rate, well established knowledge were analyzed to propose the composition of these meals. Variables such a rates of digestion, gastric emptying, osmolality of nutrients, absorption, oxidation and thermogenic effect of different nutrients were considered. This evaluation led to a proposed meal composed by whey protein, medium-chain triglycerides (MCT), fructose and sucrose-rich fruits, potato rich in amylopectin starch and/or maltodextrin (high glycemic index). To optimize this strategy, other factors were explained such as the interval/frequency of including the thermogenic meals, glycogen stores level, de novo lipogenesis, carbohydrate content in the customary diet and physical activity. If these assumptions become confirmed, one implication of the presented hypothesis is a more permanent long-term loss of body fat and weight with dieting. Besides the metabolic implications, the proposed strategy would have other several repercussions associated with the psychological state, such as turning diet less arduous, reduction of aversive feelings of being hungry (and potentially depression and anxiety), improvement of the mood, and the consequently strengthening of the adherence to dieting and related treatments. All these metabolic and behavioral consequences are expected to promote a permanent long-term body fat and weight loss. 
The proposed intervention in the traditional low calorie diets could therefore contribute to the treatment of obesity, diabetes, dyslipidemia and related diseases.

Keywords: fasting, cafeteria diet, snack, uncoupling proteins, exercise. 
ANEXOS

ANEXO A. Normas da revista Medical Hypotheses, que o manuscrito foi submetido medical hypotheses

Articles \& Issues For Authors Journal Info $~$ Subscribe More Periodicals

All Content $\quad$ Search Advanced Search

Guidelines for Authors on the construction of articles

The purpose of Medical Hypotheses is to publish interesting theoretical papers. The journal will consider radical, speculative and non-mainstream scientific ideas provided they are coherently expressed.

Medical Hypotheses is not, however, a journal for publishing workaday reviews of the literature, nor is it a journal for primary data (except when preliminary data is used to lend support to the main hypothesis presented). Many of the articles submitted do not clearly identify the hypothesis and simply read like reviews.

These notes are designed to help authors formulate an article for Medical Hypotheses in such a way that the article is clearly distinguishable from a review. These are guidelines only and the Editor is happy to accept other formats provided that the principal requirements are met.

\section{An hypothesis}

Roughly speaking, an hypothesis should be an organized logical structure (or model) that accounts for (some) known facts, and which has real world consequences that are (in principle) observable.

The consequences of an hypothesis constitute predictions that may be tested against observations and experiments to determine whether some of them are (apparently) fulfilled.

Most articles for Medical Hypotheses should fulfil the requirements of an hypothesis, and the logic of the proposals should be clearly stated and evaluated.

Medical Hypotheses is a general journal and articles need to be intelligible to a wide audience in medicine and bioscience, including those who may not be specialists in the field. Clarity of presentation and concision are key requirements.

\section{Abstract/ Summary}

The abstract should present the paper in microcosm. It should contain explicit details of the hypothesis being advanced, the main lines of supporting evidence and the most important implications. 


\section{Introduction/Background}

The introduction should be a concise introduction to the scientific area to be addressed, supported by appropriate references and should set the scene for the hypothesis. The introduction should not be an attempt to review the evidence in detail.

\section{The Hypothesis/Theory}

The hypothesis needs to be set out in explicit detail. Typically it should be clear why and how the hypothesis is different from current thinking, how the idea has evolved, and why it is important.

The scientific logic of the hypothesis should be clearly evident (eg. the steps in its causal assumptions).

\section{Evaluation of the hypothesis/idea}

The proposed hypothesis should be evaluated in the light of known and published information. Generally, this entails an evaluation of both evidence in support and evidence (apparently) against the hypothesis. Only relevant, and critically evaluated, papers should be cited.

An hypothesis should, if correct, have implications and make predictions. These predictions are (in principle) amenable to further observation and experimentation that could tend to confirm or refute the hypothesis. Typically, authors would be expected to indicate how their hypothesis might be tested.

\section{Empirical data}

Inclusion of extensive new data is not usually acceptable in Medical Hypotheses papers. However, at the Editor's discretion, pilot data may be included when it is required for support of the proposed hypothesis, and when it is unlikely to be published in its own right

\section{Consequences of the hypothesis and discussion}

The importance of the hypothesis may need to be stated explicitly, with a discussion of the potential implications for the area of science under discussion if the hypothesis were to be confirmed.

\section{References}

As a general rule, references should be limited to those that have a direct bearing on the understanding of the hypothesis.

\section{Figures and Tables}

Diagrams, figures or tables may be invaluable in explaining the hypothesis. Tables may be a good way of presenting evidence for and against a hypothesis in a way which makes the strengths and weaknesses of the argument quickly apparent to the reader. Explanatory diagrams and figures are welcome - so long as they clarify the argument.

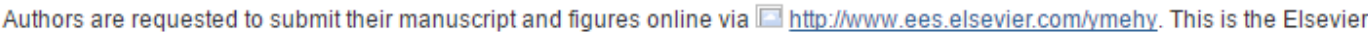
web-based submission and review system. You will find full instructions located at this site - a Guide for Authors and a Guide for Online Submission. Please follow these guidelines to prepare and upload your article. Once the uploading is done, our system automatically generates an electronic pdf proof, which is then used for reviewing. All correspondence, including notification of the Editor's decision and requests for revisions, will be managed via this system.

Paper submissions are not normally accepted. If you cannot submit electronically, please email the editorial office for assistance on medicalhypotheses@elsevier.com. Manuscripts may also be submitted to: Editorial Office, clo Joanne Hodgkinson. Elsevier Limited, The Boulevard, Langford Lane, Kidlington, OX5 1GB, UK.

The Editors cannot accept responsibility for damage to or loss of typescripts. A paper is accepted for publication on the understanding that it has not been submitted simultaneously to another journal in the English language. Rejected papers will not be returned to authors except on request.

The Editors reserve the right to make editorial and literary corrections. Any opinions expressed or policies advocated do not necessarily reflect the opinions or policies of the Editors.

\section{Document Lay Out}

Papers should be set out as follows, with each section beginning on a separate sheet: title page, summary, text, acknowledgements, references, tables, captions to illustrations.

\section{Title}

The title page should give the following information: (1) title of article; (2) initials and name of each author, with highest academic degree(s); (3) name and address of the department or institution to which the work should be attributed; (4) name, address, telephone and fax numbers and E-mail address of the author responsible for correspondence and to whom requests for offprints should be sent; and (5) sources of support in the form of grants.

\section{Abstract}

The abstract is the most important section of the paper since it will be widely and freely disseminated by scientific indexing systems, and will be read far more often than the whole paper. Great care should therefore be taken to provide an informative abstract which summarizes the main argument of the paper. The maximum length allowed is 400 words. The abstract should not contain any references, because it will sometimes be disseminated in isolation from the rest of the paper. Please ensure that you submit your abstract within the first page of your manuscript. 


\section{Within the Text}

Papers should be subdivided as the author desires, bearing in mind that the use of headings usually enhances the reader's comprehension. Major heading should be in capital letters at the centre of the page, minor headings in lower case letters (with an initial capital letter) at the left hand margin. It is suggested that authors bear in mind that hypotheses may be more persuasive when their implications are made explicit - for example, including suggestions for observational or experimental testing.

\section{Maximum Length}

Papers should normally be restricted in length to a maximum of 40 pages of double spaced 12 point type including tables, illustrations and references.

\section{Reference Format}

The accuracy of references is the responsibility of the author. References should be entered consecutively by Arabic numerals in parentheses in the text. The references should be listed in numerical order on a separate sheet in double or triple spacing. References to journals should include the authors' names and initials (list all authors when six or fewer; when seven or more, list only the first three and add 'et al.', full title of paper, abbreviated journal title, using Index Medicus abbreviations, year of publication, volume number, first and last page numbers. Internet references should include author, title, web address, date of publication (if known), and the date on which the website was accessed.

\section{Figures}

All line illustrations should present a crisp black image on an even white background. The illustrations should be $127 \times 173 \mathrm{~mm}(5 \times 7$ in) in size, or no larger than $203 \times 254 \mathrm{~mm}(8 \times 10 \mathrm{in})$.

Photographic illustrations and radiographs should be submitted as clear, lightly contrasted black-and-white prints (unmounted), sizes as above. Photomicrographs should have the magnification and details of staining techniques shown. X-ray films should be submitted as photographic prints, carefully made to bring out the detail to be illustrated, with an overlay indicating the area of importance.

Figures should be submitted appropriately lettered in capitals. The size of the letters should be appropriate to that of the illustration, taking into account the necessary size reduction.

All illustrations should be clearly marked (by a label pasted on the back or by soft crayon) with figure number and author's name, and the top of the figure should be indicated by an arrow. Never use ink of any kind. Do not use paper clips, as these can scratch or mark illustrations. Illustrations in colour cannot be accepted unless the cost of origination and publication is paid by the author. Captions should be typed, double-spaced, on separate sheets from the typescript.

Where illustrations must include recognizable individuals, living or dead and of whatever age, great care must be taken to ensure that consent for publication has been given. If identifiable features are not essential to the illustration, please indicate where the illustration can be cropped. In cases where consent has not been obtained and recognizable features may appear, it will be necessary to retouch the illustration to mask the eyes or otherwise render the individual 'officially unrecognizable' 
These should be double-spaced on separate sheets and contain only horizontal rules. Do not submit tables as photographs. A short descriptive title should appear above each table and any footnotes, suitably identified, below. Care must be taken to ensure that all units are included. Ensure that each table is cited in the text.

\section{Units \& Abbreviations}

Avoid abbreviations in the title and abstract. All unusual abbreviations should be fully explained at their first occurrence in the text. All measurements should be expressed in SI units. Imperial units are acceptable from USA contributors. For more detailed

recommendations, authors may consult the Royal Society of Medicine publication entitled Units, Symbols and Abbreviations: A Guide for Biological and Medical Editors and Authors.

\section{Correspondence}

Medical Hypotheses welcomes correspondence, especially when letters are linked to previous publications in the journal. Alternatively, letters can summarise extensions of previous work, draw attention to new evidence relating to theories, describe new ideas, or make general comments concerning the journal or its field of interest. Letters should be 400 words maximum length, inclusive of any references.

\section{Reviewers}

Authors are asked to supply the names and email addresses of at least 3 and up to 5 potential reviewers for their manuscript. Please do not suggest reviewers from your own institution, previous or current collaborators or Editorial Board members. Without reviewer suggestions, processing of the manuscript may be delayed. Please do not contact any reviewers that you have suggested.

\section{Open access}

This journal offers authors a choice in publishing their research:

Open access

- Articles are freely available to both subscribers and the wider public with permitted reuse

- An open access publication fee is payable by authors or on their behalf e.g. by their research funder or institution

Subscription

- Articles are made available to subscribers as well as developing countries and patient groups through our universal access

programs ( $\mathrm{http://www.elsevier.com/access)}$.

- No open access publication fee payable by authors.

Regardless of how you choose to publish your article, the journal will apply the same peer review criteria and acceptance standards.

For open access articles, permitted third party (re)use is defined by the following Creative Commons user licenses:

Creative Commons Attribution-NonCommercial-NoDerivs (CC BY-NC-ND)

For non-commercial purposes, lets others distribute and copy the article, and to include in a collective work (such as an anthology), as long as they credit the author(s) and provided they do not alter or modify the article.

The open access publication fee for this journal is USD 2000, excluding taxes. Learn more about Elsevier's pricing policy: If http://www.elsevier.com/openaccesspricing. 


\section{DISCUSSÃO GERAL E CONCLUSÕES}

Alterações da taxa metabólica decorrentes das flutuações no provimento de oxigênio ou disponibilidade de nutrientes são fundamentais para a sobrevivência em condições desfavoráveis, tanto para humanos quanto para os demais animais. Buscar entender os mecanismos em situações de estresses metabólicos é importante para viabilizar possíveis soluções. E intercambiar as diversas áreas do conhecimento permite traçar hipotéses que sejam difíceis de reproduzir na prática humana.

A presente dissertação foi composta por quatro estudos envolvendo alterações da taxa metabólica por provimento de oxigênio advindo de alterações do sistema circulatório e respiratório e substratos da cadeia de transporte de elétrons mitocondrial. No primeiro estudo (capítulo1) foi realizado experimentos em laboratório com girinos de Lithobates catesbeianus, com o objetivo de avaliar às alterações do sistema redox, causado pela falta de provimento de oxigênio advindo de alterações respiratórias, por meio de medições dos danos oxidativos. Após meses de muitos experimentos, períodos de ambientação dos animais e insucessos em sua manutenção (100\% de mortalidade em algumas das ambientações), foi realizado experimento da hipóxia progressiva, por meio da exposição aérea, o qual não teve sucesso, desta forma foi realizado experimento de hipóxia aquática, a qual verificou que hipóxia inicial não gerou danos oxidativos. O segundo estudo (capítulo 2) envolveu experimentos de laboratório nos quais se pretendeu inicialmente avaliar o efeito da diminuição do provimento de oxigênio advindo de alterações do sistema circulatório e respiratório através da desidratação. Após diversas tentativas experimentais, chegou-se à conclusão de que a espécie animal escolhida, um anfíbio muito estudado mundialmente e altamente disponível por ser usado na culinária, não seria a mais adequada para se investigar as respostas metabólicas à hipóxia através de exposição aérea e também à desidratação. O terceiro estudo apresentado (capítulo 3) foi composto de uma revisão dos fatores que determinam a taxa metabólica com ênfase na disponibilização de substratos energéticos e, dentro dela, de uma revisão sistemática e uma breve análise estatística dos dados da literatura revisada. Nesta análise, foi possível verificar que há uma relação positiva entre o pico de efeito térmico de uma refeição com seu efeito térmico total. Neste capítulo, algumas possíveis explicações para esta relação são apresentadas. A revelação da relação entre pico de efeito térmico de uma refeição com seu efeito térmico total permitiu construir a hipótese de que a elaboração e ingestão de refeições que proporcionem uma alta disponibilidade de substratos nas células e 
mitocôndrias teriam uma capacidade de causar maiores aumentos da termogênese pósprandial. O quarto estudo (capítulo 4) é um manuscrito resultante do capítulo 3 e se trata da apresentação da hipótese da relação entre disponibilidade de substratos e termogênese e de uma proposta de intervenção nutricional considerando tal relação com o objetivo de se aumentar a taxa metabólica e contribuir para o combate à obesidade e doenças relacionadas.

O conjunto de tais estudos permitiu um estudo aprofundado dos mecanismos pelos quais o provimento dos diferentes substratos (oxigênio e nutrientes) repercute no metabolismo e na saúde dos animais. Tal provimento é letal quando está insuficiente. Quando diminuído, ele gera adaptações que permitem a sobrevivência de animais (como na hipóxia) e humanos (como no caso de escassez de alimentos). A adaptação metabólica, porém, também contribui para a existência de doenças metabólicas. Já a oferta elevada de diferentes substratos gera prejuízos para a saúde, oxigênio excessivo causa estresse oxidativo e nutrientes em excesso causam doenças metabólicas. Os conhecimentos dessas diversas áreas permitem se ter uma visão mais ampla dos fenômenos bioquímicos e fisiológicos relacionados à saúde. 


\section{REFERÊNCIAS BIBLIOGRÁFICAS}

Andreyev AY, Kushnareva YE, Starkov AA. Mitochondrial metabolism of reactive oxygen species. Biochemistry (Moscow). 2005; 70(2), 200-214.

Brown GC. Control of respiration and ATP synthesis in mammalian mitochondria and cells. Biochem. J. 1992; 284, 1-13.

Cini M, Fariello RG, Bianchetti A, Moretti, A. Studies on lipid peroxidation in the rat brain. Neurochemical research. 1994; 19(3), 283-288.

Dulloo AG, Jacquet J. Adaptive reduction in basal metabolic rate in response to food deprivation in humans: a role for feedback signals from fat stores. The American journal of clinical nutrition. 1998; 68(3), 599-606.

Gregory EM, Fridovich I. Induction of superoxide dismutase by molecular oxygen. Journal of Bacteriology. 1973; 114(2), 543-548.

Guppy M, Fuery CJ, Flanigan JE. Biochemical principles of metabolic depression. Comparative Biochemistry and Physiology Part B: Comparative Biochemistry. 1994; 109(2), 175-189.

Guppy M, Withers P. Metabolic depression in animals: physiological perspectives and biochemical generalizations. Biological Reviews of the Cambridge Philosophical Society. 1999; 74(01), 1-40.

Hermes-Lima M. Oxygen in biology and biochemistry: role of free radicals. Functional metabolism: Regulation and adaptation. 2004; 1, 319-66.

Nohl H, Hegner D. Do mitochondria produce oxygen radicals in vivo?. European Journal of Biochemistry. 1978; 82(2), 563-567.

Ramos GR, Alves ALH, Hermes-Lima M. Radicais livres, antioxidantes e a adaptabilidade animal. El-Hani, CN; Videira AAP O que é vida. 2000; 208-231.

Ravussin E, Lillioja S, Anderson TE, Christin L, Bogardus, C. Determinants of 24hour energy expenditure in man. Methods and results using a respiratory chamber. Journal of Clinical Investigation. 1986; 78(6), 1568.

Storey, KB, Storey JM. Metabolic rate depression: the biochemistry of mammalian hibernation. Advances in clinical chemistry. 2010; 52, 78. 
